Check for updates

Cite this: Mater. Adv., 2021, 2, 115

Received 12th October 2020, Accepted 9th November 2020

DOI: $10.1039 / \mathrm{d} 0 \mathrm{ma} 00790 \mathrm{k}$

rsc.li/materials-advances

\title{
Wide bandgap polymer donors for high efficiency non-fullerene acceptor based organic solar cells
}

\begin{abstract}
Keqiang He, Pankaj Kumar, Yi Yuan and Yuning Li (D) *
In the past few years, the power conversion efficiency (PCE) of organic solar cells (OSCS) has improved rapidly with the milestone value exceeding $18 \%$, primarily owing to the development of novel nonfullerene acceptors (NFAs) as well as matching polymer donors. The molecular structure of a polymer donor fundamentally determines its molecular packing (crystal structure and morphology) and optoelectronic properties, which influence the photovoltaic processes and the ultimate PCE of the OSC device. The structure-property-cell performance relationships of polymer donors with respect to the specific acceptor are very complex, involving numerous parameters, but are extremely important towards the development of high-performance polymer donors to achieve high PCE. This review provides a timely analysis of the top-performing wide bandgap (WBG) polymer donors that have been developed to match the three most representative narrow bandgap NFAs, ITIC, IT-4F, and Y6, in terms of their structural design, fine-tuning of their optoelectronic properties, and control of the morphology and crystallinity of their blends with NFAs. We hope that this article provides deeper insight into the structure-property-cell performance relationships of polymer donors and a collection of useful guidelines and strategies for the design and processing of novel polymer donors for matching with NFAs for achieving ultrahigh performance OSCs.
\end{abstract}

\section{Introduction}

Organic solar cells (OSCs) have attracted much attention as a promising technology to convert solar energy into electricity because of their advantages in fabricating flexible, lightweight, large-area, and low-cost solar cells. ${ }^{1-4}$ Since the first report by Heeger et al. ${ }^{5}$ in 1995 , OSCs with a bulk heterojunction (BHJ) structure composed of a blend active layer, comprising a p-type conjugated polymer as a donor and an n-type organic semiconductor as an acceptor, have attracted tremendous attention due to their excellent solution processability and mechanical properties that allow high throughput, roll-to-roll manufacturing. Significant improvements in the OSC performance (with the highest PCE exceeding 18\%) have been achieved, largely by the judicious design and delicate synthesis of matching polymer donor and acceptor materials..$^{6-10}$

The first generation acceptor materials for $\mathrm{BHJ}$ OSCs comprise fullerene derivatives such as phenyl- $\mathrm{C}_{61}\left(\right.$ or $\mathrm{C}_{71}$ )-butyric acid methyl ester $\left(\mathrm{PC}_{61} \mathrm{BM}\right.$ or $\left.\mathrm{PC}_{71} \mathrm{BM}\right)$, which were first developed by Wudl et al. ${ }^{11}$ They have good solubility in organic solvents, high electron mobility $\left(\mu_{\mathrm{e}}\right)$, and high electron

Department of Chemical Engineering and Waterloo Institute for Nanotechnology (WIN), University of Waterloo, 200 University Ave West, Waterloo, Ontario, N2L 3G1, Canada. E-mail: yuning.li@uwaterloo.ca; Fax: +1-519-888-4347; Tel: $+1-519-888-4567$ ext. 31105 affinity. ${ }^{12,13}$ Among various polymer donors developed to match these acceptors, a benzo[1,2-b:4,5- $\left.b^{\prime}\right]$ dithiophene (BDT)-based polymer, PTB7, developed by Liang et al. ${ }^{7}$ in 2010, showed a high PCE of $7.4 \%$ and $9.2 \%$ using a conventional and inverted device structure, respectively, when blended with $\mathrm{PC}_{71} \mathrm{BM}^{7,14}$ The highest PCE of $11.7 \%$ for single-junction binary-blend fullerene-based OSCs was achieved using PffBT4T$\mathrm{C}_{9} \mathrm{C}_{13}$ as a donor by Zhao et al. in $2016 .{ }^{15}$ Since then, the development of fullerene-based OSCs has become subdued because of their weak absorption in the visible spectral region, limited energy level tunability, and inadequate long-term stability of the devices caused by the susceptibility to dimerization and gradual aggregation.

To overcome the drawbacks of fullerene-based acceptors, nonfullerene acceptors (NFAs) have been developed. ${ }^{16,17}$ ITIC, developed by Lin et al. in 2015, is one of the most efficient NFAs. It has a rigid indacenodithienothiophene (IDTT) central unit and a narrow bandgap of $1.59 \mathrm{eV}^{8}$ OSCs using ITIC as an acceptor and PTB7-Th as a donor showed a moderate PCE of $6.8 \%$ due to their similar absorption range with poor absorption in the shorter wavelength region of the solar spectrum. The PCE of ITIC-based OSCs rapidly improved to $\sim 10 \%$ when WBG polymer donors with complementary absorption such as J51 (9.26\%), ${ }^{18} \mathrm{~J} 61(9.53 \%),{ }^{19}$ and PBDB-T $(11.21 \%)^{16}$ were used. Recently, a new WBG polymer donor, PBTAPSF, was developed by Li et al. ${ }^{20}$ to match with ITIC to realize complementary absorption. OSCs based on PBTA-PSF:ITIC 
achieved a PCE of $13.91 \%$, which is by far the highest among ITICbased OSCs. At the same time, incorporation of electron-donating (e.g., methyl in IT-M and IT-DM) ${ }^{21}$ and electron-withdrawing (e.g., fluorine in IT-4F) ${ }^{22}$ groups, side chain engineering of the ITIC core structure (e.g. $m$-ITIC, ${ }^{23}$ ITIC $2,{ }^{24}$ ITIC-Th, ${ }^{25}$ ITIC-Th $1,{ }^{26}$ and IDIC $^{27}$ ) and optimization of the central core (AOIC, ${ }^{28} \mathrm{INIC}^{29}{ }^{29} \mathrm{FIC},{ }^{30}$ and FOIC $^{31}$ ) further improved the PCEs when appropriate matching polymer donors were used. In 2019, Yuan et al. ${ }^{9}$ developed a new high performance NFA, Y6, which has a slightly electron-deficient dithienothiophen[3.2-b]-pyrrolobenzothiadiazole core that helps achieve a narrower bandgap of $1.33 \mathrm{eV}$ compared to ITIC. Y6 achieved a very high PCE of $15.7 \%$ when blended with donor polymer PM6 owing to the largely improved photocurrent. The record PCE of $18.22 \%$ was obtained using $\mathrm{Y} 6$ as an acceptor and a novel WBG $(1.98 \mathrm{eV})$ polymer D18 as a donor. ${ }^{10}$

Because $\mathrm{BHJ}$ OSCs utilize both donor and acceptor materials in the active layer blend, matching of the optoelectronic properties (frontier molecular orbital (FMO) energy levels, optical absorption, etc.) and morphological compatibility (miscibility, phase separation, crystallinity, etc.) between donor and acceptor materials are vital for achieving high photovoltaic performance. Compared to the previous review articles that focus on donors $^{4,32-35}$ and acceptors, ${ }^{36-41}$ respectively, this review will provide a perspective from a different angle by placing emphasis on the matching between donors and acceptors to gain a better understanding of the relationships between the structures, properties, and device performances of representative donors with different prominent acceptor materials.

Firstly, we briefly discuss the working mechanism of OSCs and the general relationships between the molecular structure, nano-/microstructure, properties, and cell performance. Next, we select and classify some high-performance polymer donors that have been used to match the three most representative NFAs, ITIC, IT-4F, and Y6, to achieve PCEs above 10\%. Then, we discuss the properties and photovoltaic performances of different donors and provide some guidelines for the design and processing of polymer donors to match with a certain acceptor to achieve high solar cell performance. Finally, a summary of the key findings in terms of the structure-property-cell performance relations of WBG high-performance polymer donors and an outlook for the future development of this type of materials and OSCs in general are provided.

\section{Structure-property-cell performance relationships of polymer donors}

A typical OSC device is made of an electron donor (commonly a polymer material) and an electron acceptor (commonly a small molecule material) that form a $\mathrm{BHJ}$ (photo)active layer with interpenetrating donor and acceptor phases at the nanometer scale. ${ }^{5}$ This active layer is sandwiched between an anode and a cathode, which collect the holes and electrons generated in the active layer, respectively. Usually, a hole transport layer (HTL) such as PEDOT:PSS or $\mathrm{MoO}_{3}$ is inserted between the active layer (a)

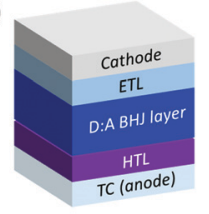

(d)

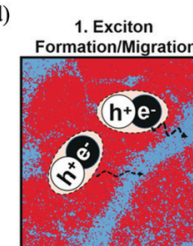

(b)

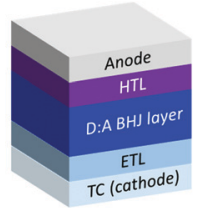

(c)

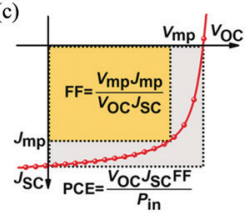

Fig. 1 (a) Conventional and (b) inverted OSC architectures; (c) solar cell figures-of-merit: short circuit current density $\left(J_{\mathrm{SC}}, \mathrm{mA} \mathrm{cm}{ }^{-2}\right)$, open circuit voltage $\left(V_{O C}, V\right)$, fill factor (FF) and $\mathrm{PCE}^{42}$ and (d) working mechanism of the $\mathrm{BHJ}$ layer in OSCs (red and blue areas represent donor and acceptor domains, respectively). ${ }^{42}$ Reproduced from ref. 42 with permission from John Wiley and Sons, copyright 2019.

and the anode to facilitate the collection of holes and/or blocking of the electrons. A counterpart electron transport layer (ETL) such as ZnO is placed between the active layer and the cathode to extract electrons and/or block holes. At least one electrode, the cathode or anode, is made of a transparent conductor (TC) such as indium-doped tin oxide (ITO) to allow transmission of light to reach the active layer. The two most commonly adopted OSC architectures are shown in Fig. 1a and $\mathrm{b}$; the conventional one has a TC anode (Fig. 1a), while the inverted one has a TC cathode (Fig. 1b).

The donor material in the active layer is a p-type semiconductor that has relatively high-lying highest occupied molecular orbital $\left(E_{\text {Номо }}\right)$ and lowest unoccupied molecular orbital ( $\left.E_{\text {LUMo }}\right)$ energy levels, which can stabilize and transport the photogenerated holes. On the contrary, the acceptor material is an n-type semiconductor that has low $E_{\mathrm{HOMO}}$ and $E_{\mathrm{LUMO}}$ with respect to those of the donor material, which can stabilize and transport the photogenerated electrons. One or both of the donor and acceptor materials should strongly absorb sunlight.

The ultimate photovoltaic performance parameter of an OSC is the PCE or $\eta$, which is the percentage of electric energy generated by an OSC out of the total photo energy incident on the active layer conventionally under the standardized AM 1.5G solar spectrum with an intensity of $100 \mathrm{~mW} \mathrm{~cm} \mathrm{~cm}^{-2}$. As shown in Fig. 1c, the PCE is contributed by three factors, the short circuit current density $\left(J_{\mathrm{SC}}\right.$, $\left.\mathrm{mA} \mathrm{cm}^{-2}\right)$, open circuit voltage $\left(V_{\mathrm{OC}}, \mathrm{V}\right)$, and fill factor $(\mathrm{FF})$, obtained from the current density-voltage $(J-V)$ curve of an OSC based on the relationship PCE $=\left(J_{\mathrm{SC}} \times V_{\mathrm{OC}} \times \mathrm{FF}\right) / P_{\text {in }}$, where $P_{\text {in }}$ is the input power density $\left(100 \mathrm{~mW} \mathrm{~cm}^{-2}\right)$ of the light source under AM 1.5G conditions. The FF represents the ratio of the product of $J_{\mathrm{mp}} \times V_{\mathrm{mp}}$ (at the maximum power point on the $J-V$ curve) over the product of $J_{\mathrm{SC}}$ and $V_{\mathrm{OC}}$. The FF values are typically $0.5-0.7$ for highperforming OSCs. Broader light absorption in the solar spectrum by the active layer increases $J_{\mathrm{SC}}$ of the OSC; however, absorption of long wavelength (lower energy) photons results in a lower $V_{\mathrm{OC}}$. Therefore, it is preferred that an active layer absorbs the maximum number of photons in the low wavelength region of $\sim 400-925 \mathrm{~nm}$ 
(or energies of $\sim 3-1.34 \mathrm{eV}$ ) based on the Shockley-Queisser (S-Q) limit. ${ }^{43}$ The portion of sunlight with wavelengths longer than $925 \mathrm{~nm}$ can be effectively utilized by developing a tandem OSC with two or more OSC devices combined. ${ }^{44-47}$ Research into tandem OSCs has also attracted much attention, but faces numerous issues since deposition of an increased number of well-defined thin active layers and interlayers is very challenging and the charge transport in these multilayered devices is too complicated to control. Although tandem OSCs can achieve higher PCE intrinsically, single junction OSCs still perform better at the moment.

A typical OSC device undergoes photovoltaic processes as follows (Fig. 1d): ${ }^{48-50}$ (1) excitons (hole-electron pairs) are produced in the $\mathrm{BHJ}$ active layer (in the donor, the acceptor, or both phases) upon absorption of photons from sunlight; (2) the formed excitons diffuse towards the donor-acceptor (D-A) interfaces; (3) the excitons are dissociated into free holes and electrons at the D-A interfaces; and (4) the free holes and electrons travel through the donor and acceptor phases and are collected at the anode and cathode, respectively.

An OSC works through close collaboration of matching donor and acceptors. Fig. 2 illustrates the complex hierarchical relationships between the cell performance, properties, and the molecular and nano-/microstructures of polymer donor materials. Each of the cell performance parameters, $J_{\mathrm{SC}}, V_{\mathrm{OC}}$, or FF, is influenced by the photovoltaic processes and material properties, which are ultimately governed by the molecular structure of the polymer donor.

Specifically, $J_{\mathrm{SC}}$ is influenced by all the photovoltaic processes, where (1) the number of excitons generated (or photons absorbed) depends largely on the absorption coefficient $(\alpha)$ and the bandgap $\left(E_{\mathrm{g}}\right)$ of the donor; (2) exciton diffusion is influenced by the electronic structure of the conjugated building block, the dielectric constant $\left(\varepsilon_{\mathrm{r}}\right)$, and the morphology (phase size) of the donor; (3) exciton dissociation is influenced by the electronic structure of the building block, the dielectric constant, and the HOMO and LUMO energy offsets, $\Delta E_{\mathrm{HOMO}}$ and $\Delta E_{\mathrm{LUMO}}$, between the donor and the acceptor; and (4) transport and collection of charge carriers (holes) are determined by the hole mobility $\left(\mu_{\mathrm{h}}\right)$ of the donor and its balance with the electron mobility $\left(\mu_{\mathrm{e}}\right)$ of the acceptor. A higher dielectric constant can decrease the exciton binding energy, reducing exciton recombination events. If the donor phase is too large, excitons generated in a region with a distance to the donor and acceptor interface greater than the exciton diffusion length would recombine, leading to a reduction in $J_{\mathrm{SC}}$.

$V_{\mathrm{OC}}$ is determined by the difference between $E_{\mathrm{LUMO}}$ of the acceptor and $E_{\text {HOMO }}$ of the donor as well as the dielectric constant of the donor (and acceptor). A lower $E_{\text {Hомо }}$ of the donor helps achieve a high $V_{\mathrm{OC}}$, while a large dielectric constant can reduce the exciton binding energy, which would help reduce the required donor-acceptor energy offset $\Delta E_{\mathrm{LUMO}}$ for exciton dissociation, achieving a higher $V_{\mathrm{OC}}$. Additionally, the type of building block (electronic structure) often plays a critical role in determining the minimal energy offset required for exciton dissociation, which is directly related to $V_{\mathrm{OC}}$.

The FF is critically influenced by $\mu_{\mathrm{h}}$ of the donor and its balance with $\mu_{\mathrm{e}}$ of the acceptor. High and balanced $\mu_{\mathrm{h}}$ and $\mu_{\mathrm{e}}$ of $>10^{-4}$ $\mathrm{cm}^{2} \mathrm{~V}^{-1} \mathrm{~s}^{-1}$ are usually required to achieve a high FF. The morphology of the donor and acceptor blend film also exerts some influence on the FF. ${ }^{51-53}$ The carrier mobility is influenced by several factors including the building block, side chain, crystallinity (degree of crystallinity and crystal orientation), film morphology, and amount of structural defects. A face-on lamellar packing

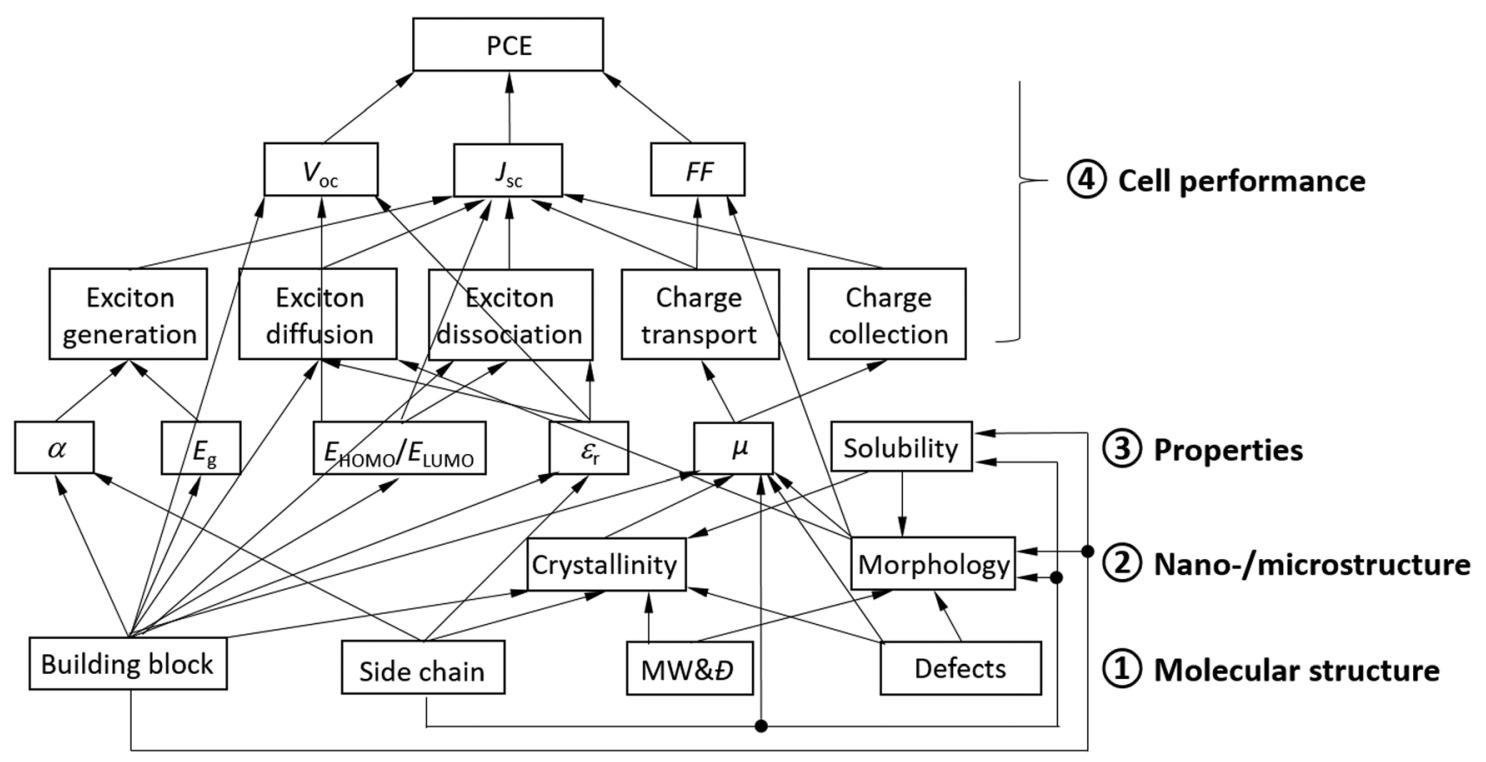

Fig. 2 Scheme of the structure-property-cell performance relationships of a polymer donor for OSCs, where $\alpha$ is the absorption coefficient, $\varepsilon_{\mathrm{r}}$ is the dielectric constant (or relative permittivity), $\mu$ is the mobility, and MW and $\Theta$ are the molecular weight and its distribution, respectively, of the polymer donor. Defects may include terminal groups, homo coupled units in a copolymer, random arrangements of comonomers in a copolymer, regio-irregular units, branching, lightly cross-linked units, oligomers, etc. Some or all of these relationships may apply to small molecule donors as well as polymer and small molecule acceptors. 
motif for the polymer donor in an OSC is desirable because the charge transport is facilitated through the vertically aligned $\pi-\pi$ stacks in this type of crystal motif. Structural defects refer to the terminal groups, homo coupled units in a copolymer, random arrangements of comonomers in a copolymer, regio-irregular units, branching, lightly cross-linked units, oligomers, etc. Most structural defects are difficult to determine but are often largely responsible for the poor cell performance since they have adverse effects on the crystallinity, morphology, and charge transport.

Additionally, although not shown in Fig. 2, the properties of the interfaces between the active layer and the HTL and/or ETL determine the efficiency of charge collection, which influences $J_{\mathrm{SC}}, V_{\mathrm{OC}}$, and/or the $\mathrm{FF}$.

As can be clearly seen in Fig. 2, the molecular structure fundamentally dictates the nano-/microstructure, properties, and OSC performance of a polymer donor. In particular, the $\pi$-conjugated building block used to construct a donor determines all the properties of the donor and the performance parameters of its OSC.

Characterization of the structures and properties of donors, acceptors, and their blends is nontrivial and often encounters great challenges. The widely used methodologies for characterization of their key structural features and properties are briefly described as follows:

(1) $E_{\mathrm{g}}$ : UV-vis-NIR spectroscopy is a simple and the most widely used method to obtain the bandgap of the donor or acceptor using the absorption onset wavelength. However, many materials, particularly polymers, are non-monodisperse and contain disordered structures, resulting in a tail in their absorption spectra with ill-defined onset edges. Measurements using the intersection of the normalized absorption and emission spectra can overcome this issue. ${ }^{54,55}$ Alternatively, $E_{\mathrm{g}}$ can be calculated from the onset of the EQE spectrum of the OSC device to minimize the influence of the film morphology. ${ }^{55}$

(2) $E_{\mathrm{HOMO}} / E_{\text {LUMO }}$ : due to its low-cost and easy operation, cyclic voltammetry (CV) is the most popular method used to estimate $E_{\mathrm{HOMO}}$ and $E_{\mathrm{LUMO}}$ of the donor or acceptor by using the onset oxidation and reduction potentials, respectively, with a reference having a known $E_{\text {Номо }}$ such as ferrocene $\left(E_{\text {Номо }}=\right.$ $-4.8 \mathrm{eV})$. However, most donors and acceptors only show the oxidation or the reduction process, respectively, in their $\mathrm{CV}$ diagrams. In such cases, the optical bandgap obtained by UVvis-NIR and $E_{\text {Номо }}$ or $E_{\text {LUMO }}$ obtained by $\mathrm{CV}$ are usually combined to calculate $E_{\mathrm{LUMO}}$ or $E_{\text {Номо }}$ of the donor or acceptor, respectively. The energy levels calculated in this way are often inaccurate because of the large exciton binding energy (up to $\sim 0.3-1 \mathrm{eV}$ ) associated with organic semiconductors. The energy levels determined by $\mathrm{CV}$ measurements also have large variations caused by different experimental conditions ${ }^{56,57}$ and thus the values reported for the same materials in the literature often vary largely. Nonetheless, the $E_{\mathrm{HOMO}}$ and $E_{\mathrm{LUMO}}$ values obtained by CV under similar conditions are still very useful and quite reliable for comparing the energy levels of different materials. A combination of ultraviolet photoelectron spectroscopy (UPS) and (low-energy) inverse photoemission spectroscopy (IPES), which are much more expensive and complex to operate compared to the electrochemical setup used for the CV measurements, can also be used to more accurately measure the ionization potential (IP) and electron affinity (EA) values, which correspond to $E_{\mathrm{HOMO}}$ and $E_{\mathrm{LUMO}}$, respectively. ${ }^{56-58}$

(3) Crystallinity: wide-angle X-ray diffraction (WAXD) is the standard characterization method to study the crystal structure. When this method is used for thin films $(\sim 100 \mathrm{~nm})$, a grazing incidence geometry is used and the method is termed as GIWAXS or GIXD. GIWAXS can be used to obtain information about the structure, orientation, and ordering of crystallites. ${ }^{59}$ Particularly, two-dimensional (2-D) GIWAXS measured with a powerful synchrotron X-ray source can reveal the in-plane and out-of-plane crystal structures of the finely mixed BHJ blend film at the nanometer scale. ${ }^{60-62}$

(4) Morphology/phase separation: atomic force microscopy (AFM) is a surface analysis technique commonly used to probe morphological features (on the nanometer to micron-scale) such as film roughness, phase segregation, and domain size. Transmission electron microscopy (TEM) has also been used to extract information about phase segregation, grain size, and grain connectivity. ${ }^{59}$ Resonant soft X-ray scattering (RSoXS) is another evolving method to investigate multi-component, multi-phase systems like the active layer of an OSC, where the contrast of the donor and acceptor components can be tuned by selection of the incident X-ray energy to quantitatively reveal the molecular orientation, domain purity, and domain spacing..$^{59,60,63,64}$

(5) Exciton dissociation, collection, and recombination: the trend of photocurrent density $J_{\mathrm{ph}}\left(J_{\mathrm{ph}}=J_{\mathrm{L}}-J_{\mathrm{D}}\right.$, where $J_{\mathrm{L}}$ is the current density under illumination and $J_{\mathrm{D}}$ is the current density in the dark) versus effective voltage $\left(V_{\text {eff }}=V-V_{0}\right)$ gives insights into the charge generation and exciton dissociation characteristics of the device. Here $V_{0}$ is called the compensation voltage or the voltage at which $J_{\mathrm{ph}}=0$ and $V$ is the applied voltage. ${ }^{65,66}$ $J_{\text {ph }}$ reaches a saturation value $\left(J_{\text {sat }}\right)$ with increasing $V_{\text {eff }}$, which means that all the photogenerated excitons are dissociated into free carriers and collected by the electrodes with the assistance of large reverse bias. Thus, the exciton dissociation probability, defined as $P_{\text {diss }}=J_{\mathrm{SC}} / J_{\text {sat }}$, reflects the efficiency of exciton dissociation, charge transport, and charge collection. ${ }^{65}$ The photoinduced charge transfer efficiency (from the donor to the acceptor or vice versa) can also be probed via photoluminescence (PL) quenching and decay measurements of the blend films relative to the neat films. ${ }^{67,68}$

The light intensity dependence of $V_{\mathrm{OC}}$ can directly indicate the role of trap-assisted recombination (or SRH recombination) versus bimolecular recombination under open circuit conditions. For this analysis the slope $S_{1}$ (or ideality factor) is defined as $S_{1}=\frac{q \partial V_{\mathrm{OC}}}{k T \partial \ln \left(P_{\text {light }}\right)}$, where $q$ is the elementary charge, $k$ is the Boltzmann constant, $T$ is the absolute temperature, and $P_{\text {light }}$ is the light intensity. ${ }^{69-71}$ A value of $S_{1}$ close to 1 indicates more ideal recombination, whereas values $>1$ indicate more trap-assisted/ SRH recombination in the device. ${ }^{65,71}$ Moreover, $J_{\mathrm{SC}}$ of an OSC follows a power law dependence with respect to the light intensity $\left(P_{\text {light }}\right)$ (i.e. $J_{\mathrm{SC}} \propto P_{\text {light }}^{S_{2}}$ ), where $S_{2}$ is the exponential factor. A value 
of $S_{2}$ close to unity indicates negligible bimolecular recombination during sweep-out under short circuit conditions. ${ }^{72-74}$

(6) Mobility: the methods for measuring the carrier mobility along the direction vertical to the film (relevant to the charge transport in OSC devices) include space-charge-limited current (SCLC), ${ }^{75-77}$ time of flight (TOF) ${ }^{78,79}$ carrier extraction by linearly increasing voltage (CELIV), ${ }^{80,81}$ photogenerated charges in CELIV (photoCELIV), ${ }^{82-84}$ and impedance spectroscopy (IS). ${ }^{85,86}$ The SCLC method is most widely used.

(7) Dielectric constant: the exciton binding energy $\left(E_{\mathrm{b}}\right)$ estimated by the coulomb interaction depends inversely on the dielectric constant, $\varepsilon_{\mathrm{r}}: E_{\mathrm{b}}=q^{2} / 4 \pi \varepsilon_{0} \varepsilon_{\mathrm{r}} r$, where $q$ is the elementary charge, $\varepsilon_{0}$ is the permittivity of a vacuum, and $r$ is the electron and hole separation distance. ${ }^{87-92}$ Therefore, to facilitate exciton diffusion and dissociation, semiconductors with high dielectric constant values are preferred. The capacitance-voltage $(\mathrm{C}-\mathrm{V})$ measurement at different frequencies (impedance spectroscopy) of a film sandwiched between two electrodes can be performed to obtain the dielectric constant value. ${ }^{93-98}$

\section{High performance WBG polymer donors for NFAs}

On the basis of the optical bandgap, polymer donors can be divided into narrow-bandgap or low-bandgap (LBG, bandgap $<1.6 \mathrm{eV}$ ), medium-bandgap (MBG, $1.6 \mathrm{eV}<$ bandgap $<1.8 \mathrm{eV}$ ) and wide-bandgap (WBG, bandgap $>1.8 \mathrm{eV}$ ). ${ }^{35}$ To form complementary absorption with narrow-bandgap NFAs, polymer donors with medium- or wide-bandgaps are needed. Regioregular, headto-tail poly(3-hexylthiophene-2,5-diyl) (P3HT), which can be synthesized at low cost and shows high $\mu_{\mathrm{h}}$, has been extensively studied as a donor for OSCs based on fullerene acceptors. ${ }^{50,99,100}$ However, P3HT has a rather high $E_{\text {HOMO }}(c a .-5.1 \mathrm{eV})$, which leads to a low $V_{\text {OC }}$, limiting its solar cell performance. ${ }^{101-105}$ On the other hand, donor-acceptor (D-A) polymers containing alternating D and A building blocks on the backbone (Fig. 3) have been extensively developed as donor materials since their optical bandgaps and FMO (i.e. HOMO and LUMO) energy levels can be conveniently tuned through intramolecular charge transfer (ICT) by choosing different D and A units. ${ }^{32,35,49,106-108} \mathrm{D}-\mathrm{A}$ polymers also have enhanced $\mu_{\mathrm{h}}$ due to intermolecular D-A interactions. D-A polymers have shown far better solar cell performances than P3HT in both fullerene and NFA-based OSCs.

The D building blocks mostly used to construct highperforming D-A polymer donors for NFA-based OSCs are thiophene-containing moieties such as thiophene (T), thieno[3,2$b]$ thiophene (TT), and benzo[1,2- $\left.b: 4,5-b^{\prime}\right]$ dithiophene (BDT) (Fig. 3), owing to their appropriate electron-donating effect to tune $E_{\mathrm{HOMO}}$, lower steric effect to maintain backbone coplanarity, rich chemistry, and good chemical stability. Two or more D blocks are often used to constitute a D unit in a D-A polymer. The frequently used A building blocks include 3-fluorothieno[3,4- $b]$ thiophene-2carboxylate (FC-TT), ${ }^{109}$ thieno[3.4-c]pyrrole-4,6-dione (TPD), ${ }^{110}$ benzo[1,2-c:4,5- $\left.c^{\prime}\right]$ dithiophene-4,8-dione (BDD), ${ }^{111}$ difluorobenzotriazole (FBTA), ${ }^{112}$ quinoxaline (Qx), ${ }^{113}$ and benzothiadiazole (BT) ${ }^{114}$ which have an electron-withdrawing ester, imide, fluorine, diketone, and N-containing heterocycle substituting or fused to the thiophene or benzene ring. One or more linear or branched alkyl side chains $\left(\mathrm{R}_{1}\right.$ and $\left.\mathrm{R}_{2}\right)$ are anchored to $\mathrm{D}, \mathrm{A}$, or both units to render the polymer soluble and control the packing of polymer chains in the solid state.

By analysing the chemical structures of high-performing D-A polymer donors, one would notice that the majority of them contain the fused ring structure BDT as the D building block. Therefore, in this review, the polymer donors are classified as BDTbased polymers and non-BDT based polymers. The BDT-based polymers are further classified according to the A units: (1) ester or imide substituted building blocks (FC-TT and TPD), (2) diketone derivatives (BDD), (3) N-heterocycles containing $\mathrm{sp}^{2}$ nitrogen (FBTA and Qx), and (4) other A units (such as BT) (Fig. 3). ${ }^{4,49,106,114}$ The structures of the polymer donors discussed in this review are shown in Fig. 4 and 5 based on this classification. Their key optoelectronic properties are listed in Table 1.

As mentioned in the previous section, good matching between donor and acceptor materials is vital for achieving high OSC performance. Therefore, developing a polymer donor material having its photophysical properties matching with those of a certain NFA material on purpose is the most adopted and effective strategy. From a large number of high performance NFAs, ${ }^{36-38,40}$ we deliberately select the three most representative ones, ITIC, IT-4F, and Y6, which have been widely

\section{D-A polymer donor}
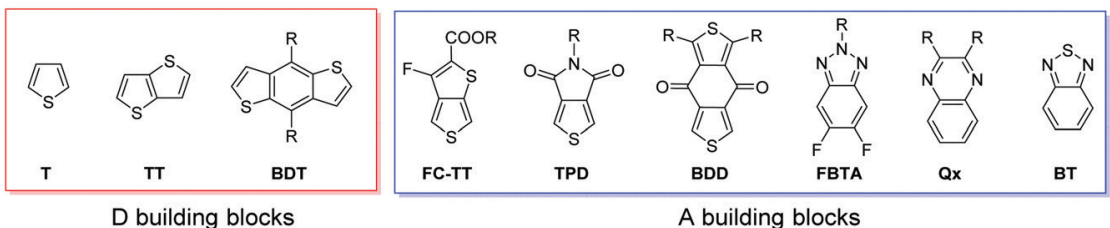

A building blocks

Fig. 3 Chemical structures of representative $D$ and $A$ building blocks used for high performance $D-A$ polymers, where $R_{1}$ or $R_{2}$ is a side chain chosen from alkyl, alkoxy, alkylthio, and aryl groups, etc., and $x$ or $y$ is an appropriate integer. 

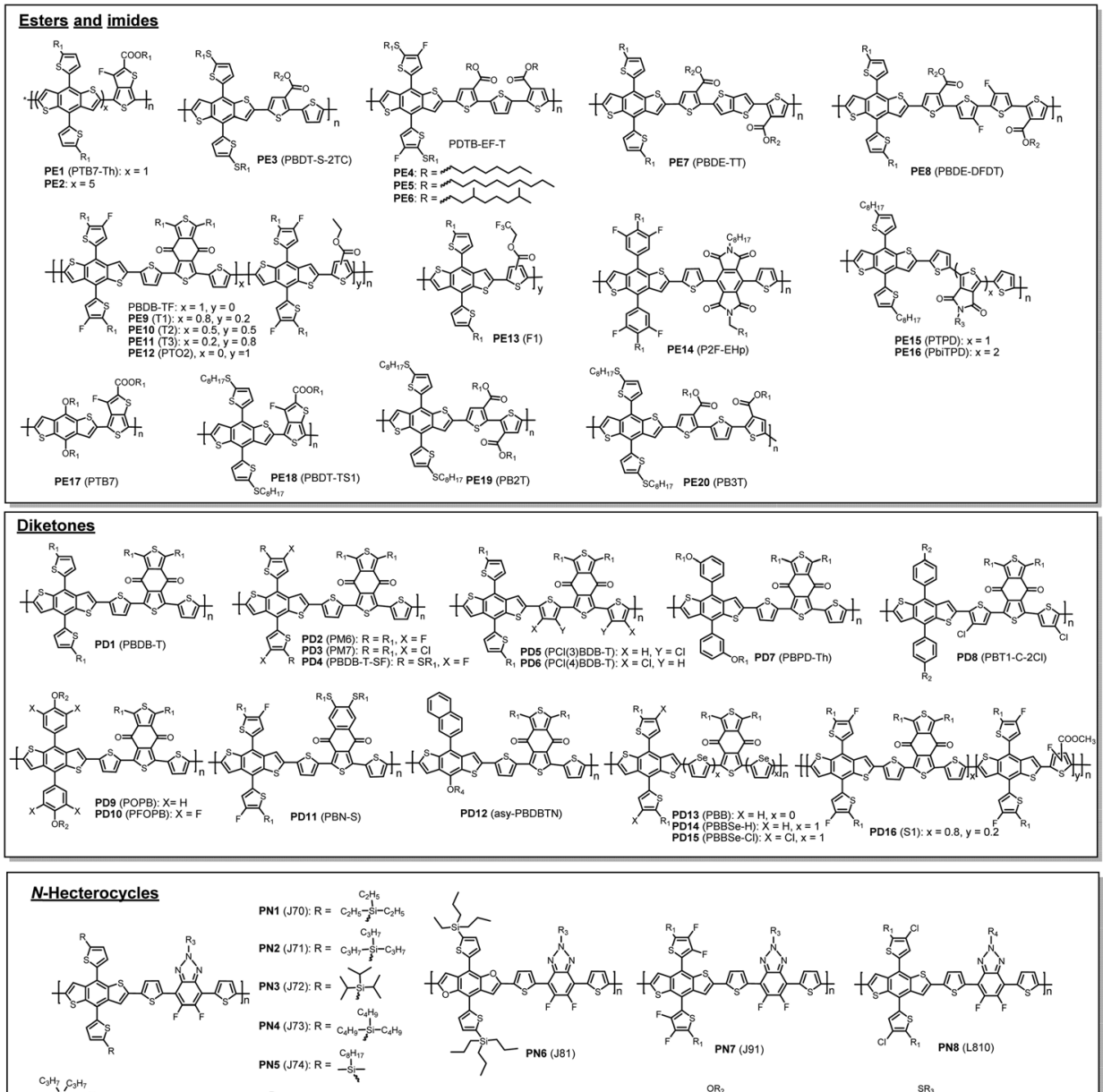

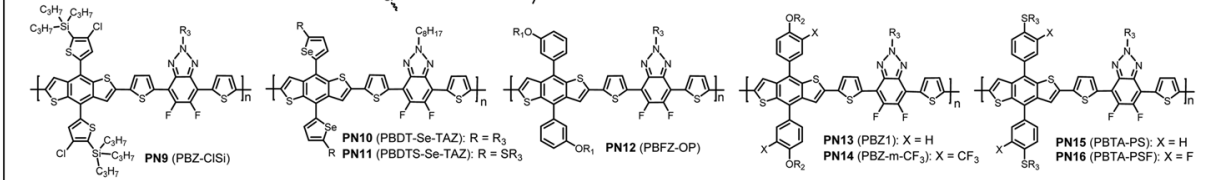
(P)

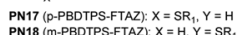

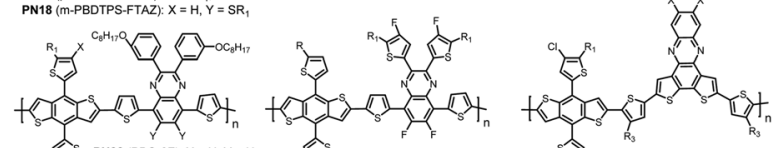

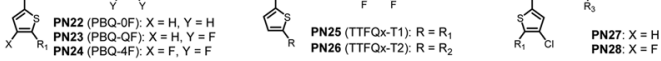
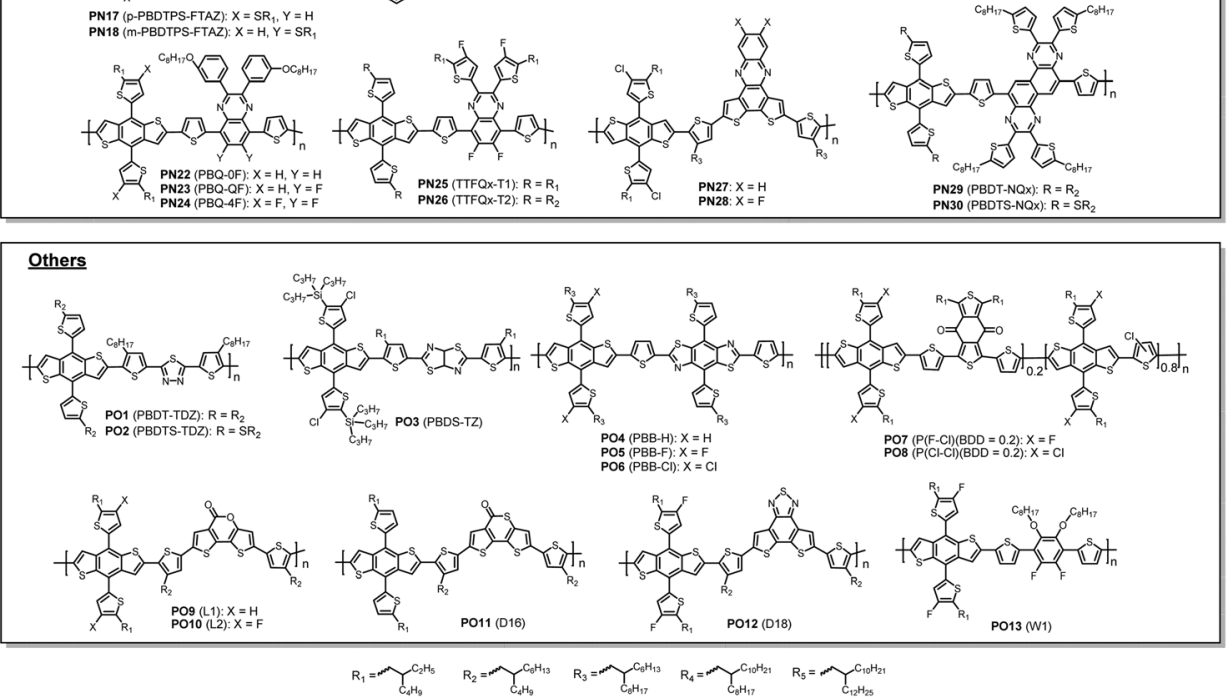

Fig. 4 Chemical structures of BDT-based polymer donors discussed in this review. Their properties are listed in Table 1. Names in parentheses are used in the original publications. 

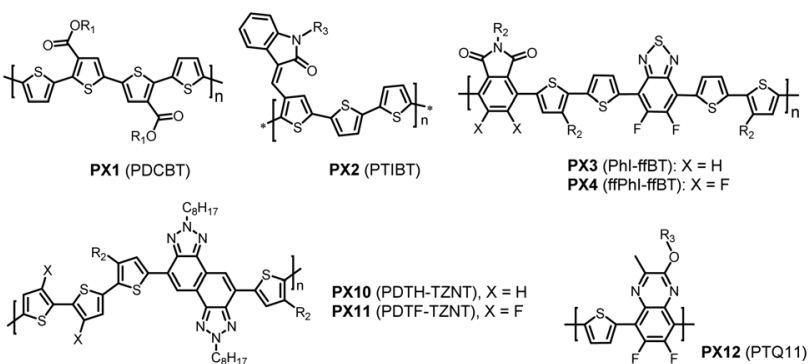

PX3 (Phl-ffBT): $X=H$ PX4 (ffPhl-ffBT): $X=$

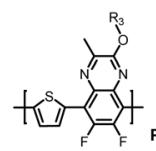

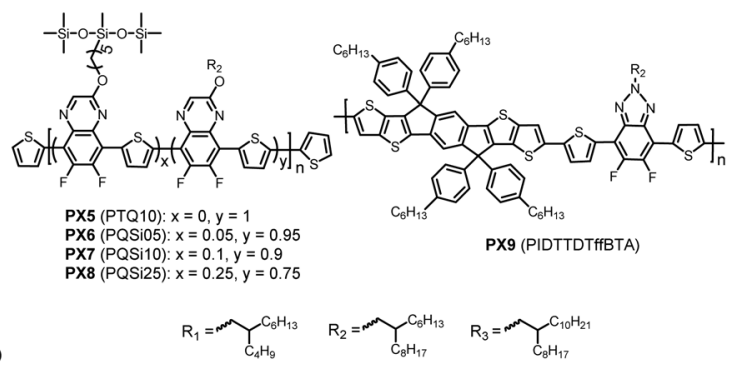

Fig. 5 Chemical structures of non-BDT-based polymer donors discussed in this review. Their properties are listed in Table 2. Names in parentheses are used in the original publications.

used for developing ultrahigh performance (PCE $>10 \%$ ) polymer donors. Their chemical structures are shown in Fig. 6, while their key optoelectronic properties are summarized in Table 2. It should be noted that the reported $E_{\mathrm{LUMO}}$ and $E_{\mathrm{HOMO}}$ values of the three NFAs, particularly ITIC, vary largely in the literature due to the different measurement conditions as mentioned earlier.

\subsection{High performance polymer donors matching with ITIC}

As a milestone for NFAs, ITIC was developed in 2015 by Lin et al. ${ }^{8}$ which has an electron-donating indacenodithienothiophene (IDTT) central unit and two electron-withdrawing 2-methylene-(3-(1,1-dicyanomethylene)-indanone) (IC) end groups. Hexyl phenyl side chains are introduced on IDTT to render the material soluble and to suppress the excessive aggregation of molecules in the solid state. ITIC has a good SCLC $\mu_{\mathrm{e}}$ of $3.0 \times 10^{-4} \mathrm{~cm}^{2} \mathrm{~V}^{-1} \mathrm{~s}^{-1}$, which approaches that of fullerene-based acceptors $\left(\sim 10^{-4}-10^{-2} \mathrm{~cm}^{2} \mathrm{~V}^{-1} \mathrm{~s}^{-1}\right) \cdot{ }^{179,180}$ Its rather high $E_{\text {LUMO }}(-3.83 \mathrm{eV})$ helps achieve a high $V_{\mathrm{OC}}$. However, ITIC has a relatively large bandgap $\left(E_{\mathrm{g}}=1.59 \mathrm{eV}\right)$, absorbing sunlight below $800 \mathrm{~nm}$, which restricts $J_{\mathrm{SC}}$ when a WBG polymer donor is used. Nonetheless, ITIC has been widely used as a model acceptor for the study and development of various polymer donors to provide significant insights into their structureproperty-cell performance relationships.

3.1.1 BDT-based polymer donors using ester or imide substituted building blocks as A units. PE1 (PTB7-Th) developed by Liao et al. ${ }^{109}$ which has 2-ethylhexyl-thienyl substituted BDT and FC-TT as D and A units, respectively, is one of the prominent D-A polymer donor materials for OSCs. PE1 has a rather narrow bandgap of $1.58 \mathrm{eV}$, which was designed as a donor material mainly for matching fullerene-based acceptors that absorb sunlight poorly. When ITIC is used as an acceptor and PE1 as a donor, their absorption profiles are mostly overlapped, which is undesirable for efficient light harvesting. Consequently, the devices based on the PE1:ITIC blend showed a moderate $J_{\mathrm{SC}}$ of $14.21 \mathrm{~mA} \mathrm{~cm}{ }^{-2}$ and PCE of $6.8 \%{ }^{8}$ In order to improve the light absorption, Kim et al. ${ }^{116}$ developed a series of polymer donors, modulating the energy levels and absorption spectra by controlling the BDT/FC-TT (D/A) ratio in the polymer backbone, and found that as the D/A ratio increases, $E_{\mathrm{HOMO}}$ downshifts and $E_{\mathrm{g}}$ widens. PE2 with a D/A ratio of $5: 1$ has the optimal $E_{\text {Номо }}$ of $-5.37 \mathrm{eV}$ and $E_{\mathrm{g}}$ of $1.74 \mathrm{eV}$ to form complementary absorption with ITIC. As a result, a higher $J_{\mathrm{SC}}$ $\left(17.24 \mathrm{~mA} \mathrm{~cm}{ }^{-2}\right)$ along with a higher $V_{\mathrm{OC}}(0.89 \mathrm{~V})$ and $\mathrm{FF}(67 \%)$ and thus a higher PCE of $10.27 \%$ were achieved compared to polymers with other D/A ratios. An et al. ${ }^{117}$ developed a polymer PE3 (PBDT-S-2TC) having a weaker electron-withdrawing ester substituted thiophene as A units. A non-substituted thiophene spacer was inserted between the ester substituted thiophene and the BDT unit to maintain the planarity of the polymer backbone. In addition, alkylthio chains were introduced onto BDT to lower $E_{\mathrm{HOMO}}(-5.47 \mathrm{eV})$. A wide bandgap of $1.94 \mathrm{eV}$ was obtained, which matches that of ITIC very well for complementary light absorption. The devices based on PE3:ITIC showed an improved $J_{\mathrm{SC}}$ and a very high $V_{\mathrm{OC}}$ of $0.96 \mathrm{~V}$, resulting in a PCE of $10.12 \%$.

3.1.2 BDT-based polymer donors using diketone derivatives as A units. Diketone substituted thiophene building block BDD is a relatively weak electron-accepting (A) unit. The D-A polymers based on BDT and BDD demonstrated excellent photovoltaic performance when paired with narrow bandgap NFAs. PD1 (PBDB-T or PBDTBDD) was the first polymer using BDD developed by Qian et al., ${ }^{111}$ which achieved a PCE of $6.67 \%$ when paired with $\mathrm{PC}_{61} \mathrm{BM}$. Later, Zhao et al. ${ }^{16}$ utilized PD1 as a donor to match ITIC since PD1 has a relatively wide bandgap of $1.80 \mathrm{eV}$. Compared with PE1:ITIC, PD1:ITIC exhibited much improved EQE values in the short wavelength range (300-500 $\mathrm{nm}$ ) due to the strong absorption by PD1 (Fig. 7b). Therefore, a higher $J_{\mathrm{SC}}\left(16.81 \mathrm{~mA} \mathrm{~cm}{ }^{-2}\right.$ for PD1:ITIC vs. $14.21 \mathrm{~mA} \mathrm{~cm}{ }^{-2}$ for PE1:ITIC) was obtained. The improved and more balanced $\mu_{\mathrm{h}}$ and $\mu_{\mathrm{e}}$ of PD1:ITIC (Table 3) led to the increased FF compared to PE1:ITIC (74.2\% vs. 59.1\%). In addition, although PD1 showed a similar $E_{\text {Номо }}(\sim-5.2 \mathrm{eV})$ to PE1, a higher $V_{\mathrm{OC}}(0.899$ vs. $0.810 \mathrm{~V})$ was obtained owing to its smaller energy loss $\left(E_{\text {loss }}\right)$. Combining all these improvements, the PD1:ITIC-based device displayed a much higher PCE of $11.21 \% .{ }^{16}$

Since then, PD1 was widely used as a star polymer donor and the PCE of devices based on PD1 was further improved to above $13 \%$ with a largely improved $J_{\mathrm{SC}}$ of up to $\sim 20 \mathrm{~mA} \mathrm{~cm}^{-2}$ through rational design of new NFAs with narrower bandgaps. ${ }^{181-185}$

Fan et al. ${ }^{133}$ synthesized a novel polymer donor PD7 (PBPD-Th) with a low-lying $E_{\mathrm{HOMO}}$ of $-5.42 \mathrm{eV}$ by replacing the 5-alkylthienyl in PD1 with $m$-alkoxyphenyl on the BDT units. OSCs based on PD7:ITIC have a smaller $E_{\text {loss }}$ and therefore achieved a high $V_{\mathrm{OC}}$ of up to $1.01 \mathrm{~V}$. Moreover, the polymer also has a wide bandgap of $1.90 \mathrm{eV}$, resulting in complementary absorption with ITIC. High $\mathrm{EQE}$ values (up to $\sim 80 \%$ ), especially in the short wavelength range 
Table 1 Key optoelectronic properties of polymer donors discussed in this review

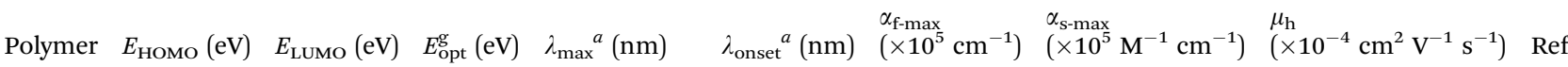

\begin{tabular}{|c|c|c|c|c|c|c|c|c|c|}
\hline PE1 & -5.22 & $-3.64^{b}$ & 1.58 & 625,690 & 785 & $1.0^{b}$ & & $11.1^{115}$ & 8 \\
\hline PE2 & -5.37 & -3.63 & 1.74 & 549 & 711 & & & & 116 \\
\hline PE3 & -5.47 & -3.58 & 1.94 & & 538 & $1^{b}$ & & & 117 \\
\hline PE4 & -5.51 & -3.59 & 1.93 & 540 & 642 & 0.79 & & $1^{b}$ & 118 \\
\hline PE5 & -5.50 & -3.59 & 1.93 & 544 & 642 & 0.81 & & $1.2^{b}$ & 118 \\
\hline PE6 & -5.54 & $-3.6^{b}$ & 1.94 & 536 & 639 & 0.72 & & 0.73 & 118 \\
\hline PE7 & -5.49 & & 1.97 & 538 & 629 & $0.726^{b}$ & $0.607^{b}$ & $1.11^{b}$ & 119 \\
\hline PE8 & -5.5 & & 1.94 & 544 & 639 & 0.758 & $0.65^{b}$ & 3.4 & 119 \\
\hline PE9 & -5.48 & -3.63 & 1.83 & & 678 & & & & 120 \\
\hline PE10 & -5.51 & -3.63 & 1.87 & & 663 & & & & 120 \\
\hline PE11 & -5.55 & -3.62 & 1.93 & & 642 & & & & 120 \\
\hline PE12 & -5.59 & -3.67 & 1.99 & 533 & 623 & 0.769 & & & 121 \\
\hline PE13 & -5.50 & -3.53 & 1.97 & 577 & 630 & 1.25 & & & 122 \\
\hline PE14 & -5.46 & -3.13 & 1.82 & & 700 & & & & 123 \\
\hline PE15 & -5.05 & -3.19 & 1.86 & 562,613 & 667 & & & & 110 \\
\hline PE16 & -5.20 & -3.45 & 1.78 & 586,630 & 670 & & & & 110 \\
\hline PE17 & $-5.15^{7}$ & $-3.31^{7}$ & 1.60 & 614,674 & 775 & & & 5.8 & 124 \\
\hline PE18 & -5.33 & -3.52 & 1.51 & 655,705 & 820 & & & $109^{125}$ & 126 \\
\hline PE19 & -5.63 & -3.63 & 2.24 & 416 & 554 & & 0.362 & 0.028 & 127 \\
\hline PE20 & -5.39 & -3.37 & 1.96 & 540 & 633 & & 0.557 & 0.94 & 127 \\
\hline PD1 & -5.23 & -3.18 & 1.80 & 581,622 & 689 & $0.86^{128}$ & & $1.11^{128}$ & 111 \\
\hline PD2 & -5.50 & -3.56 & 1.80 & 570,614 & 689 & & & 2.97 & 129 \\
\hline PD3 & -5.52 & -3.57 & 1.79 & $577,606^{128}$ & 692 & $0.99^{128}$ & & $6.67^{128}$ & 130 \\
\hline PD4 & -5.40 & -3.60 & 1.80 & 626 & 688 & 1.08 & & & 22 \\
\hline PD5 & -5.54 & -3.27 & 2.11 & 479 & 588 & & & & 131 \\
\hline PD6 & -5.48 & -3.47 & 1.78 & 622 & 697 & & & & 131 \\
\hline PD7 & -5.42 & -3.36 & 1.90 & 556 & 652 & 0.697 & 0.331 & $7.56^{132}$ & 133 \\
\hline PD8 & -5.59 & -3.53 & 1.85 & 627 & 671 & & & 13.4 & 134 \\
\hline PD9 & -5.38 & 3.57 & 1.81 & 577 & 685 & 0.531 & & 3.96 & 135 \\
\hline PD10 & -5.5 & -3.64 & 1.86 & 612 & 667 & 0.845 & & 15.1 & 135 \\
\hline PD11 & -5.48 & -3.52 & 1.75 & 632,625 & 710 & & & & 136 \\
\hline PD12 & -5.41 & -3.58 & 1.83 & 621 & 678 & 1 & & & 137 \\
\hline PD13 & -5.54 & -3.59 & 1.95 & 551 & 636 & & 2.63 & & 138 \\
\hline PD14 & -5.16 & -3.45 & 1.71 & 657 & 726 & & 5.54 & & 138 \\
\hline PD15 & -5.36 & -3.63 & 1.73 & 645 & 718 & & 7.37 & & 138 \\
\hline PD16 & -5.52 & -3.72 & 1.80 & & 689 & & & & 139 \\
\hline PN1 & -5.37 & -2.91 & 1.99 & 538,580 & 623 & 0.89 & & & 140 \\
\hline PN2 & -5.40 & -3.24 & 1.96 & 528,573 & 633 & 0.96 & & & 141 \\
\hline PN3 & -5.42 & -3.29 & 1.98 & 533,578 & 626 & 0.7 & & & 140 \\
\hline PN4 & -5.46 & -2.92 & 1.98 & 535,576 & 626 & 0.69 & & & 140 \\
\hline PN5 & -5.56 & -3.06 & 1.99 & 526 & 623 & 0.68 & & & 140 \\
\hline PN6 & -5.42 & -2.93 & 1.93 & 553,600 & 642 & & & & 142 \\
\hline PN7 & -5.50 & -3.02 & 2.00 & 536 & 620 & 0.98 & & & 143 \\
\hline PN8 & -5.57 & -3.58 & 1.99 & & 622 & 0.838 & & & 144 \\
\hline PN9 & -5.56 & -3.50 & 1.94 & 536 & 640 & 1.08 & & 10.2 & 145 \\
\hline PN10 & -5.23 & -3.43 & 1.92 & $372,550,597$ & 646 & & 0.564 & & 146 \\
\hline PN11 & -5.29 & -3.49 & 1.9 & $374,550,602$ & 653 & & 0.854 & & 146 \\
\hline PN12 & -5.33 & -3.01 & 1.99 & 530,575 & 623 & & & 7.28 & 147 \\
\hline PN13 & -5.27 & -3.06 & 1.96 & 539 & 632 & 0.523 & & 7.23 & 148 \\
\hline PN14 & -5.49 & -3.22 & 1.99 & 533 & 623 & 0.651 & & 7.86 & 148 \\
\hline PN15 & -5.34 & -3.4 & 1.94 & & 639 & & 0.73 & 5.59 & 20 \\
\hline PN16 & -5.52 & -3.54 & 1.98 & 537,577 & 626 & & 0.7 & 6.01 & 20 \\
\hline PN17 & -5.32 & -3.36 & 1.96 & 544,589 & 633 & & 0.62 & & 149 \\
\hline PN18 & -5.40 & -3.40 & 2.00 & 542,579 & 621 & & 0.60 & & 149 \\
\hline PN19 & -5.44 & -3.49 & 1.95 & & 636 & & & & 150 \\
\hline PN20 & -5.34 & -3.46 & 1.81 & 600 & 685 & 0.7 & & & 151 \\
\hline PN21 & -5.42 & -3.49 & 1.93 & 590 & 642 & & 1.1 & & 152 \\
\hline PN22 & -5.18 & -3.48 & 1.70 & 636 & 755 & 0.545 & 0.454 & & 113 \\
\hline PN23 & -5.34 & -3.62 & 1.72 & 600 & 737 & 0.731 & 0.515 & & 113 \\
\hline PN24 & -5.49 & -3.7 & 1.79 & 583 & 716 & 0.859 & 0.617 & & 113 \\
\hline PN25 & -5.31 & -3.62 & 1.69 & $361,435,652$ & 736 & 4.73 & & & 153 \\
\hline PN26 & -5.38 & -3.67 & 1.71 & $361,443,635$ & 724 & 4.64 & & & 153 \\
\hline PN27 & -5.33 & -2.94 & 1.86 & & 667 & & & 2.00 & 154 \\
\hline PN28 & -5.46 & -3.16 & 1.79 & & 693 & & & 7.74 & 154 \\
\hline PN29 & -5.24 & -3.42 & 1.80 & $374,450,632$ & 689 & & 29 & & 155 \\
\hline PN30 & -5.31 & -3.46 & 1.81 & $368,452,636$ & 685 & & 34.5 & & 155 \\
\hline PO1 & -5.35 & -2.78 & 2.07 & & 599 & & 25 & & 156 \\
\hline PO2 & -5.39 & -2.79 & 2.09 & & 593 & & 31 & & 156 \\
\hline PO3 & -5.41 & -3.46 & 1.95 & 550 & 636 & 1.13 & & & 157 \\
\hline
\end{tabular}


Table 1 (continued)

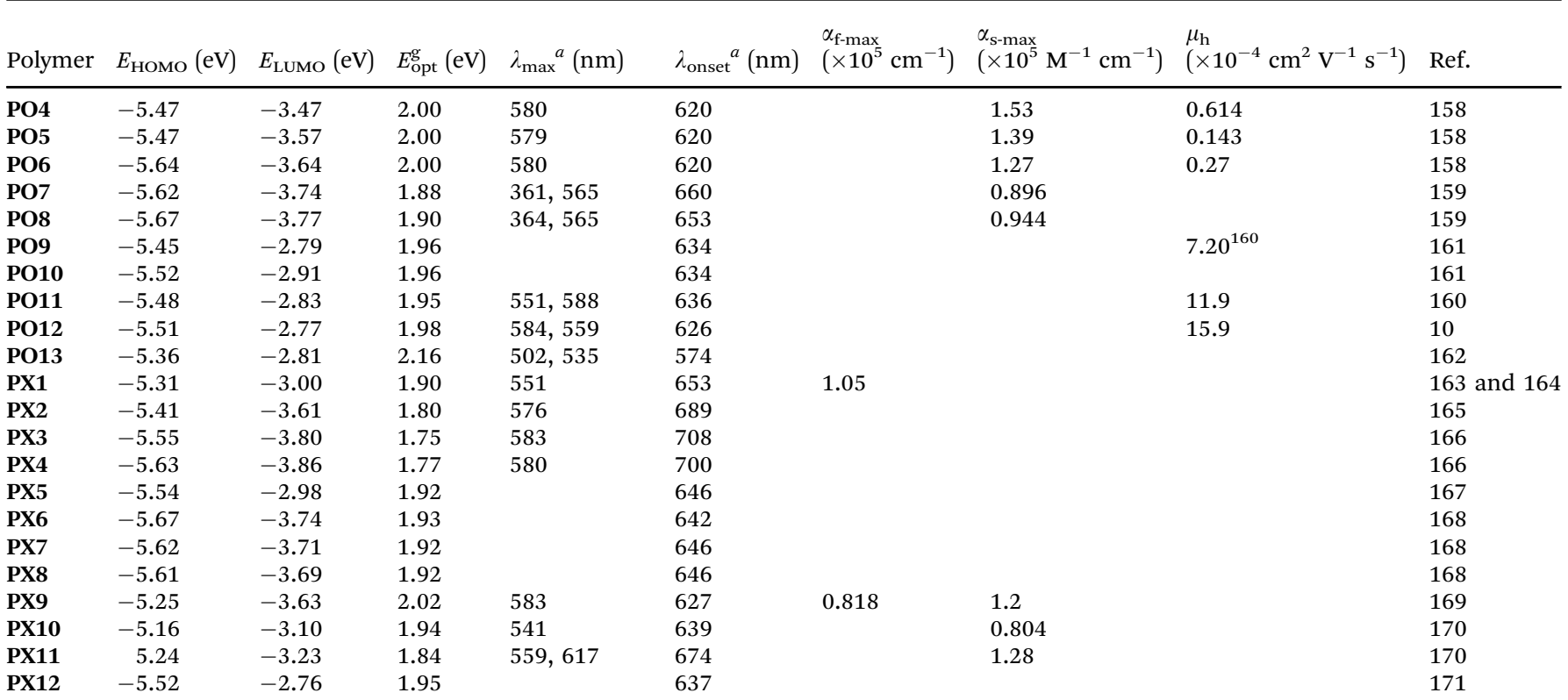

${ }^{a}$ Obtained from film absorption, $\alpha_{\mathrm{f} \text {-max }}$ represents the maximum extinction coefficient in a thin film, and $\alpha_{\mathrm{s} \text {-max }}$ represents the maximum extinction coefficient in solution. ${ }^{b}$ The numbers of significant digits of the data are adopted from the original references and may be different.
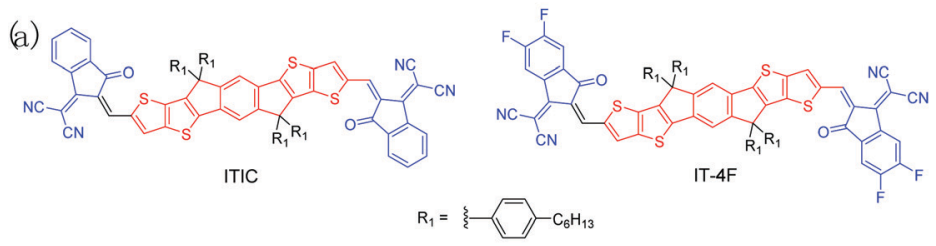

(b)

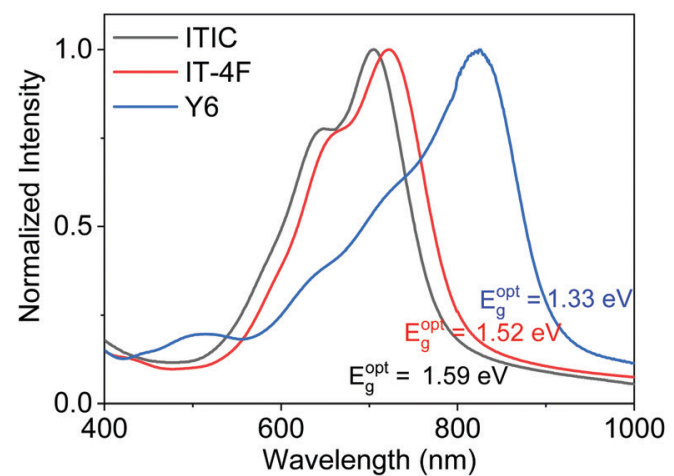

(c)

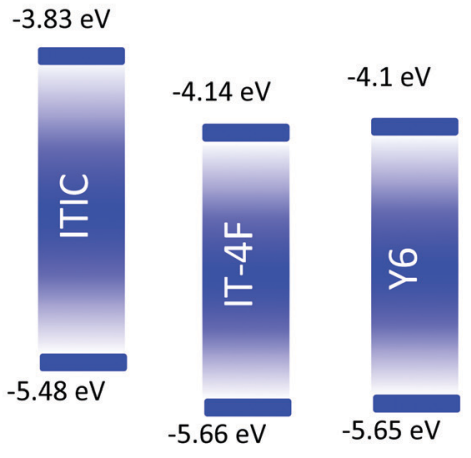

Fig. 6 Chemical structures (a), thin-film UV-vis-NIR spectra (b), and energy diagrams (c) of ITIC, ITIC-4F, and Y6.

(400-550 $\mathrm{nm}, \sim 70 \%$ on average), were obtained, which led to a high $J_{\mathrm{SC}}\left(18.1 \mathrm{~mA} \mathrm{~cm}{ }^{-2}\right)$ and thus a high PCE of $10.8 \%$.

By breaking the symmetry of the BDT unit, i.e., introducing different side chains on two sides of BDT, Li et al. ${ }^{137}$ developed an asymmetric polymer donor PD12 (asy-PBDBTN). Alkoxyl side chains were introduced to modulate the absorption spectra and solubility of the polymers (achieving enhanced light-harvesting ability and compatibility with acceptor materials, simultaneously), while a $\beta$-position linked naphthalene unit with high ionization potential and low electron density was introduced to lower $E_{\text {номо }}$. PD12 showed a low-lying $E_{\text {Номо }}$ of $-5.41 \mathrm{eV}$, a wide bandgap of $1.83 \mathrm{eV}$, and high light-harvesting ability with an $\alpha_{\mathrm{f}-\max }$ of up to $1 \times 10^{5} \mathrm{~cm}^{-1}$. OSCs based on the PD12:ITIC blend displayed a high PCE of $10.5 \% .{ }^{137}$

3.1.3 BDT-based polymer donors using $\mathbf{N}$-heterocycles as A units. By copolymerizing BDT with FBTA, Li's group developed a Jseries (J40 to J91) of polymer donors. ${ }^{19,23,142,143,186-188}$ Through optimization of the backbone conjugation dimension, variation 
Table 2 Key optoelectronic properties of NFAs discussed in this review

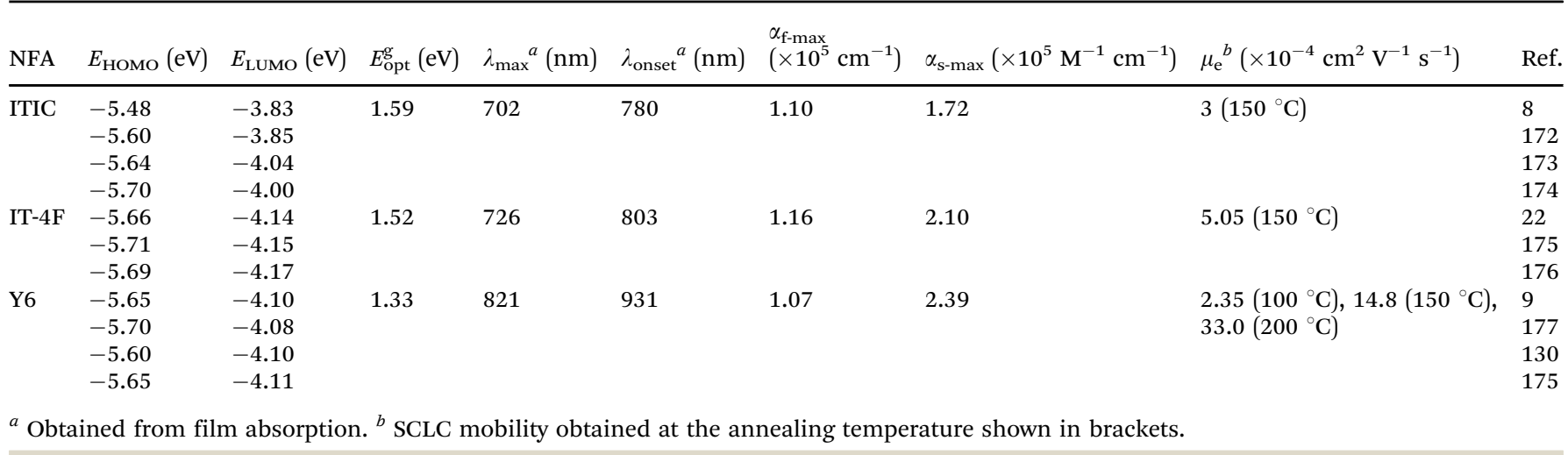
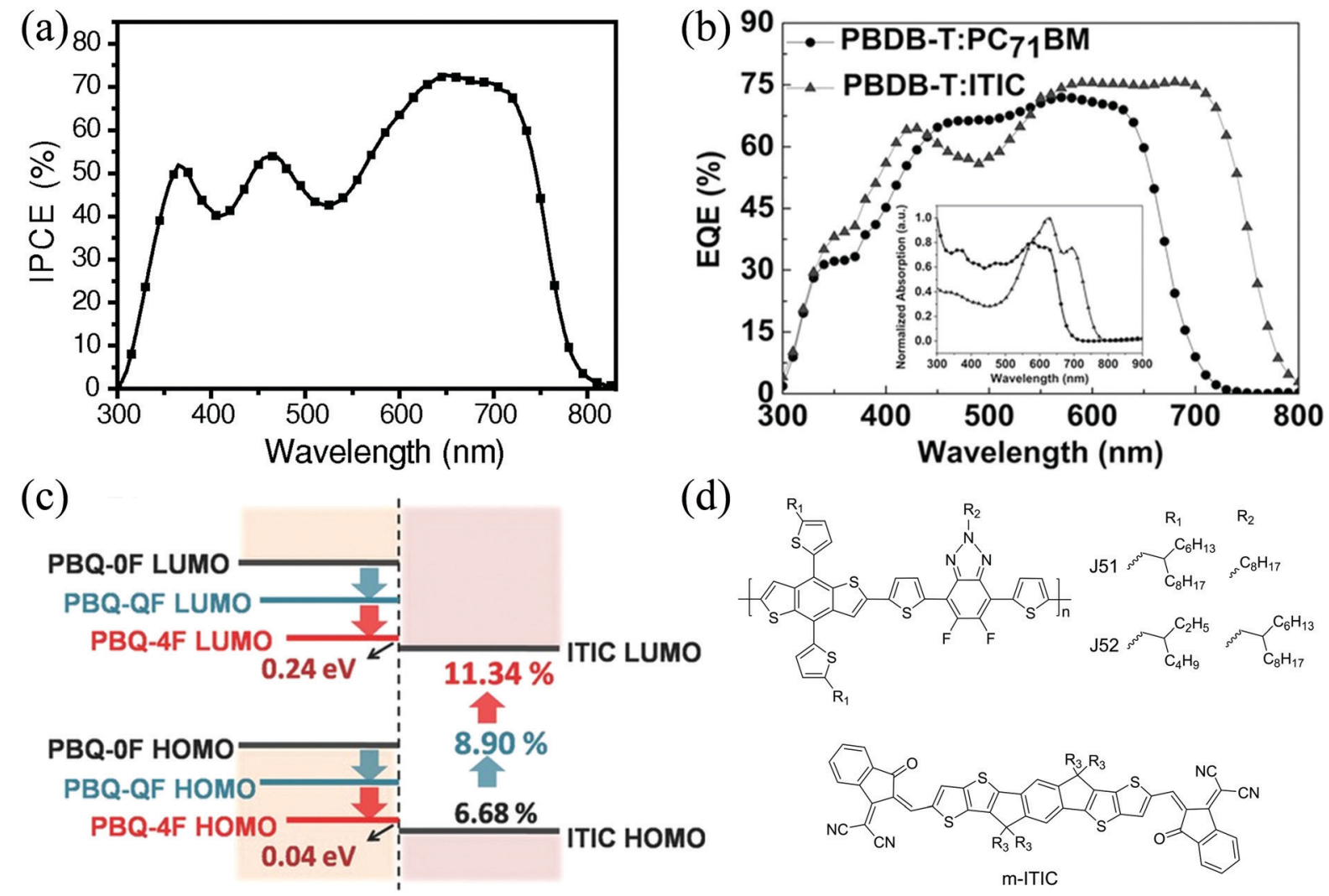

Fig. 7 (a) IPCE spectrum of the PE1:ITIC-based OSC, reproduced from ref. 8 with permission from John Wiley and Sons, copyright 2015; (b) EQE curve of the PD1:ITIC-based OSC, reproduced with permission, ${ }_{1}^{16}$ copyright 2016, John Wiley and Sons; (c) energy level schematic of PN22, PN23, PN24, and ITIC, reproduced from ref. 113 with permission from John Wiley and Sons, copyright 2016; and (d) chemical structures of J51, J52 and m-ITIC.

of side chains, and fluorination of BDT units, the PCE was increased from $6.48 \%$ to $9.53 \%$ for polymers $\mathrm{J} 40$ to $\mathrm{J} 61 .^{18,19,186}$ Furthermore, trialkylsilyl substituents were used to replace the alkyl chains on the BDT unit in J52 (Fig. 7d) to produce PN2 (J71), where the bond interaction of the low-lying $\sigma^{*}$ orbital of the Si atom with the $\pi^{*}$ orbital of the aromatic units would result in stabilization of $E_{\mathrm{LUMO}}$ and lowering of $E_{\mathrm{HOMO}}(-5.40 \mathrm{eV}) .{ }^{141}$ PN2 also showed a higher extinction coefficient of $0.96 \times 10^{5} \mathrm{~cm}^{-1}$ than that $(0.73 \times$ $10^{5} \mathrm{~cm}^{-1}$ ) of its analogue J52 with alkyl chains. OSCs based on the
PN2:ITIC blend showed a $J_{\text {SC }}$ of $17.32 \mathrm{~mA} \mathrm{~cm} \mathrm{~cm}^{-2}$, a $V_{\text {OC }}$ of $0.94 \mathrm{~V}$, and a FF of $69.77 \%$, resulting in a high PCE of $11.41 \%$. The annealed blend film showed high and balanced $\mu_{\mathrm{h}}$ and $\mu_{\mathrm{e}}$ of $3.78 \times$ $10^{-4} \mathrm{~cm}^{2} \mathrm{~V}^{-1} \mathrm{~s}^{-1}$ and $3.07 \times 10^{-4} \mathrm{~cm}^{2} \mathrm{~V}^{-1} \mathrm{~s}^{-1}$, respectively, which contributed to the high $J_{\mathrm{SC}}$ and high FF. It should be noted that $\Delta E_{\mathrm{HOMO}}$ between PN2 and ITIC is only $0.11 \mathrm{eV}$, which suggests a high hole transfer efficiency from the acceptor to the donor.

The same research group systemically investigated the effects of the size and configuration of side chains (PN1-PN5 
Table 3 Photophysical properties and OSC performance of polymer donor:ITIC blends

\begin{tabular}{|c|c|c|c|c|c|c|c|c|c|c|}
\hline Blend & $\begin{array}{l}\mu_{\mathrm{h}}, \mu_{\mathrm{e}}\left(\times 10^{-4} \mathrm{~cm}^{2} \mathrm{~V}^{-1} \mathrm{~s}^{-1}\right), \\
\left.\mu_{\mathrm{e}(\mathrm{h})} / \mu_{\mathrm{h}(\mathrm{e})}\right)\end{array}$ & $\mathrm{EQE}^{b}(\%)$ & $V_{\mathrm{OC}}(\mathrm{V})$ & $J_{\mathrm{SC}}\left(\mathrm{mA} \mathrm{cm}{ }^{-2}\right)$ & FF $(\%)$ & PCE (\%) & $S_{1}{ }^{c}$ & $S_{2}{ }^{d}$ & $P_{\text {diss }}(\%)$ & Ref. \\
\hline PE1:ITIC & $0.43,1.1,2.63$ & $72.6^{e}$ & $0.81^{e}$ & $14.21^{e}$ & $59.1^{e}$ & $6.8^{e}$ & & & & 8 \\
\hline PE2:ITIC & $0.298,0.346,1.16$ & & 0.89 & 17.24 & $67^{e}$ & $10.27^{e}$ & 1.15 & 0.927 & & 116 \\
\hline PE3:ITIC & $2.11,2.83,1.34$ & & 0.96 & $16.4^{e}$ & 64.3 & 10.12 & & & & 117 \\
\hline PD1:ITIC & $2.1,3.13,1.49$ & & $0.899^{e}$ & 16.81 & 74.2 & 11.21 & & & & 16 \\
\hline PD7:ITIC & $2.59,2.25,1.15$ & $79^{e}$ & 1.01 & 18.1 & 59 & 10.8 & 1.01 & & $86.8^{e}$ & 133 \\
\hline PD12:ITIC & $2.91,2.67,1.09$ & 76 & 0.942 & 16.81 & 66.3 & 10.5 & & & & 137 \\
\hline PN2:ITIC & $3.78,3.07,1.23$ & 76.5 & 0.94 & 17.32 & $69.77^{e}$ & 11.41 & & & & 141 \\
\hline PN1: $m$-ITIC & $1.93,8.4,4.34$ & 81.5 & 0.92 & 18.09 & 69.82 & 11.62 & & & & 140 \\
\hline PN2: $m$-ITIC & $1.09,4.66,4.28$ & & 0.944 & 18.09 & 70.59 & 12.05 & & & & 140 \\
\hline PN3: $m$-ITIC & $0.46,3.77,8.2$ & & 0.962 & 16.35 & 65.03 & 10.23 & & & & 140 \\
\hline PN4: $m$-ITIC & $0.38,3.12,8.2$ & & 0.974 & 16.45 & 66.87 & 10.71 & & & & 140 \\
\hline PN5: $m$-ITIC & $0.24,4.0,16.66$ & & 0.99 & 15.89 & 61.18 & 9.63 & & & & 140 \\
\hline PN6:ITIC & $3.66,4.06,1.11$ & & 0.95 & 15.27 & 73.08 & 10.6 & & $0.94^{e}$ & $96^{e}$ & 142 \\
\hline PN6: $m$-ITIC & $4.08,4.67,1.15$ & & 0.96 & 16.48 & 69.83 & 11.05 & & 1.01 & 97 & 142 \\
\hline PN7: $m$-ITIC & $1.016,3.002,2.95$ & & 0.984 & 18.03 & 65.54 & 11.63 & & $1.028^{e}$ & & 143 \\
\hline PN10:ITIC & $13.3,8.7,1.53$ & 78 & 0.81 & 18.63 & 66.7 & 10.07 & & & & 146 \\
\hline PN11:ITIC & $24.7,20.3,1.22$ & 80 & 0.84 & 19.51 & 75.1 & 12.31 & & & & 146 \\
\hline PN12:ITIC & $3.25,2.62,1.24$ & 82 & 0.91 & 18.7 & 61.8 & 10.5 & 1.26 & 0.94 & & 147 \\
\hline PN13:ITIC & $4.36,2.98 .1 .46$ & 72 & 0.74 & 15.7 & 49.8 & 5.8 & 1.8 & 0.93 & & 148 \\
\hline PN14:ITIC & $5.08,3.96,1.28$ & 84 & 0.94 & 18.4 & 60.2 & 10.4 & 1.32 & 0.99 & & 148 \\
\hline PN15:ITIC & $4.94,3.81,1.3$ & & 0.94 & 18.23 & 69.19 & 11.85 & & 0.93 & 93 & 20 \\
\hline PN16:ITIC & $5.46,5.251 .04$ & & 1.01 & 18.51 & 74.4 & 13.91 & & 0.97 & 95.4 & 20 \\
\hline PN17:ITIC & $1.15,3.93,3.42$ & & 0.89 & 18.12 & 67.37 & 10.86 & & 0.92 & 93 & 149 \\
\hline PN18:ITIC & $4.16,3.16,1.32$ & & 0.95 & 18.76 & 73.85 & 13.16 & & 0.96 & 95 & 149 \\
\hline PN19:ITIC & $2.132,3.397,1.59$ & 83 & 0.936 & 18.21 & 67.8 & 11.56 & & & & 150 \\
\hline PN20:ITIC & $0.86,0.23,3.74$ & & 0.87 & 18.29 & 64.34 & 10.24 & & 0.971 & & 178 \\
\hline PN22:ITIC & $7.8,8.2,1.05$ & & 0.69 & 16.16 & 59.91 & 6.68 & 1.33 & 0.952 & 88 & 113 \\
\hline PN23:ITIC & $8.6,8.3,1.04$ & & 0.83 & 17.16 & 62.49 & 8.9 & 1.23 & 0.981 & 95 & 113 \\
\hline PN24:ITIC & $10,10,1$ & & 0.95 & 17.87 & 66.8 & 11.34 & & & & 113 \\
\hline PN25:ITIC & $1.13,1.6,1.42$ & 75 & 0.9 & 16.88 & 69.24 & 10.52 & & 0.96 & 97.2 & 153 \\
\hline PN26:ITIC & $0.139,0.68,4.89$ & 66.4 & 0.94 & 13.75 & 56.11 & 7.22 & & 0.9 & 96.3 & 153 \\
\hline PN29:ITIC & $1.8,0.56,3.2$ & 71 & 0.87 & 16.21 & 64.6 & 9.11 & 1.37 & 0.92 & 89 & 155 \\
\hline PN30:ITIC & $2.5,1.3,1.9$ & 78 & 0.92 & 17.86 & 69.8 & 11.47 & 1.25 & 0.96 & 94 & 155 \\
\hline PO1:ITIC & $8.5,6.8,1.25$ & & 1.01 & 17.15 & 67.7 & 11.72 & & & & 156 \\
\hline PO2:ITIC & $12,7.2,1.67$ & & 1.1 & 17.78 & 65.4 & 12.8 & & & & 156 \\
\hline P3HT:ITIC & $1.4,1.68,1.2$ & & 0.52 & 4.22 & 56.93 & 1.25 & 1.14 & 0.99 & 92 & 163 \\
\hline PX1:ITIC & $2.4,16.3 .6 .79$ & 75 & 0.94 & 16.5 & 65.67 & 10.16 & & & & 163 \\
\hline PX2:ITIC & $1.79,1.20,1.49$ & 72.5 & 0.66 & 15.19 & 57 & 5.72 & & & & 165 \\
\hline
\end{tabular}

(J70-J74)) on the OSC performance of their blends with an ITIC isomer, $m$-ITIC (Fig. 7d), which has meta-alkyl-phenyl substitution and shows a higher degree of self-organization and crystallinity. ${ }^{140}$ Among these five polymers, they found that the film absorption coefficients and hole mobilities decreased, while the $E_{\text {НОмо values downshifted, with increasing length }}$ and complexity (linear to branched) of the alkyl substituents, which resulted in decreased $J_{\mathrm{SC}}$ and $\mathrm{FF}$, but enhanced $V_{\mathrm{OC}}$. Among this series of polymers, PN2 showed the highest PCE of $12.05 \%$.

When the thiophene rings in the BDT units were replaced with furan rings to form benzo[1,2- $\left.b: 4,5-b^{\prime}\right]$ difuran (BDF), the resultant polymer PN6 (J81), which is analogous to PN1, showed a lower $E_{\text {Номо }}-5.42 \mathrm{eV}$, achieving a high PCE of $11.05 \%$ when paired with $m$-ITIC. ${ }^{142}$ On the other hand, when the thiophene side chains on the BDT units in PN1 were disubstituted with electron-withdrawing fluorine atoms, the formed PN7 (J91) exhibited a further down-shifted $E_{\text {Номо }}$ $(-5.50 \mathrm{eV}) .{ }^{143}$ OSCs based on PN7: $m$-ITIC showed an even higher PCE of $11.63 \%$, resulting from the increased $V_{\mathrm{OC}}$ and $J_{\mathrm{SC}}$.
Compared with thiophene, selenophene shows lower aromaticity and enhanced ground-state quinoid resonance character, which would result in improved planarity, increased effective conjugation length, and a lowered bandgap of the polymer. In addition, improved interchain interactions and charge carrier transport could also be observed for selenophene-containing polymers because of the stronger heteroaromatic interactions induced by selenium atoms. ${ }^{189,190}$

When the thiophene side chains on BDT units of J51 (Fig. 7d) ${ }^{18}$ were replaced with selenophene side chains, the obtained PN10 (PBDT-Se-TAZ) exhibited similar $E_{\text {HOMO }}(-5.23$ vs. $-5.26 \mathrm{eV})$ and $E_{\mathrm{g}}$ (1.92 vs. $1.91 \mathrm{eV}$ ) to those of J51. ${ }^{146}$ However, the PN10:ITIC blend showed much higher $\mu_{\mathrm{h}}$ and $\mu_{\mathrm{e}}$ of $13.3 \times 10^{-4} \mathrm{~cm}^{2} \mathrm{~V}^{-1} \mathrm{~s}^{-1} / 8.7 \times$ $10^{-4} \mathrm{~cm}^{2} \mathrm{~V}^{-1} \mathrm{~s}^{-1}$ compared to $51\left(4.32 \times 10^{-4} \mathrm{~cm}^{2} \mathrm{~V}^{-1} \mathrm{~s}^{-1} / 3.74 \times\right.$ $10^{-4} \mathrm{~cm}^{2} \mathrm{~V}^{-1} \mathrm{~s}^{-1}$ ), indicating much improved charge transport in PN10 due to the presence of selenophene side chains. Consequently, the devices based on PN10:ITIC showed improved performance $\left(J_{\mathrm{SC}}=18.63 \mathrm{~mA} \mathrm{~cm}{ }^{-2} ; V_{\mathrm{OC}}=0.81 \mathrm{~V} ; \mathrm{FF}=66.7 \%\right.$; and PCE $=10.07 \%)$ compared to the devices based on J51:ITIC $\left(J_{\mathrm{SC}}=\right.$ $16.47 \mathrm{~mA} \mathrm{~cm}{ }^{-2} ; V_{\mathrm{OC}}=0.82 \mathrm{~V} ; \mathrm{FF}=0.69 ;$ and $\left.\mathrm{PCE}=9.26 \%\right)$. 
Once the alkyl selenophene side chains in PN10 were changed to alkylthio selenophene side chains, the resulting PN11 (PBDTSSe-TAZ) showed a slightly lower $E_{\text {Номо }}(-5.29 v s$. $-5.23 \mathrm{eV})$, a slightly narrower $E_{\mathrm{g}}(1.90$ vs. $1.92 \mathrm{eV})$, and a higher $\alpha_{\mathrm{s}-\max }$ (the maximum extinction coefficient in solution $)\left(8.54 \times 10^{4}\right.$ vs. $5.64 \times$ $10^{4} \mathrm{M}^{-1} \mathrm{~cm}^{-1}$ ) compared to PN10. ${ }^{146}$ The PN11:ITIC blend showed greatly enhanced and more balanced $\mu_{\mathrm{h}}$ and $\mu_{\mathrm{e}}(2.47 \times$ $10^{-3} \mathrm{~cm}^{2} \mathrm{~V}^{-1} \mathrm{~s}^{-1} / 2.03 \times 10^{-3} \mathrm{~cm}^{2} \mathrm{~V}^{-1} \mathrm{~s}^{-1}$ ), and thus less recombination and higher exciton dissociation and charge collection efficiencies (Table 3). Therefore, PN11:ITIC displayed higher $V_{\text {OC }}(0.84 \mathrm{~V}), J_{\text {SC }}\left(19.51 \mathrm{~mA} \mathrm{~cm}^{-2}\right), \operatorname{FF}(75.1 \%)$, and PCE $(12.31 \%){ }^{146}$

Replacing thiophene side chains on BDT units with benzene side chains is a strategy to lower $E_{\text {Hомо }}$ as mentioned previously (in the case of PD7). Li et al. ${ }^{147}$ synthesized PN12 (PBFZOP) based on meta-alkoxy-phenyl-substituted BDT (BDT- $m$-OP) and FBTA units. $E_{\text {HOMO }}$ was lowered to $-5.33 \mathrm{eV}$ compared with J52 with thiophene side chains $\left(E_{\text {Hомо }}=-5.21 \mathrm{eV}\right) .{ }^{19}$ PN12 also showed a wider bandgap of $1.99 \mathrm{eV}$ than that of J52 $(1.96 \mathrm{eV})$, which could form a more complementary absorption profile when paired with ITIC. Much improved cell performance $\left(V_{\mathrm{OC}}=0.91 \mathrm{~V} ; J_{\mathrm{SC}}=18.7 \mathrm{~mA} \mathrm{~cm}{ }^{-2} ; \mathrm{FF}=0.618 ;\right.$ and $\mathrm{PCE}=$ 10.50\%) was obtained for the PN12:ITIC blend compared with the J52:ITIC blend $\left(V_{\mathrm{OC}}=0.73 \mathrm{~V} ; J_{\mathrm{SC}}=13.1 \mathrm{~mA} \mathrm{~cm}^{-2} ; \mathrm{FF}=0.578\right.$; and $\mathrm{PCE}=5.50 \%$ ).

Later, the same group changed the alkoxy substituent of the phenyl side chains on BDT from the meta to the para position (PN13 (PBZ1)) and introduced a $\mathrm{CF}_{3}$ group on the meta position (PN14 (PBZ-m-CF $)$ ) to further lower $E_{\text {HOMO }}{ }^{148}$ Compared with PN12, both polymers showed a similar bandgap (1.96 eV for PN13 and $1.99 \mathrm{eV}$ for PN14). PN13 showed a slightly higher $E_{\text {Hомо }}$ of $-5.27 \mathrm{eV}$, while PN14 showed a much lower $E_{\text {HOMO }}$ of $-5.49 \mathrm{eV}$. Between these two polymers, PN14 exhibited a higher $\alpha_{\mathrm{f}-\max }\left(6.51 \times 10^{4}\right.$ vs. $\left.5.23 \times 10^{4} \mathrm{~cm}^{-1}\right)$, smaller $\pi-\pi$ distance (3.60 vs. $3.69 \AA$ ) , and slightly higher $\mu_{\mathrm{h}}\left(7.86 \times 10^{-4}\right.$ vs. $7.23 \times$ $\left.10^{-4} \mathrm{~cm}^{2} \mathrm{~V}^{-1} \mathrm{~s}^{-1}\right)$. The PN14:ITIC blend showed a much higher PCE of $10.4 \%$ than PN13:ITIC (5.8\%).

Li et $a .^{20}$ synthesized another similar pair of polymers, using $p$-alkylthiophenyl without or with fluorine at the meta position as the side chains to BDT units, PN15 (PBTA-PS) and PN16 (PBTAPSF), respectively. A wider bandgap of $1.98 \mathrm{eV}$ and a much lower $E_{\text {HOMO }}$ of $-5.52 \mathrm{eV}$ were obtained for PN16 compared to PN15 $\left(E_{\mathrm{g}}=1.94 \mathrm{eV}\right.$; and $\left.E_{\mathrm{HOMO}}=-5.34 \mathrm{eV}\right)$. When paired with ITIC, both showed a high $V_{\mathrm{OC}}$ of $\sim 1 \mathrm{~V}$ and high $J_{\mathrm{SC}}$ of $\sim 18 \mathrm{~mA} \mathrm{~cm}^{-2}$. The device based on PN16:ITIC showed a much improved FF of $74.4 \%$ (vs. 69.19\% for PN15:ITIC) due to its higher and more balanced $\mu_{\mathrm{h}}$ and $\mu_{\mathrm{e}}$, less recombination and higher exciton dissociation and charge collection efficiencies (Table 3). Therefore, while PN15:ITIC showed a PCE of $11.85 \%$, the PN16:ITIC blend exhibited a much higher PCE of $13.91 \%$, which is the highest value achieved among ITIC-based OSCs by far. The results indicate that alkylthiophenyl substitution on BDT is very beneficial for the improvement of the OSC performance of the resulting polymer. On other hand, fluorination on the phenyl ring could further enhance the cell performance.

Chen et al. ${ }^{149}$ conducted a further study to compare the effects of the position of alkylthio chains on phenyl (para or meta) on the OSC performance of this type of polymers. Compared with the polymer with alkylthio chains at the para position (PN17 ( $p$-PBDTPS-FTAZ)), the one with the chains at the meta position, PN18 ( $m$-PBDTPS-FTAZ), showed a lower $E_{\text {HOMO }}$ and blue-shifted absorption. When blended with ITIC, higher and more balanced $\mu_{\mathrm{h}}$ and $\mu_{\mathrm{e}}$, less recombination, and higher exciton dissociation and charge collection efficiencies were observed. As a result, a higher PCE of 13.16\% was achieved for the PN18:ITIC blend compared to PN17:ITIC (10.86\%).

Liu et al. ${ }^{150}$ developed a series of polymer donors having the BDT unit asymmetrically substituted with an alkylthiolthienyl group on one side and a phenyl and naphthyl (or $p$-biphenyl) on the other. It was found that the long alkylthiolthienyl substituent can lower $E_{\text {номо }}$, broaden the absorption spectrum, and improve the solubility. The non-substituted rigid aryl substituent (benzene, naphthalene and $p$-biphenyl) can be regarded as a lever arm to disturb the ITIC phase and weaken the polymer chain entanglements, which helps realize a favorable morphology even without post-treatment. When the polymer with the naphthyl substituent, PN19 (PBDTTAZ-NaPh), was blended with ITIC, the obtained film exhibited a homogeneous morphology with finely separated domains. A high PCE of $11.56 \%$ was obtained with this blend film.

Fan et al. ${ }^{151}$ used alkylimide to replace the two fluorine atoms on benzotriazole in FBTA to form an acceptor unit, TZBI, which was used to make a copolymer PN20 (PTZBI) with BDT. PN20 possesses a more delocalized electron distribution across the conjugated backbone, which lowers $E_{\text {Hомо }}$ and enhances the carrier mobility. A high PCE of $10.24 \%$ was obtained with the PN20:ITIC blend. ${ }^{178}$

Qx is another moderate electron-accepting $\mathrm{N}$-heterocylic building block that is widely used in constructing WBG conjugated D-A polymer donors for OSCs. ${ }^{34,191}$ Zheng et al. ${ }^{113}$ conducted a systematic study on the correlations between the energy level alignment, performance, and device physics by finely tuning the FMO energy levels through introducing different numbers of $\mathrm{F}$ atoms. Three polymers with 0,2 and $4 \mathrm{~F}$ atoms in one repeat unit, PN22 (PBQ-0F), PN23 (PBQ-QF) and PN24 (PBQ-4F), respectively, were synthesized. With an increasing number of $\mathrm{F}$ atoms, $E_{\mathrm{LUMO}}$ and $E_{\text {Номо }}$ downshifted gradually. PN24 showed the lowest $E_{\text {HOMO }}$ of $-5.49 \mathrm{eV}$, and so achieved the highest $V_{\text {OC }}$ of $0.95 \mathrm{~V}$ when blended with ITIC. It should be noted that although the energy offsets between PN24 and ITIC are very small $\left(\Delta E_{\mathrm{HOMO}}=0.04 \mathrm{eV}\right.$ and $\Delta E_{\mathrm{LUMO}}=$ $0.24 \mathrm{eV}$ ), the devices exhibited efficient charge generation, which is an outstanding advantage over fullerene-based OSCs, which require a large energy offset of $>0.3 \mathrm{eV}$ for efficient exciton dissociation. ${ }^{87,121,192-195}$ A high $J_{\mathrm{SC}}\left(17.87 \mathrm{~mA} \mathrm{~cm}{ }^{-2}\right)$ and $\mathrm{FF}(66.80 \%)$ were also obtained owing to the stronger interchain interaction, resulting in higher carrier mobility. Therefore, this blend afforded a high PCE of $11.34 \%$. A mixture of non-halogenated solvents THF and IPA was used for processing the active layer, demonstrating the potential for environmentfriendly fabrication of OSCs.

The thiophene donor building block possesses higher electron density and smaller steric hindrance, providing better 
absorption and charge transport to the resulting polymer than the benzene building block. $\mathrm{Xu}$ et al. ${ }^{153}$ replaced the phenyl side chains of Qx units with alkyl substituted fluorothiophene and introduced alkyl chains with different lengths on BDT units to form polymers PN25 (TTFQx-T1) and PN26 (TTFQxT2). When paired with ITIC, the blend based on PN25 with short alkyl chains on BDT showed higher and more balanced $\mu_{\mathrm{h}}$ and $\mu_{\mathrm{e}}$, less recombination, and higher exciton dissociation and charge collection efficiencies (Table 3). Therefore, it exhibited a much improved $J_{\text {SC }}\left(16.88\right.$ vs. $\left.13.75 \mathrm{~mA} \mathrm{~cm}{ }^{-2}\right)$ and $\mathrm{FF}$ (69.24\% vs. $56.11 \%)$ and thus a higher PCE (10.52\% vs. $7.22 \%)$ compared with the PN26:ITIC blend. This result indicated that the alkyl chain length has notable influences on the photovoltaic properties.

Building blocks with an enlarged planar aromatic structure are favorable for ordered molecular packing and thus improved photovoltaic performance. ${ }^{196,197}$ In addition, alkylthiothiophene side chains can further reduce $E_{\text {Hомо }}$. Based on these principles, Yu et al. ${ }^{155}$ used quinoxalino[6,5-f]quinoxaline (NQx) as A units and introduced alkylthiophene and alkylthiothiophene as side chains of BDT units to form PN29 (PBDT-NQx) and PN30 (PBDTS-NQx), respectively. The latter showed a lower $E_{\text {номо }}(-5.31 v s .-5.24 \mathrm{eV})$ and higher $\alpha_{\text {s-max }}\left(3.45 \times 10^{6} v s\right.$. $\left.2.9 \times 10^{6} \mathrm{M}^{-1} \mathrm{~cm}^{-1}\right)$. The devices based on PN30:ITIC showed a higher PCE of $11.47 \%$ than those based on PN29:ITIC (9.11\%).

3.1.4 Other BDT-based polymers and non-BDT-based polymers. 1,3,4-Thiadiazole (TDZ) is highly polarizable with large electron affinity, which can be used as an excellent A building block for constructing high-performance D-A copolymers for OSCs. ${ }^{198} \mathrm{Xu}$ et al. ${ }^{156}$ copolymerized TDZ with BDT units to form PO1 (PBDT-TDZ) and PO2 (PBDTS-TDZ), which employed alkylthiophene and alkylthiothiophene as side chains of BDT units, respectively. PO2 showed a slightly lower $E_{\text {HOMO }}(-5.39 v s$. $-5.35 \mathrm{eV})$ and higher $\alpha_{\mathrm{s}-\max }\left(3.1 \times 10^{6}\right.$ vs. $\left.2.5 \times 10^{6} \mathrm{M}^{-1} \mathrm{~cm}^{-1}\right)$ than PO1. The PO2:ITIC blend showed higher crystallinity and higher $\mu_{\mathrm{h}}$ and $\mu_{\mathrm{e}}$ (Table 3). As a result, a higher PCE of $12.8 \%$ for PO2:ITIC was obtained compared to PO1:ITIC (11.72\%).

The primary driving force for OSC research is the potential of manufacturing OSC products at a much lower cost than Si solar cells. The synthetic complexity (SC), which considers the number of reaction steps, purification methods, reaction yields, use of hazardous materials, etc., can be used to estimate the synthetic cost of the materials. ${ }^{199}$ Although BDT-based polymers showed high cell performance, the tedious synthesis of the BDT tin monomer alone would result in a high SC $(>30 \%)$. P3HT can be synthesized with a very low SC $(7.75 \%)$, but its OSC performance is rather low mainly due to its high $E_{\mathrm{HOMO}}$. To overcome the disadvantageous high-lying $E_{\mathrm{HOMO}}$ of P3HT, Zhang et al. ${ }^{163}$ introduced electron-withdrawing carboxylate substituents on half of the thiophene rings in the backbone of polythiophene to form PX1 (PDCBT). $E_{\mathrm{HOMO}}$ of PX1 down-shifted to $-5.26 \mathrm{eV}$, much lower than that of P3HT $(\sim-5.0 \mathrm{eV})$. Therefore, a much higher $V_{\mathrm{OC}}$ for the PX1:ITIC blend was obtained (0.94 V for PX1:ITIC vs. $0.52 \mathrm{~V}$ for P3HT:ITIC). Furthermore, in contrast to P3HT, PX1 predominantly adopted a face-on crystal orientation in the blend film, which is beneficial for the charge transport in the vertical direction. Combined with lower recombination and higher exciton dissociation and charge collection efficiencies, the devices based on PX1:ITIC showed a largely improved PCE of up to $10.16 \%$ compared to the PCE of $1.25 \%$ for P3HT:ITIC, demonstrating the potential of polythiophenes for achieving high photovoltaic performance. Another strategy to improve the photovoltaic performance of polythiophenes is to design novel D-A polymer donors with conjugated $\mathrm{D}$ and $\mathrm{A}$ units located at the backbone and side chains, respectively, which was demonstrated by He et al. ${ }^{165}$ with a polymer PX2 (PTIBT) that has an electron-rich polythiophene backbone and electron-accepting indolin-2-one side chains. The polymer with the so-called donor-backbone-acceptor-side-chain structure showed a very high dielectric constant of 7.70 due to the largely separated donor and acceptor units, which is beneficial for the exciton diffusion to the donor:acceptor interface and subsequent dissociation into free electrons and holes. Although the PCE was moderate (5.72\%) for the PX2:ITIC blend, this novel polymer design showed potential for achieving high performance through increasing the dielectric constant of the material. It should be mentioned that this polymer could be synthesized with a very low SC of $23.5 \%$.

\subsection{High performance polymer donors matching with IT-4F}

In the previous section it was pointed out that ITIC has a rather large bandgap (1.59 eV), which can only absorb sunlight below $800 \mathrm{~nm}$. In 2017, Zhao et al. ${ }^{22}$ introduced $\mathrm{F}$ atoms on the end IC groups of ITIC to form IT-4F (Fig. 6). Compared with ITIC, IT-4F has a narrower bandgap (1.52 eV) with red-shifted absorption and higher $\alpha_{\mathrm{s} \text {-max }}$ and $\alpha_{\mathrm{f}-\max }$ values along with lower $E_{\mathrm{LUMO}}$ $(-4.14 \mathrm{eV})$ and $E_{\text {Hомо }}(-5.66 \mathrm{eV})$. OSCs based on IT-4F have demonstrated improved photovoltaic performance compared to ITIC-based devices.

3.2.1 BDT-based polymer donors using ester or imide substituted building blocks as A units. We have mentioned earlier that in addition to $\mathrm{F}$ or $\mathrm{Cl}$ atoms, ester groups can also downshift $E_{\text {Hомо }}$ and enhance the interchain interactions. $\mathrm{Li}$ et $a{ }^{118}$ developed a novel polymer donor by using BDT and ester substituted thiophene (EST) as the D and A units, respectively, to form PDTB-EF-T polymers and investigated the influence of different alkyl chains of the ester groups on the cell performance. Three polymers with different alkyl chains, PE4, PE5 and PE6, showed similar FMO energy levels and bandgaps, while the polymer with linear decyl chains (PE5) exhibited the strongest absorption and highest $\mu_{\mathrm{h}}$ due to the most planar backbone and strongest intermolecular interactions. When using IT-4F as an acceptor, similar $V_{\mathrm{OC}}$ values were obtained for the three blends, but the PE5:IT-4F blend showed the highest chain ordering, the highest and most balanced $\mu_{\mathrm{h}}$ and $\mu_{\mathrm{e}}$, the most suppressed recombination, and the highest exciton dissociation and charge collection efficiencies (Table 4), resulting in the highest $J_{\mathrm{SC}}, \mathrm{FF}$, and PCE (14.2\%).

Despite the high performance of EST-based polymer donors, the steric effects of the ester groups lead to twisted backbone structures. To improve the planarity of this kind of polymers, $\mathrm{Li}$ et al. ${ }^{119}$ inserted a TT unit and a difluorinated 2,2'-bithiophene (DFDT) unit as a $\pi$-spacer between two EST units to form PE7 
Table 4 OSC device performances based on blends of polymer donors and IT-4F

\begin{tabular}{|c|c|c|c|c|c|c|c|c|c|c|}
\hline Blend & $\begin{array}{l}\mu_{\mathrm{h}}, \mu_{\mathrm{e}}\left(\times 10^{-4} \mathrm{~cm}^{2} \mathrm{~V}^{-1} \mathrm{~s}^{-1}\right) \\
\mu_{\mathrm{e}(\mathrm{h})} / \mu_{\mathrm{h}(\mathrm{e})}\end{array}$ & $\mathrm{EQE}^{b}(\%)$ & $V_{\mathrm{OC}}(\mathrm{V})$ & $J_{\mathrm{SC}}\left(\mathrm{mA} \mathrm{cm}^{-2}\right)$ & FF $(\%)$ & PCE (\%) & $S_{1}{ }^{c}$ & $S_{2}{ }^{d}$ & $P_{\text {diss }}(\%)$ & Ref. \\
\hline PE4:IT-4F & $1.51,4.12,2.7$ & & $0.896^{e}$ & $20.05^{e}$ & 64 & 11.5 & & $1^{e}$ & $93^{e}$ & 118 \\
\hline PE5:IT-4F & $3.46,3.95,1.1$ & $82^{e}$ & $0.9^{e}$ & 20.73 & 76 & 14.2 & & $0.91^{e}$ & 95 & 118 \\
\hline PE7:IT-4F & $0.553,0.918,1.7$ & & 0.883 & 19.34 & 65 & 11.1 & 1.11 & 0.95 & 86 & 119 \\
\hline PE8:IT-4F & $1.94,2.21,1.1$ & 82 & 0.865 & 21.83 & 75 & 14.16 & & & 96 & 119 \\
\hline PE9:IT-4F (CB/DIO) & & & 0.899 & $21.5^{e}$ & 78 & 15.1 & & & & 120 \\
\hline PD4:IT-4F & $3.25,4.32,1.33$ & 83 & 0.88 & 20.5 & 71.9 & 13 & 1.2 & $0.999^{e}$ & 93 & 22 \\
\hline PD2:IT-4F & $9.76,7.15,1.37$ & & 0.84 & 22.2 & 72.5 & 13.5 & & & $97.8^{e}$ & 200 \\
\hline PD3:IT-4F & & & 0.86 & 21.8 & 77 & 14.4 & & & & 201 \\
\hline PD5:IT-4F & & & 0.88 & 0.88 & 23.74 & 0.18 & & & & 131 \\
\hline PD6:IT-4F & $0.0574,0.0516,1.1$ & & 0.84 & 20.6 & 71.09 & 12.33 & & 0.93 & & 131 \\
\hline PD8:IT-4F & $10.7,5.4,1.98$ & & 0.85 & 19.74 & 76 & 12.7 & & & 97 & 134 \\
\hline PO3:IT-4F & $5.01,2.71,1.85$ & & 0.804 & 20.05 & 73.1 & 12.01 & & 1.01 & 95.7 & 157 \\
\hline PO4:IT-4F & $0.84,4.1,5$ & & 0.82 & 21.5 & 67.8 & 12.0 & 1.37 & 0.96 & 98 & 158 \\
\hline PO5:IT-4F & $3.4,2.9,1.17$ & & 0.92 & 22.4 & 71.1 & 14.7 & 1.21 & 0.98 & 98 & 158 \\
\hline PO6:IT-4F & $7.0,5.7,1.22$ & & 0.94 & 21.8 & 72.5 & 14.8 & 1.24 & 0.99 & 98 & 158 \\
\hline PO7:IT-4F & $4.91,5.60,1.14$ & 85 & 0.813 & 24.06 & 65.0 & 12.70 & & & & 159 \\
\hline PO8:IT-4F & $6.76,6.11,1.11$ & 85 & 0.891 & 23.40 & 67.0 & 13.97 & & & & 159 \\
\hline PX3:IT-4F & $14.2,5.49,2.59$ & & 0.91 & 19.41 & 76 & 13.31 & & & & 166 \\
\hline PX4:IT-4F & $5.61,2.21,2.54$ & & 0.94 & 19.01 & 71 & 12.74 & & 0.95 & & 166 \\
\hline PX5:IT-4F & & & 0.931 & 20.52 & 66.96 & 12.79 & & 0.938 & 95.9 & 168 \\
\hline PX6:IT-4F & $2.60,2.24,1.16$ & & 0.911 & 21.42 & 69.48 & 13.56 & & 0.929 & 96.4 & 168 \\
\hline PX7:IT-4F & 1.31. $1.81,1.38$ & & 0.911 & 21.12 & 69.28 & 13.32 & & 0.924 & 96.3 & 168 \\
\hline PX8:IT-4F & $0.7,1.64,2.4$ & & 0.891 & 21.07 & 69.75 & 13.1 & & 0.94 & 95.5 & 168 \\
\hline
\end{tabular}

(PBDE-TT) and PE8 (PBDE-DFDT). The latter had much better coplanarity due to the F..S non-bonding interaction, which enhanced the optical absorption, strengthened the interchain $\pi-\pi$ interaction, and shortened the $\pi-\pi$ distance, resulting in much improved $\mu_{\mathrm{h}}\left(3.4 \times 10^{-4} \mathrm{~cm}^{2} \mathrm{~V}^{-1} \mathrm{~s}^{-1}\right.$ for PE8 vs. $1.11 \times$ $10^{-4} \mathrm{~cm}^{2} \mathrm{~V}^{-1} \mathrm{~s}^{-1}$ for PE7). When blended with IT-4F, more compact and ordered packing, higher and more balanced $\mu_{\mathrm{h}}$ and $\mu_{\mathrm{e}}$, suppressed recombination, and higher exciton dissociation and charge collection efficiencies were obtained for the PE8:IT-4F blend. As a result, a higher PCE of $14.16 \%$ was obtained for PE8:IT-4F compared to PE7:IT-4F (11.1\%).

PE12 (PTO2) having BDT and EST building blocks as D and A units, respectively, was developed by Yao et al. ${ }^{121}$ PE12 showed a low-lying $E_{\text {HOMO }}$ of $-5.56 \mathrm{eV}$, so a high $V_{\mathrm{OC}}$ of $0.91 \mathrm{~V}$ was achieved when blended with IT-4F. $\Delta E_{\text {HOMO }}$ between PE12 and IT- $4 \mathrm{~F}$ is very small $(0.07 \mathrm{eV})$, but highly efficient exciton dissociation and charge separation were still observed. Through DFT calculations, they found that PE12 and IT-4F have a very large difference in molecular electrostatic potential (ESP) and the induced intermolecular electric field (IEF) may assist the separation of excitons. A high $J_{\mathrm{SC}}$ and $\mathrm{FF}$ and thus a high PCE of up to $14.7 \%$ were achieved for PE12:IT-4F.

Although using ternary blends can enhance the optical absorption and thus the PCE, a third component would lead to a much more complicated blend morphology and mixing of incompatible materials would result in severe molecular disorder, hampering the device performance. As an alternative, incorporation of an additional building block to form a ternary polymer (terpolymer) is a feasible method to optimize the optical absorption and energy levels. Cui et al. ${ }^{120}$ introduced different amounts of the EST building block into PD2 to tune the electron-withdrawing property of the A units. The introduction of EST led to larger steric effects, but the desired downshifted $E_{\text {HOMO }}$ and broadened absorption. When PE9, which contained $20 \%$ EST in the A units, was used as a donor to blend with IT-4F, PCEs of $15.1 \%$ for the blend film processed from a chlorobenzene (CB)/1,8-diiodooctane (DIO) system and 14.2\% for the blend film processed from a non-halogenated tetrahydrofuran (THF)/ $N$-methyl pyrrolidone (NMP) system were obtained.

Compared with $\mathrm{F}$ atoms, $\mathrm{CF}_{3}$ groups also have strong electron-withdrawing ability, and can be more easily introduced. Meng et al. ${ }^{122}$ introduced $\mathrm{CF}_{3}$ groups at the terminal of the ester groups of PE12, but eliminating $\mathrm{F}$ atoms on the thiophene side chains, to form PE13 (F1). Compared with the polymer without the $\mathrm{CF}_{3}$ groups (F0), PE13 showed a lower

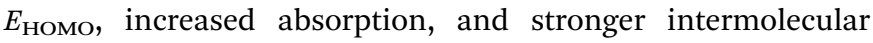
interactions. DFT results also suggested that the introduction 
of $\mathrm{CF}_{3}$ groups did not lead to larger steric hindrance. OSC devices based on the PE13:IT-4F blend showed a much higher PCE of $13.5 \%$ than those based on the polymer without $\mathrm{CF}_{3}$ groups $(4.9 \%)$.

3.2.2 BDT-based polymer donors using diketone derivatives as A units. To match with IT-4F, a polymer donor PD4 (PBDB-T-SF) was developed by simultaneously introducing $\mathrm{F}$ and alkylthio chains on the thienyl substituents of BDT in PD1 (Fig. 8a). ${ }^{22}$ PD4 has a low-lying $E_{\text {HOMO }}$ of $-5.40 \mathrm{eV}$ and a wide bandgap of $1.80 \mathrm{eV}$. The PD4:IT-4F blend showed a broader optical absorption band, a higher absorption coefficient, and more ordered intermolecular arrangements in comparison with the PD1:ITIC blend. As a result, a high PCE of $13 \%$ was obtained for PD4:IT-4F. In addition, the devices maintained a high PCE of $11.99 \%$ after storage for $1700 \mathrm{~h}$ in an $\mathrm{N}_{2}$-filled glovebox, demonstrating the excellent device stability. Fan et $a{ }^{200}$ used PD2 as a donor to blend with IT-4F. The strong crystallinity of PD2 is beneficial for forming a favorable blend morphology to suppress recombination, which led to a high PCE of $13.5 \%$.

Although fluorination is an effective way to tune the FMO energy levels and molecular packing, the tedious synthesis and low yield would limit further industrial application. Zhang et $a .^{201}$ replaced the $\mathrm{F}$ atoms in $\mathrm{PD} 2$ with $\mathrm{Cl}$ atoms to form PD3 (PM7). The lower material cost, much shorter synthetic route, and simpler purification of the intermediates made the synthetic cost of PD3 potentially much lower than that for PD2. In addition, introduction of $\mathrm{Cl}$ atoms resulted in higher dipole moments and a more delocalized HOMO of the polymer. Except for a slightly lowered $E_{\text {Hомо }}$, the absorption profile, aggregation effect in solution, and film morphology of PD3 were similar to those of PD2. However, a very high PCE of 14.4\% was obtained for the PD3:IT-4F blend. Furthermore, the same group introduced $\mathrm{Cl}$ atoms at different positions on the thiophene spacers of PD1 to form PD5 and PD6. ${ }^{131}$ These differences had dramatic effects on the molecular packing and thus the photovoltaic performance. PD6 showed a large redshift of $140 \mathrm{~nm}$ in its absorption spectrum with a narrower bandgap of $1.78 \mathrm{eV}$ than PD5 $\left(E_{\mathrm{g}}=2.11 \mathrm{eV}\right)$. On the other hand, PD5 showed much weaker aggregation behaviour, poorer crystallinity, and almost no SCLC mobility due to the larger steric effects. Consequently, an extremely low PCE of $0.18 \%$ was obtained for PD5:IT-4F, while a much higher PCE of $12.33 \%$ was obtained for PD6:IT-4F.

Ye et al. ${ }^{134}$ developed a similar polymer donor, PD8 (PBT1-C$2 \mathrm{Cl}$ ), using $p$-alkylphenyl groups as the side chains of BDT units (a)
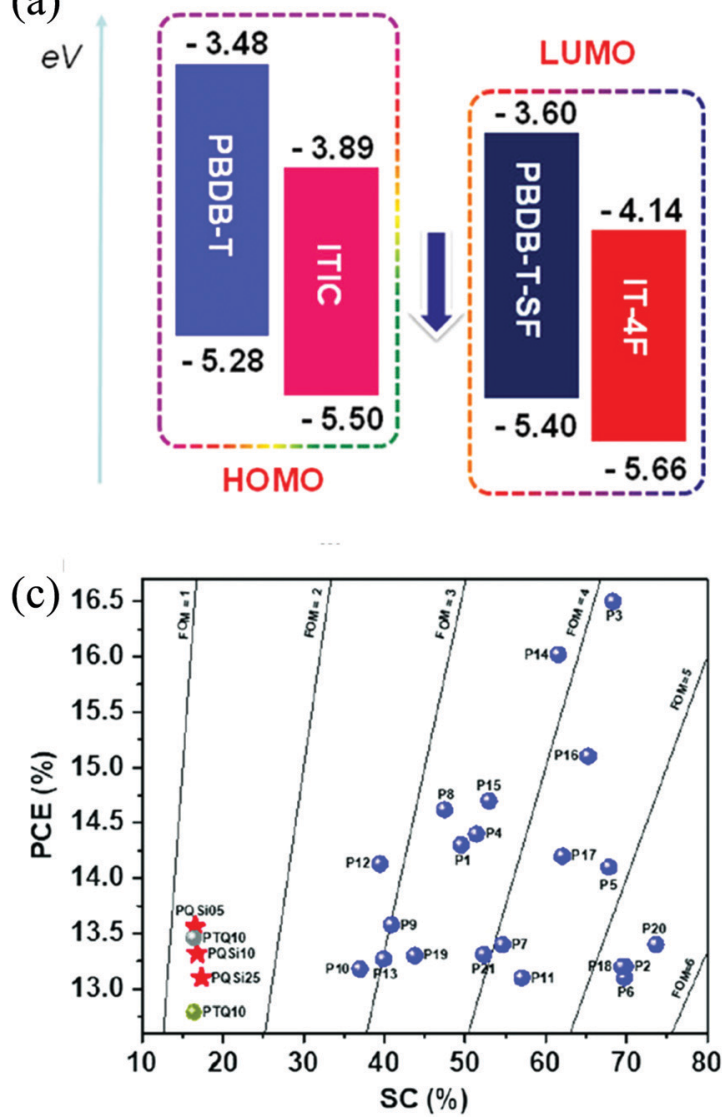

(b)

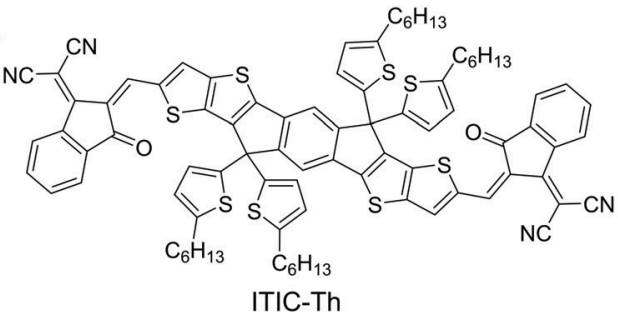
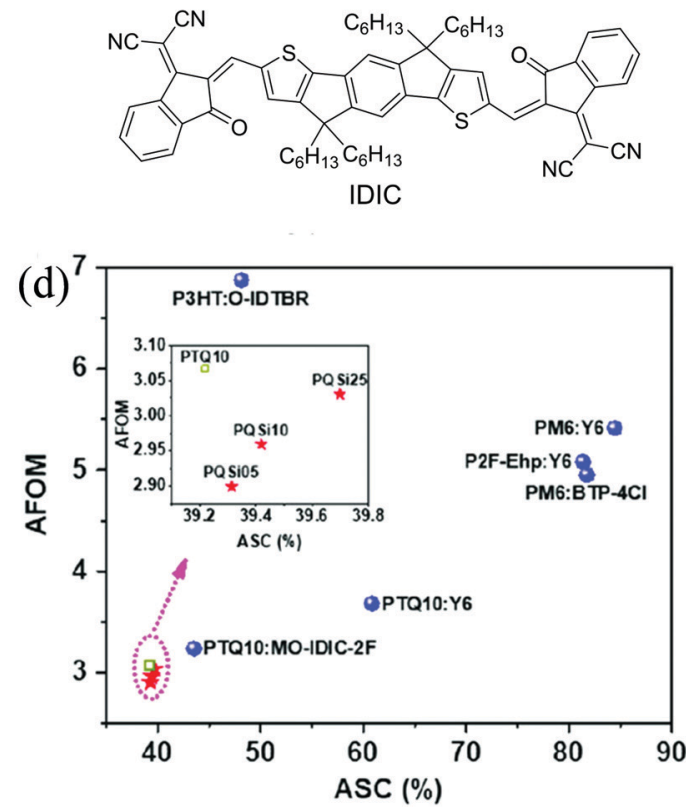

Fig. 8 (a) Molecular energy levels of PBDB-T, ITIC, PBDB-T-SF and IT-4F, reproduced from ref. 22 with permission from the American Chemical Society, copyright 2017; (b) chemical structures of ITIC-Th and IDIC; (c) the maximum PCE versus SC of some polymers; and (d) the AFOM versus ASC for the active layers showing high PCEs in single-junction OSCs. Reproduced from ref. 168 with permission from John Wiley and Sons, copyright 2017. 
and introducing $\mathrm{Cl}$ atoms on the 4-position of the thiophene spacer. Compared with PD6, $P D 8$ exhibited a lower-lying $E_{\text {Hомо }}$ of $-5.59 \mathrm{eV}$ and a slightly wider bandgap of $1.85 \mathrm{eV}$. The devices based on PD8:IT-4F showed much enhanced $\mu_{\mathrm{h}}$ and $\mu_{\mathrm{e}}$ (Table 4), and therefore a higher FF of $76 \%$ than that of PD6:IT-4F (70.5\%). Thus, a slightly higher PCE of $12.7 \%$ was obtained for PD8:IT-4F.

Li et al. ${ }^{135}$ used fluorinated alkoxyphenyl groups as side chains of BDT to form PD10 (PFOPB). Compared with PD9 (POPB) without fluorination, PD10 possessed a deeper $E_{\text {HOMO, }}$ higher extinction coefficient, and higher $\mu_{\mathrm{h}}$. Higher crystallinity with a smaller phase separation size was obtained for the PD10:IT-4F blend. As a result, a higher PCE of $11.7 \%$ was obtained. They also replaced the BDD unit with a naphtho[2,3-c] thiophene-4,9-dione (NTDO) unit as the latter possesses a planar structure and offers several loci in the phenyl ring for functionalization. ${ }^{202}$ Alkylthio side chains were also introduced to lower $E_{\mathrm{HOMO}}$. The resultant PD11 (PBN-S) showed a low-lying $E_{\mathrm{HOMO}}$ of $-5.48 \mathrm{eV}$, high crystallinity, and ordered molecular packing. Benefitting from the efficient charge separation, high and balanced $\mu_{\mathrm{h}}$ and $\mu_{\mathrm{e}}$, ordered molecular packing, appropriate aggregations, and complementary absorption in the active layer, the devices based on PD11:IT-4F demonstrated a high PCE of $13.10 \%$. The devices showed good storage stability, retaining $88 \%$ of their initial PCE after 100 days storage in a nitrogen-filled glove-box. ${ }^{136} \mathrm{~A}$ PCE of up to $10.21 \%$ with an active area of $100 \mathrm{~mm}^{2}$ was obtained, demonstrating the area scalability of these OSCs.

3.2.3 BDT-based polymer donors using $\mathrm{N}$-heterocycles as A units. Polymers based on BDT and FBTA units showed high cell performance when blended with ITIC. Liao et al. ${ }^{144}$ optimized the side chains on FBTA units and introduced $\mathrm{Cl}$ atoms onto BDT units to synthesize PN8 in order to optimize the planarity, aggregation property, light-harvesting ability, energy levels, molecular face-on orientation, and packing distance. The devices based on PN8 (L810):IT-4F showed a high PCE of $12.1 \%$. Based on the success of chlorination and alkylsilyl substitutions (PN1-PN5), Su et al. ${ }^{145}$ employed these two strategies to obtain PN9 (PBZ-ClSi). This polymer showed a lower $E_{\text {Hомо, }}$ an increased absorption coefficient, and improved charge mobility compared to its parent polymer PBZ. ${ }^{203}$ The PN9:IT-4F blend showed high and balanced $\mu_{\mathrm{h}}$ and $\mu_{\mathrm{e}}$, less recombination, and higher charge separation and collection efficiencies, which led to a high PCE of $12.8 \%$ in OSCs.

3.2.4 Other BDT-based polymers and non-BDT-based polymers. Although alkylsilyl substituted BDT-based polymers showed a high PCE over $10 \%$, the devices based on this kind of polymers always suffered from low FF. The thiazolo[5,4d]thiazole (TZ) building block with excellent planarity and electron-withdrawing properties has been used to construct polymer donors with a high FF of $\sim 75 \%$ when blended with NFAs. ${ }^{204} \mathrm{Xu}$ et al. $^{157}$ synthesized PO3 (PBDS-TZ) using alkylsilyl BDT and TZ as the D and A unit, respectively, to lower $E_{\text {HOMO }}$ and improve the backbone planarity and charge transport. The PO3:IT-4F blend film showed high and balanced $\mu_{\mathrm{h}}$ and $\mu_{\mathrm{e}}$, resulting in suppressed recombination and high exciton dissociation and charge collection efficiencies. A high FF of 73.1\% was achieved, which contributed largely to a high PCE of 12.01\% for the PO3:IT-4F-based OSCs.

Benzo[1,2- $\left.d: 4,5-d^{\prime}\right]$ bis(thiazole) (BBT) is a weak electronwithdrawing building block for structural modification to improve $\mu_{\mathrm{h}}$ and the stability of polymer donors. Wen et al. ${ }^{158}$ employed BDT and BBT both with alkylthiophene side chains as the D and A units, respectively, and introduced different halogen atoms ( $\mathrm{F}$ and $\mathrm{Cl}$ ) on the thiophene side chains of the BDT units to form polymers PO4 (PBB-H), PO5 (PBB-F), and PO6 (PBB-Cl). When blended with IT-4F, similarly high $J_{\mathrm{SC}}$ values were obtained for these three polymers due to their high extinction coefficient and favourable face-on orientation. Fluorination and chlorination lowered the energy levels, improved the charge transport, and suppressed recombination, which led to a higher $V_{\text {OC }}$ and FF. Among them, the devices based on PO6:IT-4F showed the highest PCE of $14.8 \%$.

Jeon $e$ e $a .^{205}$ synthesized a simple, potentially low cost polymer donor $\mathrm{P}(\mathrm{Cl})$ by using BDT and 3-chlorothiophene as D and A units, respectively. $\mathrm{P}(\mathrm{Cl})$ showed a high $\mathrm{PCE}$ of $12.14 \%$ when blended with ITIC-Th (Fig. 8b). Although fluorination or chlorination on BDT units can improve the device performance, the molecular weight and solubility would decrease with the introduction of $\mathrm{F}$ or $\mathrm{Cl}$ atoms. To achieve a balance between molecular weight and solubility, they introduced a small amount of BDD as A units to form two ternary polymers, PO7 $(\mathrm{P}(\mathrm{F}-\mathrm{Cl})(\mathrm{BDD}=0.2))$ and $\mathbf{P O 8}$ $(\mathrm{P}(\mathrm{Cl}-\mathrm{Cl})(\mathrm{BDD}=0.2)) .{ }^{159}$ Both polymers had higher molecular weights and showed better solubility than those without BDD units $(\mathrm{P}(\mathrm{F}-\mathrm{Cl})$ and $\mathrm{P}(\mathrm{Cl}-\mathrm{Cl}))$. High $\mathrm{PCE}$ values of $12.7 \%$ and $13.97 \%$ were obtained for PO7:IT-4F and PO8:IT-4F-based OSCs, respectively, when processed from eco-friendly solvents. For the BDTbased polymers, the $\pi$-orbitals of BDT show a high degree of localization, which is not beneficial for intramolecular charge carrier delocalization, resulting in low mobilities. ${ }^{49}$ Replacing the BDT units with imide-oligothiophene can greatly improve the carrier mobility. ${ }^{206}$ Yu et al. ${ }^{166}$ developed two polymer donors with $\mathrm{D}-\mathrm{A}_{1}-\mathrm{D}-\mathrm{A}_{2}$ structures using thiophenes as $\mathrm{D}$ units and difluorobenzothiadiazole (ffBT) and phthalimide (PhI) or difluoro phthalimide (ffPhI) as the two A units to form PX3 (PhI-ffBT) and PX4 (ffPhI-ffBT), respectively. These polymers are highly crystalline and show a high field effect $\mu_{\mathrm{h}}$ of $0.6-0.9 \mathrm{~cm}^{2} \mathrm{~V}^{-1} \mathrm{~s}^{-1}$. PX4 has predominantly edge-on polymer backbone orientation, which is not beneficial for the charge transport in the vertical direction in an OSC. Therefore, the PX4:IT-4F blend showed a lower SCLC $\mu_{\mathrm{h}}$ than that of PX3:IT-4F. The PX3:IT-4F blend exhibited tighter $\pi-\pi$ stacking and less recombination and higher exciton dissociation and charge collection efficiencies. A higher PCE of $13.31 \%$ was obtained for PX3:IT-4F compared to PX4:IT-4F (12.74\%).

Sun et al. ${ }^{167}$ synthesized PX5 (PTQ10) using thiophene and difluorinated quinoxaline as D and A units, respectively, in only two reaction steps with a high overall yield of $87.4 \%$. PX5 possessed a low $E_{\text {Hомо }}$ of $-5.54 \mathrm{eV}$ and a wide bandgap of $1.92 \mathrm{eV}$ and showed a high PCE of $12.70 \%$ when an ITIC derivative, IDIC (Fig. 8b), was used as an acceptor. Yuan et $a{ }^{168}$ adopted a combinatory side chain strategy to keep the low synthetic cost while achieving high efficiencies. 
Siloxane terminated alkoxy and alkoxy groups with different ratios were incorporated to modify PX5 to obtain PX6 (PQSi05), PX7 (PQSi10), and PX8 (PQSi25). Compared with PX5, these polymers showed similar bandgaps, but increased $E_{\text {НОмо with }}$ an increasing amount of siloxane-containing side chains, which resulted in a decrease in $V_{\mathrm{OC}}$ of OSCs based on their blends with IT-4F. Among them, the PX6:IT-4F blend showed the highest and most balanced $\mu_{\mathrm{h}}$ and $\mu_{\mathrm{e}}$, least recombination and highest exciton dissociation and charge collection efficiencies (Table 4). Consequently, the devices based on the PX6:IT-4F blend showed the highest PCE of $13.56 \%$. In addition, all these polymers have a low SC and high figure-of-merit (FOM) (a parameter that is related to the manufacturability of OSCs using this material) as well as a low average SC (ASC) and average FOM (AFOM) when considering the cost of acceptors (Fig. 8c and d). ${ }^{168}$

\subsection{High performance polymer donors matching with Y6}

In 2019, Yuan et al. ${ }^{9}$ developed a novel NFA, Y6, which incorporates a BT-based fused-unit as the central core and 2FIC as the end groups (Fig. 6). Compared with ITIC and IT-4F, Y6 has a narrower bandgap of $1.33 \mathrm{eV}$ with a red-shifted optical absorption onset at $931 \mathrm{~nm}$, and a higher $\alpha_{\mathrm{s}-\max }$ of $2.39 \times 10^{5} \mathrm{M}^{-1} \mathrm{~cm}^{-1}$. The bandgap of Y6 is almost ideal for achieving the maximum PCE based on the Shockley-Queisser limit for single junction solar cells (at an $E_{\mathrm{g}}$ of $1.34 \mathrm{eV}) .{ }^{43}$ The $E_{\mathrm{LumO}}$ of $-4.1 \mathrm{eV}$ was between those of ITIC and IT-4F. Y6 is the acceptor that has achieved the record PCE of $18.22 \%$ so far. ${ }^{10}$

3.3.1 BDT-based polymer donors using imide derivatives as $\mathrm{A}$ units. Since benzotriazole functionalized with an imide moiety (TzBI) can lower $E_{\text {HOMO }}$, Ding et al. ${ }^{123}$ developed a novel polymer donor, PE14 (P2F-EHp), using this building block, which showed a low-lying $E_{\text {Hомо }}$ of $-5.46 \mathrm{eV}$ and a wide bandgap of $1.82 \mathrm{eV}$. They also synthesized a new NFA based on Y6 with a shorter central core, BTPT-4F, which has a wider bandgap of $1.45 \mathrm{eV}$ than that of Y6 $(1.33 \mathrm{eV})$. Therefore, the blend of PE14:Y6 showed much wider absorption (with an onset at about $900 \mathrm{~nm}$ ) than that of PE14:BTPT-4F. In addition, the former blend exhibited more ordered packing with a faceon orientation and smaller domain size for efficient exciton dissociation. A much higher PCE of $16.02 \%$ was obtained for PE14:Y6 than that for PE14:BTPT-4F (1.09\%). Another widely used electron-accepting building block containing the imide group is thieno[3.4-c]pyrrole-4,6-dione (TPD). Huang et al. ${ }^{110}$ synthesized two polymers, PE15 (PTPD) and PE16 (PbiTPD), using BDT and one or two TPD units in one repeat as the D and A units, respectively. The biTPD unit has a larger planar structure and stronger electron-withdrawing ability. PE16 showed a lower $E_{\text {HOMO }}(-5.20$ vs. $-5.05 \mathrm{eV})$ and red-shifted absorption. The blend of PE16:Y6 showed favourable face-on backbone orientation and higher crystallinity. A significantly enhanced PCE of 14.2\% was obtained for PE16:Y6 compared to PE15:Y6 (5.9\%).

3.3.2 BDT-based polymer donors using diketone derivatives as A units. PD2 is the first donor used to match Y6. ${ }^{9}$ The blend showed a wide EQE curve with the onset at about $900 \mathrm{~nm}$ due to the small bandgap of Y6, resulting in a high $J_{\mathrm{SC}}$ of $25.3 \mathrm{~mA} \mathrm{~cm} \mathrm{~cm}^{-2}$ (Fig. 9a). Together with a high $V_{\mathrm{OC}}$ of $0.83 \mathrm{~V}$ and a high FF of $74.8 \%$, a high PCE of $15.7 \%$ was obtained. The PCE is relatively independent of the blend film thickness with a high PCE of $13.6 \%$ even at a thickness of $300 \mathrm{~nm}$. Although PD2:Y6 achieved a high PCE over $15 \%, V_{\text {OC }}$ was relatively low due to the small difference between $E_{\mathrm{HOMO}}$ of PD2 and $E_{\mathrm{LUMO}}$ of Y6. Since PD3 with chlorine substitution had a lower $E_{\text {HOMO }}$ than PD2 $(-5.52$ vs. $-5.50 \mathrm{eV})$, the devices based on PD3:Y6 showed a higher $V_{\mathrm{OC}}$ of $0.897 \mathrm{~V}$, leading to a much higher PCE of $17.037 \%$. $^{130}$

As PD8 had shown high performance when blended with IT$4 \mathrm{~F}$, Xie et al. ${ }^{207}$ employed Y6 as an acceptor to blend with PD8. Compared with the IT-4F blend, the Y6 blend showed much wider EQE curves due to the red-shifted absorption of Y6. A much improved $J_{\mathrm{SC}}$ of $26.1 \mathrm{~mA} \mathrm{~cm}^{-2}$ was obtained for PD8:Y6 than that for PD8:IT-4F (19.74 $\mathrm{mA} \mathrm{cm}{ }^{-2}$ ), contributing to the higher PCE of $16.1 \%$ of the former.

As mentioned previously, the $\pi$-spacer between $\mathrm{D}$ and $\mathrm{A}$ units plays a key role in improving the coplanarity of the polymer backbone. As a $\pi$-spacer, selenophene with lower aromaticity than thiophene can endow a more planar backbone and longer conjugation. Chao et al. ${ }^{138}$ synthesized three polymers, PD13 (PBB), PD14 (PBBSe-H), and PD15 (PBBSe-Cl), to
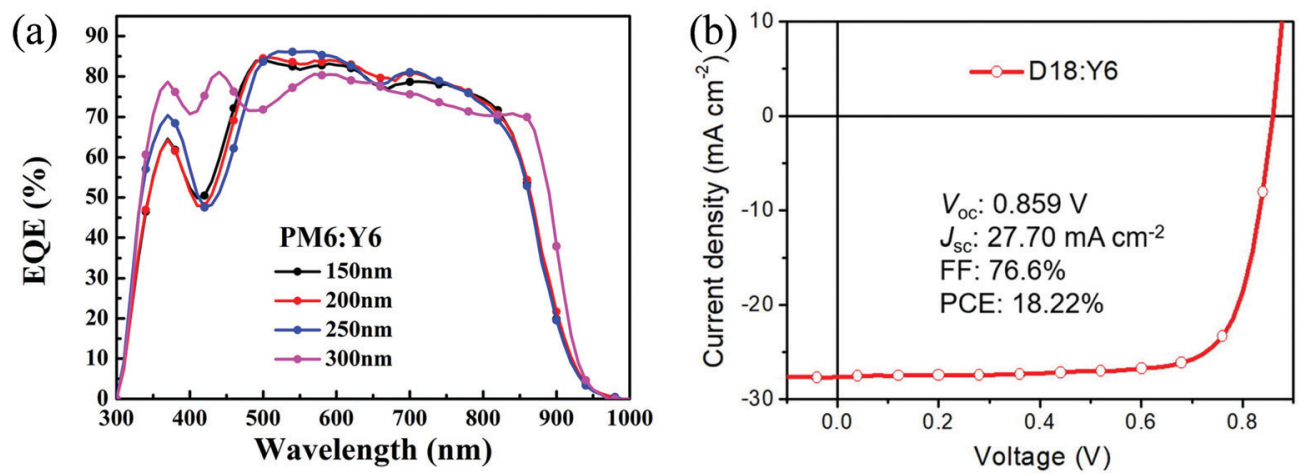

Fig. 9 (a) EQE curves of PD2:Y6-based OSCs, reproduced from ref. 9 with permission from Elsevier, copyright 2019; and (b) J-V curve for a PO12:Y6-based OSC, reproduced from ref. 10 with permission from Elsevier, copyright 2020. 
investigate the influence of selenophene $\pi$-spacers as well as chlorination on the performance of OSCs. It was found that PD13 without $\pi$-spacers and chlorination showed the most twisted structure with blue-shifted absorption. On the other hand, PD15 with $\pi$-spacers and chlorination demonstrated the strongest sunlight harvesting capability with a medium band-

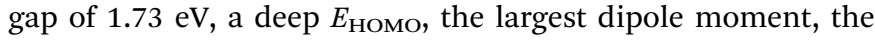
most planar polymer backbone, the strongest aggregation, and the highest charge mobility. Therefore, a high PCE of $14.44 \%$ was obtained when PD15 was blended with Y6. ${ }^{138}$

As both $\mathrm{F}$ atoms and ester groups can downshift the FMO energy levels and enhance the planarity and hence the charge transport, Sun et al. ${ }^{139}$ simultaneously introduced these two types of substituents onto the $\beta$ positions of thiophene to form FE-T as A units and made several terpolymers with BDT and BDD units via random copolymerization. The resultant polymer PD16 (S1) had a low-lying $E_{\text {HOMO }}$ of $-5.52 \mathrm{eV}$ and enhanced aggregation/crystallinity. Moreover, this ternary strategy enabled a favorable balance between crystallinity and miscibility. When this polymer was blended with Y6, a high PCE of $16.42 \%$ was obtained.

3.3.3 BDT-based polymer donors using $\mathbf{N}$-heterocycles as $\mathrm{A}$ units. The molecular conformation is crucial for the molecular packing and crystallinity, and thus the photovoltaic performance of the polymer donor. Since many D-A polymer donors employ $\pi$-spacers between the $\mathrm{D}$ and $\mathrm{A}$ units, the type of $\pi$-spacer would influence the molecular conformation. Tang et $a{ }^{152}$ utilized BDT with chlorothiophene side chains and FBTA as D and A units, respectively, and 3-hexylthieno[3,2$b]$ thiophene as $\pi$-spacers to develop a polymer PN21 (PE4). Compared with the polymer using thiophene as the $\pi$-spacers (J52-Cl), the molecular conformation of PN21 using this new spacer changed from a zigzag conformation to a linear conformation, which led to strong $\pi-\pi$ stacking, ordered lamellar packing, small phase domains, and high mobility. OSC devices based on the PN21:Y6 blend showed a high PCE of up to $14.02 \%$.

Phenazine $(\mathrm{Pz})$ can be considered as a Qx derivative with extended conjugation. Ding et $a .^{154}$ employed dithieno[3,2$\left.a: 2^{\prime}, 3^{\prime}-c\right]$ phenazine (DTPz) and 9,10-difluorodithieno[3,2-a:2', $\left.3^{\prime}-c\right]$ phenazine (FDTPz) as A units, BDT as D units, and thiophene as $\pi$ spacers to form two novel polymer donors, PN27 and PN28, respectively. Both polymers formed complementary absorption with Y6, while the fluorinated polymer PN28 showed a lower $E_{\text {HOMO }}$ of $-5.46 \mathrm{eV}$ than that of PN27 $(-5.33 \mathrm{eV})$. The devices based on the PN28:Y6 blend showed a higher $V_{\text {OC }}(0.867 v s$. $0.777 \mathrm{~V}$ ) and a similar $J_{\mathrm{SC}}$ compared with PN27:Y6. Moreover, due to the higher and more balanced $\mu_{\mathrm{h}}$ and $\mu_{\mathrm{e}}$ (Table 5), a higher FF (65.8\% vs. 61.6\%) was obtained for PN28:Y6. Thus, the PN28:Y6 blend showed a higher PCE of 15.14\% than that of PN27:Y6 $(12.3 \%)$.

3.3.4 Other BDT-based polymers and non-BDT-based polymers. Ding et al. ${ }^{161}$ used a fused-ring aromatic lactone (FRAL) with strong electron-withdrawing capability and an extended molecular plane as a building block to develop D-A polymer donors. The resulting PO9 (L1) and PO10 (L2) showed complementary absorption spectra with Y6. The higher and more balanced $\mu_{\mathrm{h}}$ and $\mu_{\mathrm{e}}$ (Table 5) of PO9:Y6 contributed to a higher $J_{\text {SC }}\left(23.93 v\right.$ s. $\left.20.52 \mathrm{~mA} \mathrm{~cm}^{-2}\right)$ and $\mathrm{FF}(74.7 \%$ vs. $70.2 \%)$ and thus a higher PCE (14.36\% vs. $12.57 \%)$ compared to PO10:Y6. They further replaced the lactone unit with the thiolactone unit to form PO11 (D16), which showed good planarity and thus stronger intermolecular $\pi-\pi$ stacking and charge carrier transport, leading to a higher PCE of $16.22 \%{ }^{160}$

Later, Ding et $a .^{10}$ used dithieno $\left[3^{\prime}, 2^{\prime}: 3,4 ; 2^{\prime \prime}, 3^{\prime \prime}: 5,6\right]$ benzo[1,2-c] $[1,2,5]$ thiadiazole (DTBT) as the A units and BDT as the D units to synthesize a polymer donor, PO12 (D18), which showed a higher $\mu_{\mathrm{e}}$ of $1.59 \times 10^{-4} \mathrm{~cm}^{2} \mathrm{~V}^{-1} \mathrm{~s}^{-1}$ than that

Table 5 OSC device performances based on blends of polymer donors and Y6

\begin{tabular}{|c|c|c|c|c|c|c|c|c|c|c|}
\hline Blend & $\mu_{\mathrm{h}}, \mu_{\mathrm{e}}\left(\times 10^{-4} \mathrm{~cm}^{2} \mathrm{~V}^{-1} \mathrm{~s}^{-1}\right), \mu_{\mathrm{e}(\mathrm{h})} / \mu_{\mathrm{h}(\mathrm{e})}{ }^{a}$ & $\operatorname{EQE}^{b}(\%)$ & $V_{\mathrm{OC}}(\mathrm{V})$ & $J_{\mathrm{SC}}\left(\mathrm{mA} \mathrm{cm}^{-2}\right)$ & $\mathrm{FF}(\%)$ & PCE (\%) & $S_{1}{ }^{c}$ & $S_{2}{ }^{d}$ & $P_{\text {diss }}(\%)$ & Ref. \\
\hline PE15:Y6 & $0.87,1.32,1.52$ & $<70$ & 0.66 & 19.5 & 46 & $5.9^{e}$ & 1.27 & 0.98 & & 110 \\
\hline PD3:Y6 & $7.46,4.66,1.60$ & & 0.897 & 25.644 & 74 & 17.037 & & & 96.7 & 130 \\
\hline PD8:Y6 & $7.1,5.1,1.39$ & & 0.84 & 26.1 & 72.5 & 16.1 & & & & 207 \\
\hline PD13:Y6 & $0.84,4.1,5$ & & 0.84 & 4.25 & 42.36 & 1.51 & & 0.9 & & 138 \\
\hline PD16:Y6 & $7.01,4.43,1.67$ & & 0.877 & 25.402 & 73.7 & 16.421 & & 0.978 & 95.8 & 139 \\
\hline PN21:Y6 & $8.04,1.14,7.05$ & & 0.84 & 22.21 & 75.43 & 14.02 & 1.27 & 1 & & 152 \\
\hline PN27:Y6 & $1.33,0.681,1.95$ & & 0.777 & 25.7 & 61.6 & 12.3 & & 0.933 & 87.9 & 154 \\
\hline PN28:Y6 & $3.42,2.42,1.41$ & & 0.867 & 26.53 & 65.8 & 15.14 & & 0.958 & 94.9 & 154 \\
\hline PO9:Y6 & $5.62,4.77,1.18$ & 76 & 0.8 & 23.93 & 74.7 & 14.63 & & 0.954 & 96.7 & 161 \\
\hline PO10:Y6 & $1.60,2.05,1.28$ & 68 & 0.87 & 20.52 & 70.2 & 12.57 & & 0.951 & 94.7 & 161 \\
\hline P011:Y6 & $2.82,2.81,1.01$ & 83 & 0.85 & 25.41 & 74.9 & 16.22 & & 0.981 & 97.8 & 160 \\
\hline
\end{tabular}

${ }^{a} \mu_{\mathrm{e}} / \mu_{\mathrm{h}}$ or $\mu_{\mathrm{h}} / \mu_{\mathrm{e}}$, whichever is $>1 .{ }^{b}$ Maximum value of EQE. ${ }^{c}$ Obtained from $V_{\mathrm{OC}} \sim S_{1} \log \left(P_{\text {light }}\right) .{ }^{d}$ Obtained from $J_{\mathrm{ph}} \sim S_{2} \log \left(P_{\text {light }}\right) .{ }^{e}$ The numbers of significant digits of the data are adopted from the original references and may be different. 
of PO11 $\left(1.19 \times 10^{-4} \mathrm{~cm}^{2} \mathrm{~V}^{-1} \mathrm{~s}^{-1}\right)$ since DTBT has a larger molecular plane. While the high and balanced $\mu_{\mathrm{h}}$ and $\mu_{\mathrm{e}}$ of the PO12:Y6 blend were responsible for the high FF (76.6\%), the complementary absorption contributed to the very high $J_{\mathrm{SC}}$ of $27.7 \mathrm{~mA} \mathrm{~cm}^{-2}$ (Table 5). A PCE of $18.22 \%$ was achieved (Fig. 9b), which is the highest value reported for single junction OSCs. They also used fluorine- and alkoxyl-substituted benzene (FAB) as A units to synthesize a new polymer donor PO13 (W1) with a low $E_{\text {HOMO }}$ of $-5.36 \mathrm{eV}$ and a wide bandgap of $2.16 \mathrm{eV}{ }^{162}$ The PO13:Y6 blend achieved a PCE of 16.16\%.

PX5 was synthesized with very low cost and showed high performance when blended with IDIC or IT-4F. ${ }^{167,168}$ When PX5 was blended with Y6, much wider absorption and EQE curves were obtained owing to the red-shifted absorption of Y6. ${ }^{208}$ In addition, higher $\mu_{\mathrm{h}}$ and $\mu_{\mathrm{e}}$ were also obtained. A largely improved $J_{\mathrm{SC}}$ of $26.65 \mathrm{~mA} \mathrm{~cm}^{-2}$ was achieved, leading to a high PCE of $16.53 \%$.

When $\mathrm{J} 52$ was blended with Y6, a low $V_{\mathrm{OC}}(0.65 \mathrm{~V})$ resulting from the high $E_{\text {Номо }}(-5.12 \mathrm{eV})$ of J52 and a low FF $(53.82 \%)$ due to the imbalanced $\mu_{\mathrm{h}}$ and $\mu_{\mathrm{e}}$ were obtained, leading to a moderate PCE of $7.15 \% .{ }^{169}$ When IDTT was used to replace BDT in J52, the resulting PX9 (PIDTT-DTffBTA) had a lower $E_{\text {Hомо of }-5.25 \mathrm{eV} .}{ }^{169}$ When blended with Y6, more balanced $\mu_{\mathrm{h}}$ and $\mu_{\mathrm{e}}$ were obtained for the blend film. Consequently, a higher $V_{\mathrm{OC}}$ of $0.74 \mathrm{~V}$, an improved $\mathrm{FF}$ of $65.73 \%$, and an enhanced PCE of $11.05 \%$ were obtained.

\subsection{General guidelines for the design of high-performance WBG polymer donors}

Based on the above discussions, some useful guidelines for the design of high-performance WBG polymer donors for matching narrow bandgap NFAs are obtained, which are briefly summarized as follows: ${ }^{42,209-212}$

(1) A combination of suitable D and A building blocks to form D-A polymers has been almost exclusively used as the strategy to develop WBG polymer donors for matching narrow bandgap NFAs since desired FMOs and bandgaps can be readily obtained by fine selection of donor and acceptor units with different abilities of electron withdrawing or donating properties. $^{35}$ Thiophene-containing building blocks have been used in the $\mathrm{D}$ units due to their appropriate electron-donating ability to obtain the desired $E_{\text {HOMO }}$ and their lower steric effects on the neighbouring units to maintain backbone planarity to achieve high hole mobility. Among them, BDT has been most frequently used due to its large and planar fused-ring extended $\pi$-conjugated structure that can facilitate hole transport and more importantly induce face-on crystal orientation for efficient charge transport along the vertical direction in the active layer. Moderately electron-withdrawing building blocks that can maintain a relatively high $E_{\text {Lumo }}$ have been utilized as the A units to construct WBG polymer donors. The electronwithdrawing groups among these building blocks are mainly esters, imides, ketones, N-heterocyles (containing $\mathrm{sp}^{2}$ nitrogen), and their combinations. In addition, an electron donating, sterically less demanding $\pi$-spacer has often been inserted between the $\mathrm{D}$ and $\mathrm{A}$ units in a $\mathrm{D}-\mathrm{A}$ type polymer donor to maintain the backbone planarity and the distance between the
$\mathrm{D}$ and $\mathrm{A}$ units to increase the electronic polarization, which possibly helps stabilize the excitons. ${ }^{213-216}$

(2) Several strategies can be used to lower $E_{\text {Hомо }}$ of the polymer donors: (i) introducing electron-withdrawing groups such as fluorine, chlorine, ester, trifluoromethyl, and alkoxy groups; $^{121,147,148,217,218}$ (ii) replacing thienyl side chains with alkoxy or alkylthio substituted phenyl side chains; ${ }^{133,219}$ and (iii) replacing the alkyl side chains with alkylthio groups. ${ }^{220}$

(3) A coplanar and rigid backbone is needed for high charge carrier mobility, which can be achieved by: (i) extending the conjugation area of the backbone by using larger fused ring building blocks; ${ }^{196}$ (ii) replacing thiophene with selenophene, which has lower aromaticity and enhanced ground-state quinoid resonance character, resulting in improved planarity and increased effective conjugation length; ${ }^{138}$ (iii) fluorination or chlorination, which enhances the intermolecular interactions; ${ }^{217,218}$ and (iv) strengthening intermolecular interactions through side chain engineering ${ }^{221}$ and introduction of $\pi$ spacers. $^{138}$

\subsection{Morphology control in WBG polymer donor:NFA systems}

The morphology of the $\mathrm{BHJ}$ blend active layer directly impacts the exciton dissociation, charge separation, and transport processes. A bicontinuous network of the donor and acceptor with domain sizes between 10 and $20 \mathrm{~nm}$ could provide a large interfacial area between the two domains to facilitate exciton dissociation, while forming a continuous and relatively pure percolating pathway to transport free charges to the corresponding electrodes. ${ }^{222-228}$ The extent of this phase separation is critical since domains that are too large (greater than the typical exciton diffusion length on the order of tens of nanometres) will favour geminate recombination, whereas too-mixed domains can increase the rate of non-geminate recombination. ${ }^{4,229-231}$ A favourable morphology can be achieved by tuning the donor:acceptor miscibility and crystallinity. ${ }^{229}$

Herein, we discuss how changing the donor properties, choosing a certain acceptor in the BHJ blend, and modifying the processing conditions would impact the morphology of the donor:acceptor blend and hence the performance of the OSC device.

3.5.1 Donor and acceptor interaction and miscibility. In most high-performance WBG donor:NFA systems, the as-cast active layer is in the metastable state and the film formation is strongly dependent on the thermodynamics and kinetics of thin film formation from the blend solution. ${ }^{232-234}$ The FloryHuggins interaction parameter $(\chi)$ has been used to predict the morphology evolution in the active layer in a number of studies. Three distinct miscibility regions have been defined by Ye et $a .^{228}$ as shown in Fig. 10 in the $\chi-\phi$ phase diagram, where $\phi$ is the polymer volume fraction; an ideal morphology is neither too pure nor too mixed. Parameter $\chi$ can be calculated by differential scanning calorimetry (DSC) measurements (melting point depression method) or surface energy measurements of the donor and acceptor (details of the equations used for the calculation can be found elsewhere). ${ }^{22,228,232,233,235,236}$

A computational approach to studying the charge separation efficiency between polymer donors and NFAs was proposed by 


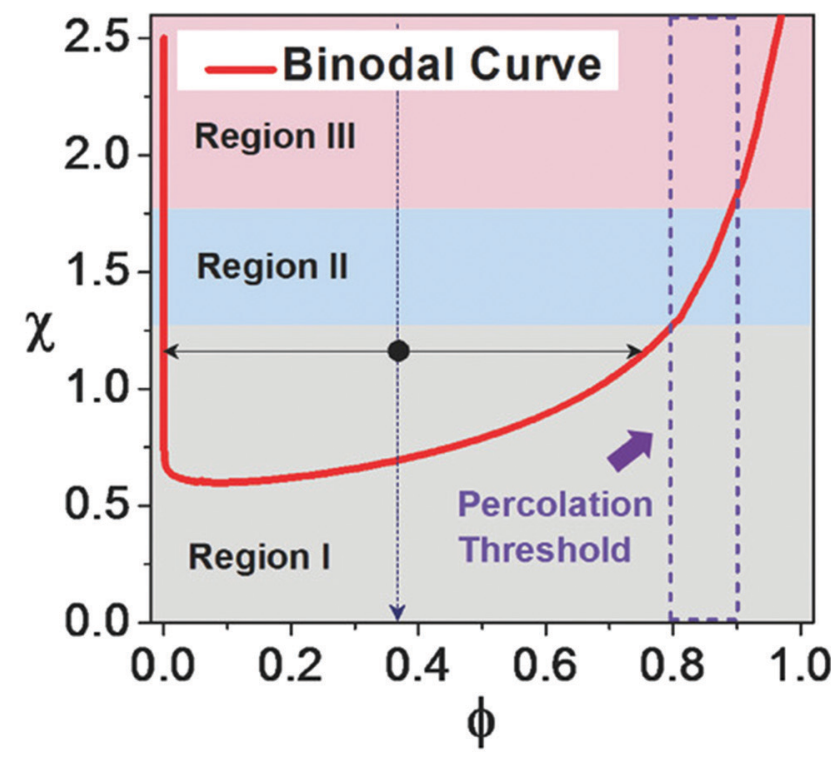

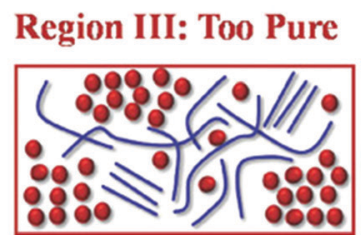

Region II: Ideal

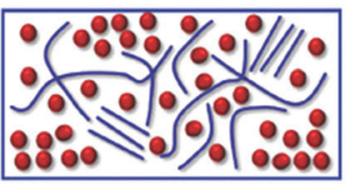

Region I: Too Miscible

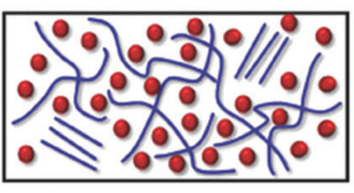

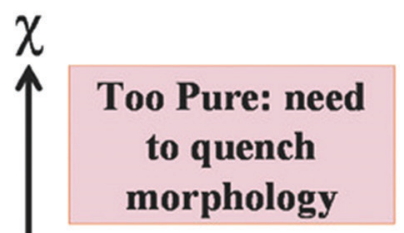

Ideal: near

percolation

threshold

\section{Too miscible: bad performance}

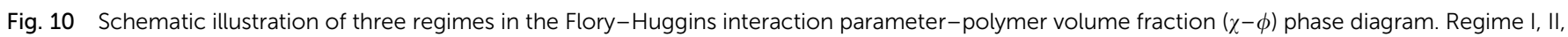

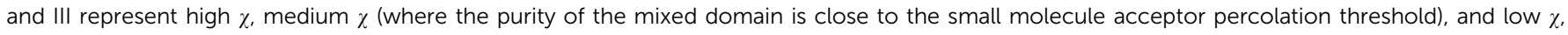

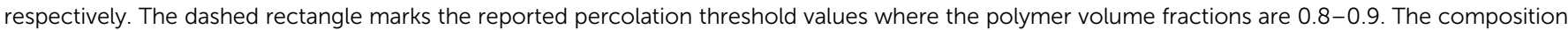

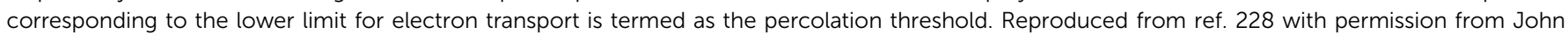
Wiley and Sons, copyright 2018.

Yao et al. ${ }^{121}$ They found that the larger electrostatic potential difference between a WBG polymer donor (PE12) and NFA (IT-4F) was responsible for a high PCE of $14.7 \%$, even though the driving force for charge separation (energy level offsets) in the blend was quite small. ${ }^{121}$

3.5.2 Active layer morphology optimization methods. During film casting, the intermolecular forces among polymer chains play a critical role in determining the properties of the resulting condensed state. These properties include the aggregation, morphology, domain purity, molecular orientation, etc. of the polymer in the blend film. For example, rigid polymers (usually polymers with rigid BDT and BDD units) with strong $\pi-\pi$ stacking lead to ordered $\mathrm{BHJ}$ films with increased domain purity. On the other hand, polymers with relatively weak $\pi-\pi$ stacking and less pronounced molecular ordering in solution (such as PX1, PE17 (PTB7), PE1 and PE18 (PBDT-TS1)) tend to form much smaller and random polymer domains upon casting. ${ }^{163,236-238}$

The morphology of the donor:acceptor blend can be controlled by pre- and post-deposition treatments of the as-cast film. These morphology optimization methods aim to achieve high average domain purity and highly ordered packing of both the donor and acceptor to minimize charge recombination in NFA-based OSCs. ${ }^{223}$

Processing solvent additives are well known for regulating the $\mathrm{BHJ}$ active layer morphology. Wang et al. ${ }^{239}$ studied the effect of different concentrations of a common solvent additive DIO (1,8diiodooctane) in the PD1:ITIC system, using a vertical stratification study of the donor and acceptor. They found an optimal DIO content of $0.5 \%$. It is noteworthy that while an increase in the DIO content (to 1\%) leads to abruptly enhanced face-on packing of PD1 (beneficial in OSCs), excessive vertical component distribution and over crystallization of ITIC occur, which results in reduced vertical carrier transport paths for both PD1 and ITIC and a reduced PCE. The device with no additive demonstrated an average PCE of $8.74 \%, J_{\mathrm{SC}}$ of $15.88 \mathrm{~mA} \mathrm{~cm} \mathrm{~cm}^{-2}, V_{\mathrm{OC}}$ of $0.892 \mathrm{~V}$, and $\mathrm{FF}$ of $61.7 \%$. With $0.5 \%$ DIO an increased $J_{\text {SC }}$ and FF of $17.23 \mathrm{~mA} \mathrm{~cm}^{-2}$ and $69.3 \%$, respectively, resulted in a high PCE of $10.75 \%$. With $1 \%$ DIO, both $J_{\text {SC }}$ and the FF dropped to $15.23 \mathrm{~mA} \mathrm{~cm}^{-2}$ and $66.8 \%$, respectively, thereby leading to a lower PCE of $9.27 \%$.

Solvent vapor annealing (SVA) is an efficient post-processing technique to control the morphology of the active layer. It serves as a method for molecular level rearrangement by penetrating solvent vapor into the active layer. ${ }^{240,241}$ Jiao et $a .^{240}$ used four common annealing solvents, methylene chloride $\left(\mathrm{CH}_{2} \mathrm{Cl}_{2}\right)$, chloroform $\left(\mathrm{CHCl}_{3}\right)$, tetrahydrofuran (THF), and carbon disulfide $\left(\mathrm{CS}_{2}\right)$, to study the effect of active layer SVA treatment on the performance of PD3:IT-4Cl-based OPVs, achieving significantly improved performance compared with that of the as-cast OPVs. SVA (especially with $\mathrm{CS}_{2}$ ) enhanced the charge generation, transport, and collection efficiency. The PD3:IT-4Cl device with $\mathrm{CS}_{2}$ solvent treatment showed the highest PCE of $13.76 \%$ with a $J_{\text {SC }}$ of $20.53 \mathrm{~mA} \mathrm{~cm}^{-2}$, a $V_{\text {OC }}$ of $0.87 \mathrm{~V}$ and a $\mathrm{FF}$ of $77.05 \%$, while the control device showed a lower $J_{\mathrm{SC}}$ $\left(19.28 \mathrm{~mA} \mathrm{~cm}^{-2}\right.$ ) and $\mathrm{FF}$ (70.36\%), and a similar $V_{\mathrm{OC}}$ of $0.88 \mathrm{~V}$ with a PCE of $11.94 \%$.

Thermal annealing is another widely used simple method for morphology optimization, mostly due to the temperature-dependent aggregation behaviour of donor-acceptor phases. ${ }^{223,233,242-244}$ For example, Bin et al. ${ }^{141}$ reported a more than 25\% improvement in the PCE of the PN2:ITIC device upon annealing at $150{ }^{\circ} \mathrm{C}$ for $10 \mathrm{~min}$ due to enhanced crystalline domains with prominent face-on orientation leading to higher 
SCLC mobility (improved charge transport) as compared to unannealed devices. The as-prepared PN2:ITIC device showed a PCE of $9.03 \%$ with a $J_{\mathrm{SC}}$ of $14.81 \mathrm{~mA} \mathrm{~cm}^{-2}$, a $V_{\mathrm{OC}}$ of $0.96 \mathrm{~V}$ and a FF of $63.63 \%$, while, upon annealing, the device showed a significantly higher $J_{\mathrm{SC}}\left(17.32 \mathrm{~mA} \mathrm{~cm}^{-2}\right)$ and $\mathrm{FF}(69.77 \%)$ and a similar $V_{\text {OC }}(0.94 \mathrm{~V})$, resulting in a PCE of $11.41 \%$. Especially for the high performance WBG polymer PD1, with temperature dependent aggregation behavior, thermal annealing is necessary to achieve the optimal photovoltaic performance. ${ }^{141}$ The critical parameters that determine the effectiveness of thermal annealing for a polymer:NFA system are the glass transition temperature $\left(T_{\mathrm{g}}\right)$ and miscibility of the components $(\chi) \cdot{ }^{233}$

\section{Desirable properties of WBG polymer donors for high efficiency NFA-based OSCs}

\subsection{Molecular packing and charge transport}

The choice of polymer donor will affect not only $\mu_{\mathrm{h}}$ of the blend but also the molecular ordering of the NFAs significantly and thus $\mu_{\mathrm{e}}$ and the domain purity (miscibility). ${ }^{245}$ A coplanar polymer with reduced steric hindrance in the backbone is favorable for ordered molecular packing and intermolecular charge transport and is correlated with higher $\mu_{\mathrm{h}}$ of neat and blend films. For example, Li et al. ${ }^{119}$ employed covalent and noncovalent (F).S conformational lock) backbone rigidification strategies, respectively, to design two BDT and estermodified oligothiophene-based copolymers (PE7 and PE8). Hydrogen-bonding interactions induced in the DFDT-based unit in polymer PE8 resulted in stronger interchain $\pi-\pi$ interactions, a smaller $\pi-\pi$ distance with a longer coherence length $\left(L_{\mathrm{c}}\right)$ and thus a significantly higher $\mu_{\mathrm{h}}$ compared to its TT counterpart. A $V_{\mathrm{OC}}$ of $0.86 \mathrm{~V}$, a high $J_{\mathrm{SC}}$ of $21.83 \mathrm{~mA} \mathrm{~cm}$ and a remarkable FF of $75 \%$, and thus a high PCE of $14.16 \%$ were obtained for the PE8:IT-4F device, whereas the PE7:IT-4F device showed a significantly lower $J_{\mathrm{SC}}\left(19.34 \mathrm{~mA} \mathrm{~cm}{ }^{-2}\right)$ and FF (65\%), and thus a low PCE of $11.10 \%$. Liu et al. ${ }^{127}$ designed two new WBG polymers (PE19 (PB2T) and PE20 (PB3T)) based on BDT and oligothiophene units. PE20 exhibits a more planar geometry, whereas PE19 has a highly twisted backbone conformation; therefore, a PCE of $11.9 \%$ was achieved for the PE20:IT-M (Fig. 11) device compared to the very poor performance $(0.01 \%)$ of the PE19:IT-M device. Tang et al. ${ }^{170}$ used a backbone fluorination strategy to improve the crystallinity (lamellar and $\pi-\pi$ packing coherence length) and thus SCLC mobilities, making use of the introduced F $\cdots \mathrm{F}$, C-F $\cdots \mathrm{H}$, and $\mathrm{F} \cdots \mathrm{S}$ interactions in PX11 (PDTF-TZNT) compared to non-fluorinated counterpart PX11. Consequently, the PX10:IT-M device showed a relatively low PCE of $4.42 \%$ with a $J_{\mathrm{SC}}$ of $10.15 \mathrm{~mA} \mathrm{~cm} \mathrm{~cm}^{-2}$, a $V_{\text {OC }}$ of $0.75 \mathrm{~V}$, and a FF of $58.1 \%$, whereas the PX11:IT-M device obtained a higher PCE of $10.05 \%$ with an improved $J_{\mathrm{SC}}$ of $17.33 \mathrm{~mA} \mathrm{~cm}^{-2}$, a $V_{\mathrm{OC}}$ of $0.80 \mathrm{~V}$, and a significantly high FF of $72.5 \%$.

Achieving high FF requires efficient charge extraction capability facilitated by high mobilities of both holes and electrons. As seen in Fig. 12a, for high performance systems, blend carrier mobilities in excess of $10^{-4} \mathrm{~cm}^{2} \mathrm{~V}^{-1} \mathrm{~s}^{-1}$ can achieve a $\mathrm{FF}$ of $>70 \%$. To achieve such moderate to high mobilities in the device, the polymer donor is preferred to have a planar backbone with moderate aggregation capability, predominantly face-on orientation, and covalent and noncovalent backbone rigidification induced by strategies such as fluorination, conformation locking, and/or side chain modification. In addition, the mobility ratio, crystal sizes, and coherence length of the $\pi-\pi$ stacking order of the polymer in the blend are also crucial (OSC performance dependencies on the mobility ratio and (010) coherence length are plotted in Fig. 12b and c, respectively). For perspective, most high-performance systems utilize polymers with neat film SCLC mobilities in excess of $10^{-4} \mathrm{~cm}^{2} \mathrm{~V}^{-1} \mathrm{~s}^{-1}$ for achieving a high FF of $>60 \%$ (Fig. 12d). Importantly, an overly crystalline polymer donor can also lead to decreased miscibility with the NFA in the blend, leading to large pure aggregated domains, which is detrimental to charge transport. $^{236}$

\subsection{Matching energy levels for minimizing $E_{\text {loss }}$}

For a long time, it has been considered that a sufficient energy level offset of $\geq 0.3 \mathrm{eV}$ between organic donor and acceptor materials, $\Delta E_{\mathrm{HOMO}}$ or $\Delta E_{\mathrm{LUMO}}$, is required for efficient charge separation mostly based on observations for fullerene-based OSCs. ${ }^{87,121,192-195}$ This is due to the nature of organic semiconductors, which typically have much larger exciton binding energies $(\sim 0.3-1 \mathrm{eV})$ than inorganic semiconductors. However, due to the advent of efficient NFAs, several studies have demonstrated highly efficient OSCs with efficient and fast charge separation at a $\Delta E_{\text {Hомо }}\left(\right.$ and/or $\left.\Delta E_{\text {LUMO }}\right)$ much smaller than $0.3 \mathrm{eV}$. For example, Sun et al. ${ }^{171}$ used finely tuned WBG polymer donor:NFA acceptor system PX12 (PTQ11):TPT10 (Fig. 11) to achieve highly efficient exciton dissociation and charge transfer, resulting in a high PCE of $16.32 \%$ with a high

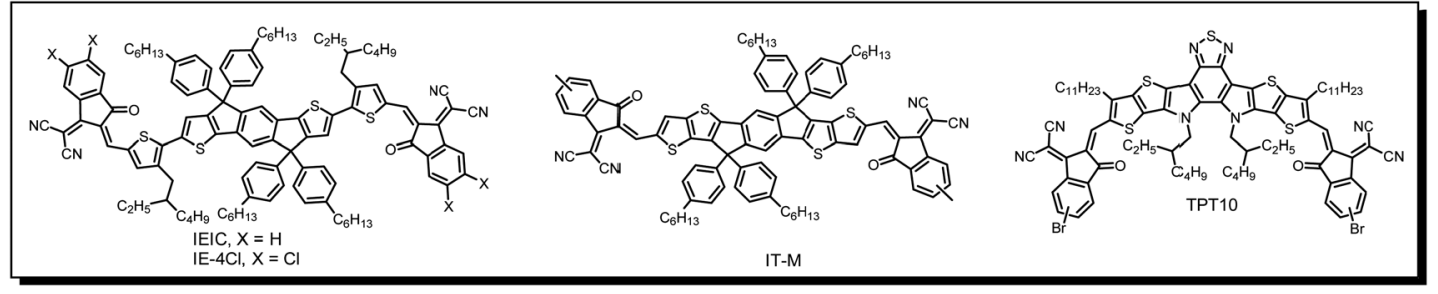

Fig. 11 Chemical structures of additional NFAs. 
(a)

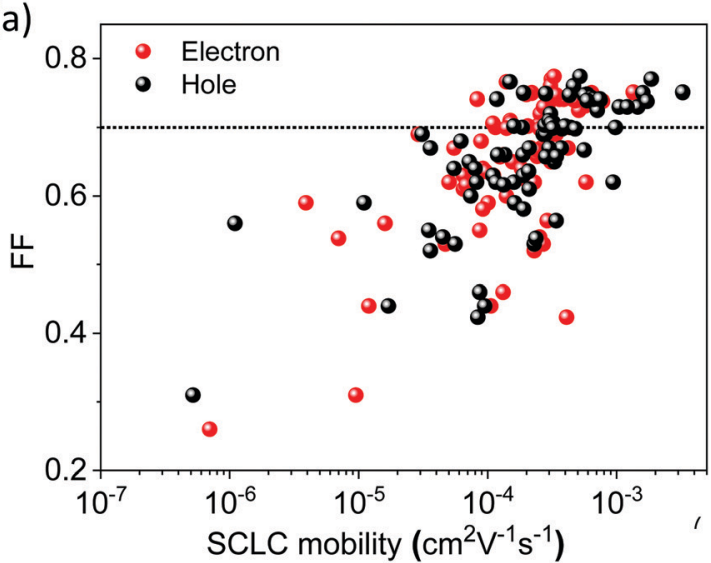

(c)

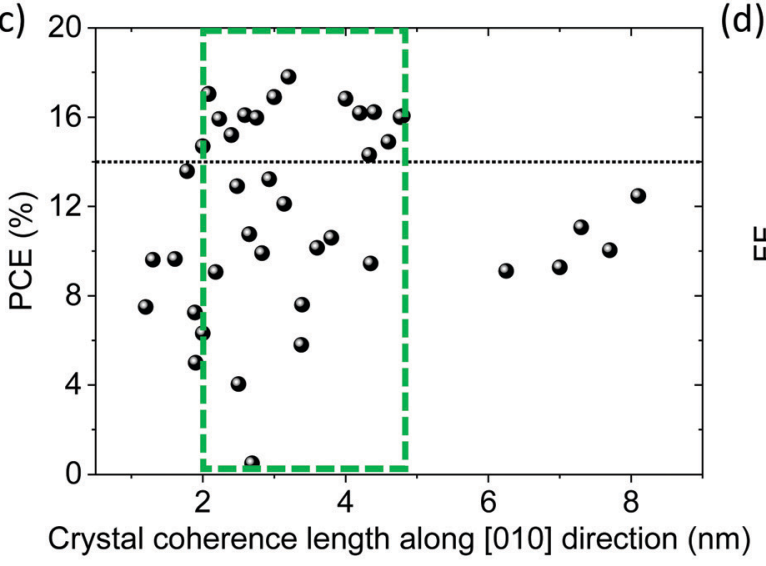

(b)

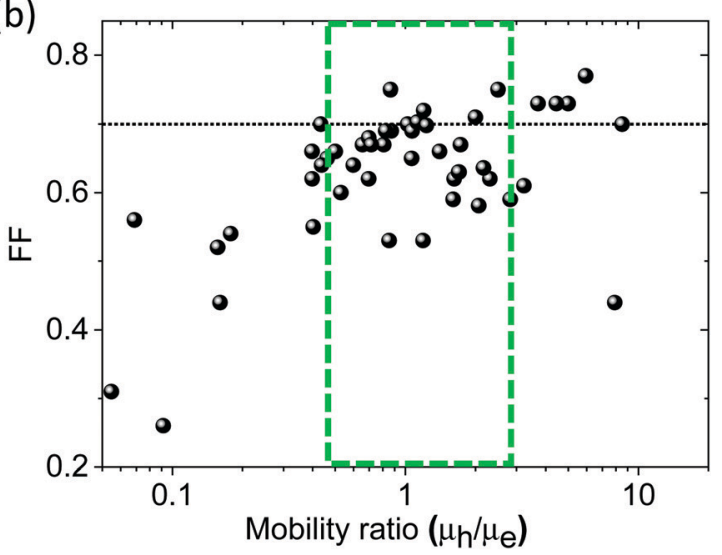

(d)

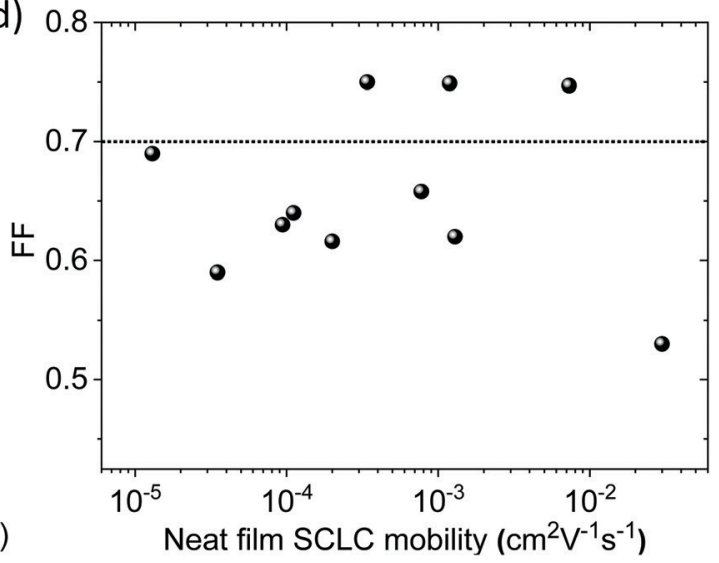

Fig. 12 Plots of (a) SCLC electron and hole mobilities measured in blend films vs. FF, (b) SCLC mobility ratio $\left(\mu_{\mathrm{h}} / \mu_{\mathrm{e}}\right)$ vs. the corresponding FF, (c) coherence length along the [010] direction of crystal packing in blend films vs. the respective PCE, and (d) neat film SCLC mobility vs. the corresponding FF in OSCs with WBG polymer donors and NFAs discussed in this review.

$V_{\mathrm{OC}}$ of $0.88 \mathrm{~V}$, a large $J_{\mathrm{SC}}$ of $24.79 \mathrm{~mA} \mathrm{~cm}^{-2}$, and a high $\mathrm{FF}$ of $74.8 \%$, despite the zero $\Delta E_{\text {Номо }}$ value. Similar instances of a high $J_{\mathrm{SC}}$ (high EQE) despite an incredibly low or zero $\Delta E_{\mathrm{HOMO}}$ or $\Delta E_{\text {LUMO }}$ have been reported elsewhere. ${ }^{65,246-250}$

The voltage loss $\left(V_{\text {loss }}\right)$, calculated from the difference between the optical bandgap of the solar cell active layer and $V_{\mathrm{OC}}$ of the device $\left(V_{\text {loss }}=E_{\mathrm{g}} / q-V_{\mathrm{OC}}\right)$, is the key concern for obtaining the maximum performance from a given pair of a WBG polymer donor and NFA. ${ }^{248,250}$ This voltage loss (also referred to as energy loss, $E_{\text {loss }}=e V_{\text {loss }}$ ) can be minimized by increasing the difference between $E_{\mathrm{LUMO}}$ of the acceptor and $E_{\mathrm{HOMO}}$ of the donor as $V_{\mathrm{OC}}$ of OSCs is proportional to this difference. Therefore, if fast and efficient charge separation can be achieved in blends with almost no energy offsets, the LUMO and HOMO of the donor polymer could align with the acceptor to minimize $\Delta E_{\text {Hомо }}$ and $\Delta E_{\mathrm{LUMO}}$, effectively decreasing $V_{\text {loss. }}{ }^{171}$ This was one of the two design criteria proposed by Qian et al., ${ }^{248}$ where they used spectroscopic and quantumchemistry approaches to identify key rules for minimizing voltage losses: (1) a low energy offset between the donor and acceptor molecular states and (2) high luminescence of the lowbandgap component.

Nevertheless, several studies have reported the need to fine tune the molecular energy alignment to provide a "certain minimum" driving force for balancing the exciton dissociation probability and $V_{\mathrm{OC}}$ loss. Yang et al. ${ }^{65}$ used structurally similar donor and acceptor combinations (with similar blend morphologies and charge transport properties) to study the performance variations corresponding to their different energy-level offsets. They found that the energy offset has no impact on the charge transport process, but it does affect the exciton dissociation process in NFA-based OSCs. A larger $\Delta E_{\text {номо }}$ between the donor and acceptor can provide sufficient driving force, which contributes to a higher exciton dissociation probability $\left(P_{\text {diss }}\right)$ and PCE. Although minimizing $\Delta E_{\text {HOMO }}$ can effectively reduce $E_{\text {loss }}$ (or improve $V_{\mathrm{OC}}$ ), the decreasing driving force will diminish the exciton dissociation process. Moreover, as $\Delta E_{\text {номо falls }}$ below a threshold, $P_{\text {diss }}$ drops sharply, reducing the overall performance of the device. ${ }^{65}$ In yet another study investigating the relationship between $E_{\text {loss }}$ and the device performance of NFA-based OSCs, Ling et al. ${ }^{249}$ found that donor and acceptor blends with an $E_{\text {loss }}$ below $0.6 \mathrm{eV}$ demonstrated inefficient charge transfer between the polymer donor and NFA, resulting in a low EQE and PCE (an example of the trade-off between device performance and energy loss). The PD1:IE-4Cl (Fig. 11)based device afforded a PCE of $11.1 \%$ (with a high $J_{\mathrm{SC}}$ of $21.49 \mathrm{~mA} \mathrm{~cm} \mathrm{~cm}^{-2}$ and a moderate $\mathrm{FF}$ of $60 \%$ ) and $E_{\text {loss }}$ of $0.64 \mathrm{eV}$, whereas the PD1:IEIC based device obtained a low 
PCE of $3.8 \%$ (with a low $J_{\mathrm{SC}}$ of $7.65 \mathrm{~mA} \mathrm{~cm}^{-2}$ and low $\mathrm{FF}$ of $45 \%$ ) despite the lower $E_{\text {loss }}$ of $0.52 \mathrm{eV}$.

The reasons as to why some polymer donor:acceptor blend systems require a very low $\Delta E_{\text {HOMO }}$ or $\Delta E_{\mathrm{LUMO}}$ for efficient charge separation and show a very low $E_{\text {loss }}$ are still not well understood, but seem to correlate with both the donor and acceptor materials. More examples are needed to probe the relationships of the structures (chemical and morphological) and optoelectronic properties of the polymer donors with $E_{\text {loss }}$ of the OSC devices, which are extremely important for maximizing the potential of OSCs.

\subsection{Characteristics of top performing polymer donors and OSCs}

The OSC performance parameters, $V_{\mathrm{OC}}, J_{\mathrm{SC}}, \mathrm{FF}$, and PCE, of the WBG polymer donors paired with ITIC, IT-4F, and Y6 discussed in this review are plotted in Fig. 13. It can be seen that $V_{\mathrm{OC}}$ decreases and $J_{\mathrm{SC}}$ increases from ITIC to IT- $4 \mathrm{~F}$ to Y6, while the FF is similar among the three NFAs even though the IT-4F based devices show a slightly higher FF. From ITIC to IT-4F to Y6, the FMO energy levels downshift and the absorption spectra red-shift, which leads to a narrowed optical bandgap, resulting in reduced $V_{\mathrm{OC}}$, but increased $J_{\mathrm{SC}}$. The overall PCE of the OSCs follows the order of ITIC $<$ IT-4F $<$ Y6, which is due to the relatively large contribution of $J_{\mathrm{SC}}$ that supersedes the reduction in $V_{\text {OC }}$. The PCE values of the top five highperforming polymer donors and the photovoltaic parameters of the best polymer donor for each NFA are shown in Fig. 14.

Some distinct characteristics of these high-performance polymer donors (in Fig. 14) can be observed. Firstly, the $E_{\text {Hомо }}$ values of the donors matching with ITIC are -5.3 to $-5.5 \mathrm{eV}$, while those of the donors matching with IT-4F and Y6 are -5.5 to $-5.6 \mathrm{eV}$, which are decided by $E_{\mathrm{HOMO}}$ of the NFAs since a sufficient $\Delta E_{\text {HOMO }}$ for efficient dissociation of excitons generated in the NFA phase is required. Secondly, these WBG polymer donors have $E_{\mathrm{g}}$ values of 1.9-2.1 eV that cover the short wavelength region (where the NFAs absorb poorly) to form complementary absorption to achieve high $J_{\mathrm{SC}}$. Lastly, these polymers have SCLC hole mobilities higher than $10^{-4} \mathrm{~cm}^{2} \mathrm{~V}^{-1} \mathrm{~s}^{-1}$, which could achieve high and balanced $\mu_{\mathrm{h}}$ and $\mu_{\mathrm{e}}$ in their blends with NFAs, leading to high FF. All these blends have a $\mu_{\mathrm{h}} / \mu_{\mathrm{e}}$ ratio very close to 1 except for PX5:Y6, which has a $\mu_{\mathrm{h}} / \mu_{\mathrm{e}}$ ratio (2.41) greater than 2 , where both $\mu_{\mathrm{h}}$ and $\mu_{\mathrm{e}}$ are higher than $10^{-3} \mathrm{~cm}^{2} \mathrm{~V}^{-1} \mathrm{~s}^{-1}$, which would probably not impede charge transport even though $\mu_{\mathrm{h}}$ and $\mu_{\mathrm{e}}$ are not well balanced in this case.
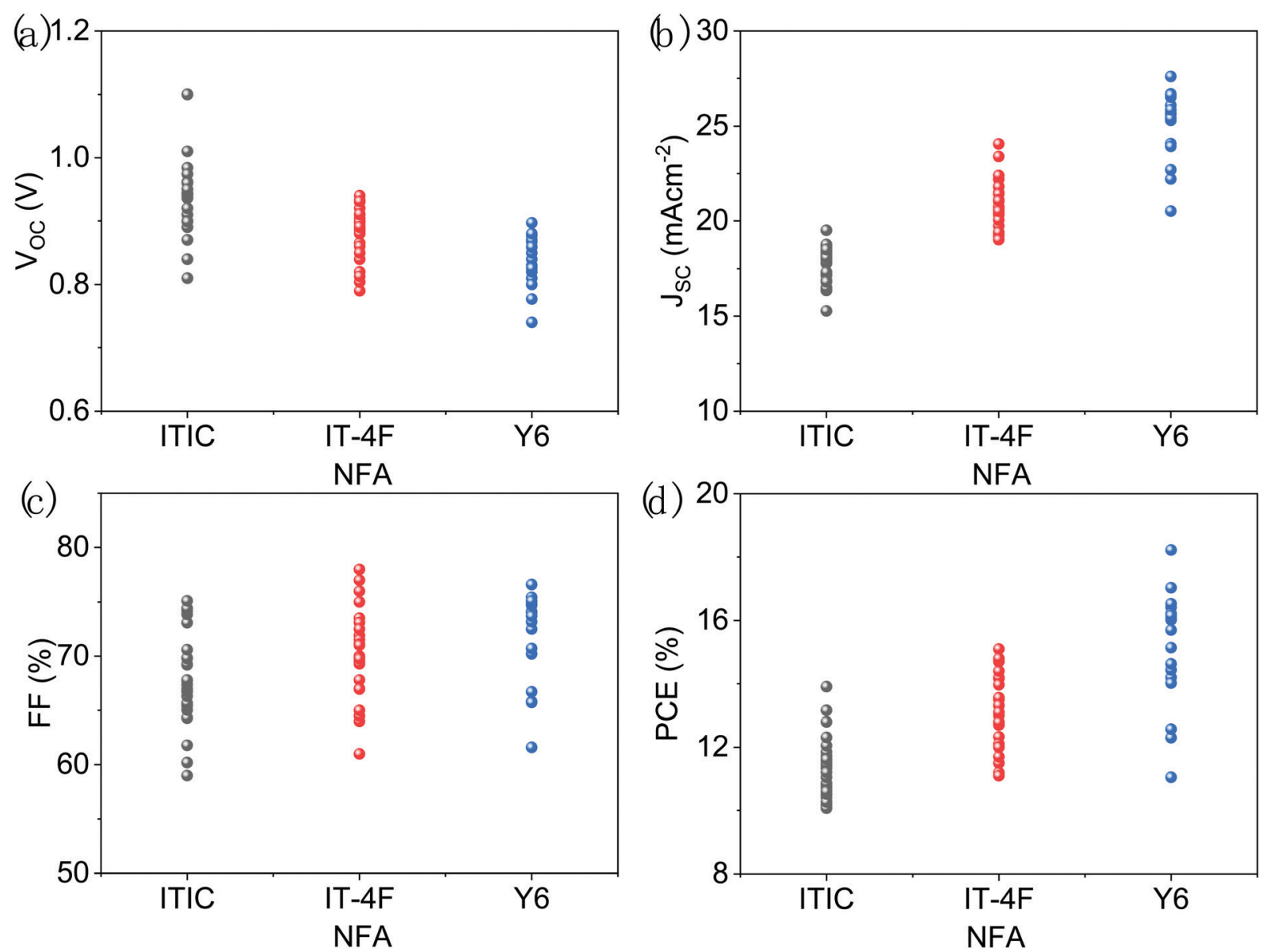

Fig. $13 V_{O C}($ a), J JC (b), FF (c), and PCE (d) of high-performance OSCs using WBG polymer donors and different NFAs, ITIC, IT-4F and Y6, discussed in this review. 


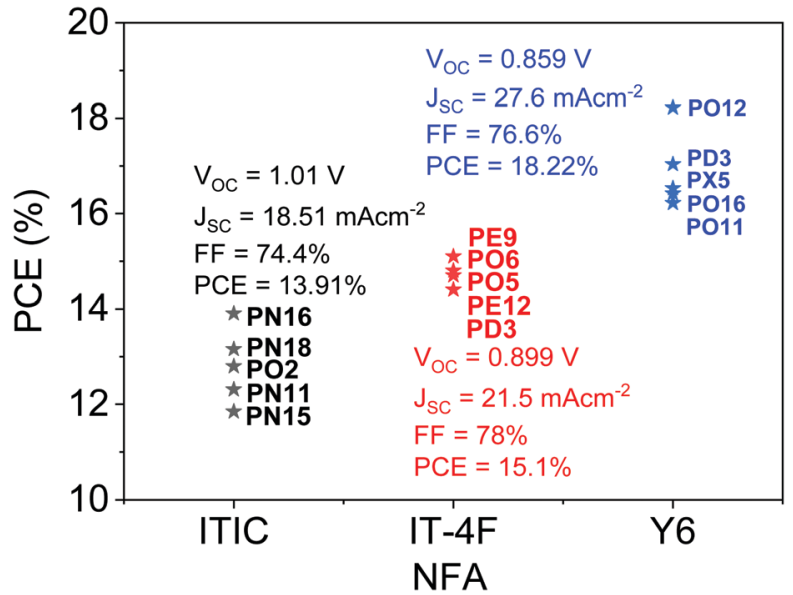

Fig. 14 Device performances of the top performing polymer donors matching with ITIC, IT-4F and Y6, where the photovoltaic parameters shown are from the best performing PN16:ITIC, PE9:IT-4F and PO12:Y6 systems.

\section{Conclusions and outlook}

In the past few years, tremendous progress has been made in the development of WBG polymer donors that match the emerging high-performance narrow bandgap NFAs, achieving remarkable PCEs of up to $18.22 \%$, which has beaten the predicted PCE limit of $\sim 10 \%$ for OSCs based on fullerene acceptors. ${ }^{251}$ In this review, we have examined the most representative WBG polymer donors that have been used to match three typical NFAs: ITIC, IT-4F, and Y6. The structure-propertycell performance relationships are probed by analysing the structural design strategies to control and finely tune the FMO energy levels, adjust the light absorption profile, and enhance the hole mobility to match those of different NFAs. The morphology control of the polymer blends to create desirable phase separation and crystallinity for achieving high device performance is also discussed.

Despite these recent advances in the development of polymer donors and OSCs in general, there is room for further improvement of the cell performance, while some challenges and issues need to be overcome in order to make OSCs a commercial reality.

\section{(1) Further boosting the PCE of OSCs}

Theoretical limit of the PCE for OSCs. According to Shockley and Queisser, ${ }^{43}$ the maximum PCE of a single-junction solar cell is $33.7 \%$ (the S-Q limit) achievable with a semiconductor having a bandgap of $1.34 \mathrm{eV}$. Hou et al. ${ }^{17}$ predicted that a PCE of $>20 \%$ for OSCs is possible if $V_{\text {loss }}$ can be lowered to $<0.45 \mathrm{~V}$, a realistic value considering that a $V_{\text {loss }}$ of $0.3 \mathrm{~V}$ has been reported recently for perovskite solar cells, ${ }^{252}$ while the current state-of-the art OSCs show a $V_{\text {loss }}$ of $c a .0 .6 \mathrm{~V}^{253,254}$ Therefore, theoretically there is still much room for further enhancement of the PCE for OSCs.

Reducing the energy loss. Organic materials with large dielectric constants in the same range as silicon $(\sim 11)$ could reduce the coulombic interaction in excitons, or the exciton binding energy, to enable highly efficient exciton dissociation..$^{87,90,95,255}$ Consequently, thicker layers could be used to maximize the absorption of light (and to ease large-scale fabrication). Moreover, the largely reduced exciton binding energy would only require very small $\Delta E_{\mathrm{HOMO}}$ and $\Delta E_{\mathrm{LUMO}}$ for exciton dissociation, which could greatly reduce the energy loss. Furthermore, the reduced exciton binding energy would enlarge the exciton diffusion distance, which may enable bilayer heterojunction OSCs without delicate and tedious morphological control of the blend layer to realize a nanoscale BHJ structure. This would be very desirable for single componentorganic solar cell devices (SC-OSCs), where the polymer in the active layer having both donor and acceptor components could greatly simplify the device fabrication process and achieve high morphological stability. ${ }^{98}$ Very recently, Jiang et al. ${ }^{256}$ achieved a record PCE of $8.40 \%$ in SC-OSCs using a double-cable conjugated polymer.

\section{(2) Long-term stability}

Despite the considerable efforts made over the past few decades, OSCs have not become a commercial reality yet. The stability of OSCs is one of the main obstacles in the path towards commercialization. Solar cells work under various operational stresses such as solar illumination, increased temperature, and exposure to air. ${ }^{102,257-262}$ The intrinsic degradation mechanisms of the active layer in OSCs include degradation in the dark caused by the morphological changes (rearrangement of donor and acceptor domains) that occur over time and photo-chemical reactions of the organic semiconductor materials in the presence of illumination. ${ }^{263-267}$ In terms of morphological stability, all-polymer solar cells have attracted much attention since a polymer donor and a polymer acceptor can be entangled to form a much more metastable blend, leading to superior thermal and mechanical stabilities compared to small molecule-based OSCs. ${ }^{268-274}$ Notable progress has been made in improving the lifetime of OSCs with extrapolated lifetimes (with $80 \%$ PCE retention) of over 20 years being demonstrated recently. ${ }^{263,275}$

\section{(3) Fabrication of large area devices}

Another big obstacle towards the commercialization of OSCs is the poor scalability of OSC devices. Most, if not all, of the OSCs showing high PCEs greater than $10 \%$ are reported with an active area of less than $1 \mathrm{~cm}^{2}$. Increasing the device active area usually results in a significant reduction in the PCE. Although promising large area modules have been reported, ${ }^{276,277}$ the lab-to-manufacturing translation seems still very challenging and requires urgent attention. ${ }^{278}$

\section{(4) Low cost}

Commercialization of OSCs will require a competitive low manufacturing cost-to-PCE ratio along with energy payback and embodied energy metrics comparable to existing silicon solar cells. ${ }^{279,280}$ It has been predicted that for OSCs having unique merits such as flexibility, lightness, and high throughput manufacturability, a module efficiency of $10 \%$ with an 
operational lifetime of 10 years and a production cost of $<\$ 0.5$ per $W_{\mathrm{p}}$ would be enough to reach the threshold of commecialization. ${ }^{281}$ For the donor:acceptor combination to be fully scalable, it should possess a high value of the industrial figure of merit (i-FOM). ${ }^{282-284}$ This parameter takes account of the synthetic complexity (SC) of the donor and acceptor materials as well as the PCE and lifetime of the OSC device. Most of the high PCE polymer donors require tedious synthesis and use of toxic substances, resulting in very high SC and thus insufficient i-FOM. The importance of developing polymer donors with low SC has been increasingly realized. On the other hand, small molecule donor materials have found increased interest in the last couple of years for their industrial scalability owing to the advantages of well-defined chemical structures, synthetic ease, high purity of materials, and outstanding repeatability from batch to batch synthesis. ${ }^{285,286}$

\section{(5) Environmentally friendly manufacturing}

Most of the high performance OSCs are fabricated using halogenated solvents such as $o$-dichlorobenzene, chlorobenzene, or chloroform, which are environmental hazards. These solvents might be suitable for proof-of-concept lab-based research, but for large scale production alternative ecofriendly solvents (green solvents) need to be used. ${ }^{287,288}$ As discussed, some polymer donors that can be processed using green solvents and yet show high PCE have been reported. ${ }^{120,289,290}$

\section{Conflicts of interest}

There are no conflicts to declare.

\section{Acknowledgements}

The authors are thankful for the support from the Discovery Grants (RGPIN-2016-04366) and Strategic Partnership Grants for Projects (STPGP 506317-17; STPGP 521458) of the Natural Sciences and Engineering Research Council of Canada (NSERC).

\section{Notes and references}

1 G. Li, R. Zhu and Y. Yang, Nat. Photonics, 2012, 6, 153-161.

2 O. Inganäs, Adv. Mater., 2018, 30, 1800388.

3 N. Matsuhisa, X. Chen, Z. Bao and T. Someya, Chem. Soc. Rev., 2019, 48, 2946-2966.

4 C. Cui and Y. Li, Energy Environ. Sci., 2019, 12, 3225-3246.

5 G. Yu, J. Gao, J. C. Hummelen, F. Wudl and A. J. Heeger, Science, 1995, 270, 1789-1791.

6 Y. Tong, Z. Xiao, X. Du, C. Zuo, Y. Li, M. Lv, Y. Yuan, C. Yi, F. Hao, Y. Hua, T. Lei, Q. Lin, K. Sun, D. Zhao, C. Duan, X. Shao, W. Li, H.-L. Yip, Z. Xiao, B. Zhang, Q. Bian, Y. Cheng, S. Liu, M. Cheng, Z. Jin, S. Yang and L. Ding, Sci. China: Chem., 2020, 63, 758-765.
7 Y. Liang, Z. Xu, J. Xia, S.-T. Tsai, Y. Wu, G. Li, C. Ray and L. Yu, Adv. Mater., 2010, 22, E135-E138.

8 Y. Lin, J. Wang, Z.-G. Zhang, H. Bai, Y. Li, D. Zhu and X. Zhan, Adv. Mater., 2015, 27, 1170-1174.

9 J. Yuan, Y. Zhang, L. Zhou, G. Zhang, H.-L. Yip, T.-K. Lau, X. Lu, C. Zhu, H. Peng, P. A. Johnson, M. Leclerc, Y. Cao, J. Ulanski, Y. Li and Y. Zou, Joule, 2019, 3, 1140-1151.

10 Q. Liu, Y. Jiang, K. Jin, J. Qin, J. Xu, W. Li, J. Xiong, J. Liu, Z. Xiao, K. Sun, S. Yang, X. Zhang and L. Ding, Sci. Bull., 2020, 65, 272-275.

11 J. C. Hummelen, B. W. Knight, F. LePeq, F. Wudl, J. Yao and C. L. Wilkins, J. Org. Chem., 1995, 60, 532-538.

12 J. Peet, J. Y. Kim, N. E. Coates, W. L. Ma, D. Moses, A. J. Heeger and G. C. Bazan, Nat. Mater., 2007, 6, 497-500.

13 Y. He, H.-Y. Chen, J. Hou and Y. Li, J. Am. Chem. Soc., 2010, 132, 1377-1382.

14 Z. He, C. Zhong, S. Su, M. Xu, H. Wu and Y. Cao, Nat. Photonics, 2012, 6, 591-595.

15 J. Zhao, Y. Li, G. Yang, K. Jiang, H. Lin, H. Ade, W. Ma and H. Yan, Nat. Energy, 2016, 1, 15027.

16 W. Zhao, D. Qian, S. Zhang, S. Li, O. Inganäs, F. Gao and J. Hou, Adv. Mater., 2016, 28, 4734-4739.

17 J. Hou, O. Inganäs, R. H. Friend and F. Gao, Nat. Mater., 2018, 17, 119-128.

18 L. Gao, Z.-G. Zhang, H. Bin, L. Xue, Y. Yang, C. Wang, F. Liu, T. P. Russell and Y. Li, Adv. Mater., 2016, 28, 8288-8295.

19 H. Bin, Z.-G. Zhang, L. Gao, S. Chen, L. Zhong, L. Xue, C. Yang and Y. Li, J. Am. Chem. Soc., 2016, 138, 4657-4664.

20 X. Li, G. Huang, N. Zheng, Y. Li, X. Kang, S. Qiao, H. Jiang, W. Chen and R. Yang, Sol. RRL, 2019, 3, 1900005.

21 S. Li, L. Ye, W. Zhao, S. Zhang, S. Mukherjee, H. Ade and J. Hou, Adv. Mater., 2016, 28, 9423-9429.

22 W. Zhao, S. Li, H. Yao, S. Zhang, Y. Zhang, B. Yang and J. Hou, J. Am. Chem. Soc., 2017, 139, 7148-7151.

23 Y. Yang, Z.-G. Zhang, H. Bin, S. Chen, L. Gao, L. Xue, C. Yang and Y. Li, J. Am. Chem. Soc., 2016, 138, 15011-15018.

24 J. Wang, W. Wang, X. Wang, Y. Wu, Q. Zhang, C. Yan, W. Ma, W. You and X. Zhan, Adv. Mater., 2017, 29, 1702125.

25 Y. Lin, F. Zhao, Q. He, L. Huo, Y. Wu, T. C. Parker, W. Ma, Y. Sun, C. Wang, D. Zhu, A. J. Heeger, S. R. Marder and X. Zhan, J. Am. Chem. Soc., 2016, 138, 4955-4961.

26 F. Zhao, S. Dai, Y. Wu, Q. Zhang, J. Wang, L. Jiang, Q. Ling, Z. Wei, W. Ma, W. You, C. Wang and X. Zhan, Adv. Mater., 2017, 29, 1700144.

27 Y. Lin, Q. He, F. Zhao, L. Huo, J. Mai, X. Lu, C.-J. Su, T. Li, J. Wang, J. Zhu, Y. Sun, C. Wang and X. Zhan, J. Am. Chem. Soc., 2016, 138, 2973-2976.

28 B. Jia, J. Wang, Y. Wu, M. Zhang, Y. Jiang, Z. Tang, T. P. Russell and X. Zhan, J. Am. Chem. Soc., 2019, 141, 19023-19031.

29 S. Dai, F. Zhao, Q. Zhang, T.-K. Lau, T. Li, K. Liu, Q. Ling, C. Wang, X. Lu, W. You and X. Zhan, J. Am. Chem. Soc., 2017, 139, 1336-1343.

30 J. Wang, J. Zhang, Y. Xiao, T. Xiao, R. Zhu, C. Yan, Y. Fu, G. Lu, X. Lu, S. R. Marder and X. Zhan, J. Am. Chem. Soc., 2018, 140, 9140-9147. 
31 T. Li, S. Dai, Z. Ke, L. Yang, J. Wang, C. Yan, W. Ma and X. Zhan, Adv. Mater., 2018, 30, 1705969.

32 Y. Ma, Z. Kang and Q. Zheng, J. Mater. Chem. A, 2017, 5, 1860-1872.

33 H. Hu, P. C. Y. Chow, G. Zhang, T. Ma, J. Liu, G. Yang and H. Yan, Acc. Chem. Res., 2017, 50, 2519-2528.

34 D. Gedefaw, M. Prosa, M. Bolognesi, M. Seri and M. R. Andersson, Adv. Energy Mater., 2017, 7, 1700575.

35 L. Sun, X. Xu, S. Song, Y. Zhang, C. Miao, X. Liu, G. Xing and S. Zhang, Macromol. Rapid Commun., 2019, 40 1900074.

36 A. Wadsworth, M. Moser, A. Marks, M. S. Little, N. Gasparini, C. J. Brabec, D. Baran and I. McCulloch, Chem. Soc. Rev., 2019, 48, 1596-1625.

37 S. Dey, Small, 2019, 15, 1900134.

38 G. Zhang, J. Zhao, P. C. Y. Chow, K. Jiang, J. Zhang, Z. Zhu, J. Zhang, F. Huang and H. Yan, Chem. Rev., 2018, 118, 3447-3507.

39 S. Suman and S. P. Singh, J. Mater. Chem. A, 2019, 7, 22701-22729.

40 H. Wang, J. Cao, J. Yu, Z. Zhang, R. Geng, L. Yang and W. Tang, J. Mater. Chem. A, 2019, 7, 4313-4333.

41 C. Yan, S. Barlow, Z. Wang, H. Yan, A. K.-Y. Jen, S. R. Marder and X. Zhan, Nat. Rev. Mater., 2018, 3, 18003.

42 G. Wang, F. S. Melkonyan, A. Facchetti and T. J. Marks, Angew. Chem., Int. Ed., 2019, 58, 4129-4142.

43 W. Shockley and H. J. Queisser, J. Appl. Phys., 1961, 32, 510-519.

44 L. Meng, Y. Zhang, X. Wan, C. Li, X. Zhang, Y. Wang, X. Ke, Z. Xiao, L. Ding, R. Xia, H.-L. Yip, Y. Cao and Y. Chen, Science, 2018, 361, 1094-1098.

45 T. Ameri, N. Li and C. J. Brabec, Energy Environ. Sci., 2013, 6, 2390.

46 G. Li, W.-H. Chang and Y. Yang, Nat. Rev. Mater., 2017, 2, 17043.

47 P. Cheng, G. Li, X. Zhan and Y. Yang, Nat. Photonics, 2018, 12, 131-142.

48 K. Ramki, N. Venkatesh, G. Sathiyan, R. Thangamuthu and P. Sakthivel, Org. Electron., 2019, 73, 182-204.

49 H. Yao, L. Ye, H. Zhang, S. Li, S. Zhang and J. Hou, Chem. Rev., 2016, 116, 7397-7457.

50 U. Mehmood, A. Al-Ahmed and I. A. Hussein, Renewable Sustainable Energy Rev., 2016, 57, 550-561.

51 M.-H. Jao, H.-C. Liao and W.-F. Su, J. Mater. Chem. A, 2016, 4, 5784-5801.

52 S. Liu, J. Yuan, W. Deng, M. Luo, Y. Xie, Q. Liang, Y. Zou, Z. He, H. Wu and Y. Cao, Nat. Photonics, 2020, 14, 300-305.

53 R. S. Gurney, W. Li, Y. Yan, D. Liu, A. J. Pearson and T. Wang, J. Energy Chem., 2019, 37, 148-156.

54 K. Vandewal, J. Benduhn and V. C. Nikolis, Sustainable Energy Fuels, 2018, 2, 538-544.

55 Y. Wang, D. Qian, Y. Cui, H. Zhang, J. Hou, K. Vandewal, T. Kirchartz and F. Gao, Adv. Energy Mater., 2018, 8, 1801352.

56 J. Sworakowski, J. Lipiński and K. Janus, Org. Electron., 2016, 33, 300-310.
57 B. Dandrade, S. Datta, S. Forrest, P. Djurovich, E. Polikarpov and M. Thompson, Org. Electron., 2005, 6, 11-20.

58 R. E. M. Willems, C. H. L. Weijtens, X. de Vries, R. Coehoorn and R. A. J. Janssen, Adv. Energy Mater., 2019, 9, 1803677.

59 J. Rivnay, S. C. B. Mannsfeld, C. E. Miller, A. Salleo and M. F. Toney, Chem. Rev., 2012, 112, 5488-5519.

60 F. Liu, Y. Gu, X. Shen, S. Ferdous, H.-W. Wang and T. P. Russell, Prog. Polym. Sci., 2013, 38, 1990-2052.

61 J. Liu, Y. Sun, X. Gao, R. Xing, L. Zheng, S. Wu, Y. Geng and Y. Han, Langmuir, 2011, 27, 4212-4219.

62 J. Liu, M. Arif, J. Zou, S. I. Khondaker and L. Zhai, Macromolecules, 2009, 42, 9390-9393.

63 J. H. Litofsky, Y. Lee, M. P. Aplan, B. Kuei, A. Hexemer, C. Wang, Q. Wang and E. D. Gomez, Macromolecules, 2019, 52, 2803-2813.

64 Y. Gu, C. Wang and T. P. Russell, Adv. Energy Mater., 2012, 2, 683-690.

65 C. Yang, J. Zhang, N. Liang, H. Yao, Z. Wei, C. He, X. Yuan and J. Hou, J. Mater. Chem. A, 2019, 7, 18889-18897.

66 V. D. Mihailetchi, L. J. A. Koster, J. C. Hummelen and P. W. M. Blom, Phys. Rev. Lett., 2004, 93, 216601.

67 M. E. Ziffer, S. B. Jo, H. Zhong, L. Ye, H. Liu, F. Lin, J. Zhang, X. Li, H. W. Ade, A. K.-Y. Jen and D. S. Ginger, J. Am. Chem. Soc., 2018, 140, 9996-10008.

68 D. Baran, N. Gasparini, A. Wadsworth, C. H. Tan, N. Wehbe, X. Song, Z. Hamid, W. Zhang, M. Neophytou, T. Kirchartz, C. J. Brabec, J. R. Durrant and I. McCulloch, Nat. Commun., 2018, 9, 2059.

69 S. R. Cowan, A. Roy and A. J. Heeger, Phys. Rev. B: Condens. Matter Mater. Phys., 2010, 82, 245207.

70 L. J. A. Koster, V. D. Mihailetchi, R. Ramaker and P. W. M. Blom, Appl. Phys. Lett., 2005, 86, 123509.

71 K. Jiang, G. Zhang, G. Yang, J. Zhang, Z. Li, T. Ma, H. Hu, W. Ma, H. Ade and H. Yan, Adv. Energy Mater., 2018, 8, 1701370.

72 R. Sun, Q. Wu, J. Guo, T. Wang, Y. Wu, B. Qiu, Z. Luo, W. Yang, Z. Hu, J. Guo, M. Shi, C. Yang, F. Huang, Y. Li and J. Min, Joule, 2020, 4, 407-419.

73 L. Arunagiri, Z. Peng, X. Zou, H. Yu, G. Zhang, Z. Wang, J. Y. Lin Lai, J. Zhang, Y. Zheng, C. Cui, F. Huang, Y. Zou, K. S. Wong, P. C. Y. Chow, H. Ade and H. Yan, Joule, 2020, 4, 1790-1805.

74 L. J. A. Koster, V. D. Mihailetchi, H. Xie and P. W. M. Blom, Appl. Phys. Lett., 2005, 87, 203502.

75 P. Mark and W. Helfrich, J. Appl. Phys., 1962, 33, 205-215.

76 D. Natali and M. Sampietro, J. Appl. Phys., 2002, 92, 5310-5318.

77 J. A. Röhr, X. Shi, S. A. Haque, T. Kirchartz and J. Nelson, Phys. Rev. Appl., 2018, 9, 044017.

78 R. Mauer, M. Kastler and F. Laquai, Adv. Funct. Mater., 2010, 20, 2085-2092.

79 W. E. Spear, J. Non-Cryst. Solids, 1969, 1, 197-214.

80 G. Juška, K. Arlauskas, M. Viliūnas and J. Kočka, Phys. Rev. Lett., 2000, 84, 4946-4949.

81 G. Juška, K. Arlauskas, M. Viliūnas, K. Genevičius, R. Österbacka and H. Stubb, Phys. Rev. B: Condens. Matter Mater. Phys., 2000, 62, R16235-R16238. 
82 A. Kokil, K. Yang and J. Kumar, J. Polym. Sci., Part B: Polym. Phys., 2012, 50, 1130-1144.

83 A. J. Mozer, C.-Q. Ma, W. W. H. Wong, D. J. Jones, P. Bäuerle and G. G. Wallace, Org. Electron., 2010, 11, 573-582.

84 K. Genevičius, R. Österbacka, G. Juška, K. Arlauskas and H. Stubb, Synth. Met., 2003, 137, 1407-1408.

85 T. Okachi, T. Nagase, T. Kobayashi and H. Naito, Thin Solid Films, 2008, 517, 1331-1334.

86 H. C. F. Martens, H. B. Brom and P. W. M. Blom, Phys. Rev. B: Condens. Matter Mater. Phys., 1999, 60, R8489-R8492.

87 T. M. Clarke and J. R. Durrant, Chem. Rev., 2010, 110, 6736-6767.

88 M. Engel, F. Kunze, D. C. Lupascu, N. Benson and R. Schmechel, Phys. Status Solidi RRL, 2012, 6, 68-70.

89 B. P. Rand, D. P. Burk and S. R. Forrest, Phys. Rev. B: Condens. Matter Mater. Phys., 2007, 75, 115327.

90 L. Zhu, Y. Yi and Z. Wei, J. Phys. Chem. C, 2018, 122, 22309-22316.

91 S. Chen, S.-W. Tsang, T.-H. Lai, J. R. Reynolds and F. So, Adv. Mater., 2014, 26, 6125-6131.

92 S. Y. Leblebici, T. L. Chen, P. Olalde-Velasco, W. Yang and B. Ma, ACS Appl. Mater. Interfaces, 2013, 5, 10105-10110.

93 B. Bernardo, D. Cheyns, B. Verreet, R. D. Schaller, B. P. Rand and N. C. Giebink, Nat. Commun., 2014, 5, 1-7.

94 J. A. Carr and S. Chaudhary, Appl. Phys. Lett., 2012, 100, 213902.

95 S. Leblebici, J. Lee, A. Weber-Bargioni and B. Ma, J. Phys. Chem. C, 2017, 121, 3279-3285.

96 J. Brebels, J. V. Manca, L. Lutsen, D. Vanderzande and W. Maes, J. Mater. Chem. A, 2017, 5, 24037-24050.

97 H.-W. Li, Z. Guan, Y. Cheng, T. Lui, Q. Yang, C.-S. Lee, S. Chen and S.-W. Tsang, Adv. Electron. Mater., 2016, 2, 1600200.

98 N. Cho, C. W. Schlenker, K. M. Knesting, P. Koelsch, H.L. Yip, D. S. Ginger and A. K.-Y. Jen, Adv. Energy Mater., 2014, 4, 1301857.

99 P. Schilinsky, C. Waldauf and C. J. Brabec, Appl. Phys. Lett., 2002, 81, 3885-3887.

100 G. Li, V. Shrotriya, J. Huang, Y. Yao, T. Moriarty, K. Emery and Y. Yang, Nat. Mater., 2005, 4, 864-868.

101 S. Holliday, R. S. Ashraf, A. Wadsworth, D. Baran, S. A. Yousaf, C. B. Nielsen, C.-H. Tan, S. D. Dimitrov, Z. Shang, N. Gasparini, M. Alamoudi, F. Laquai, C. J. Brabec, A. Salleo, J. R. Durrant and I. McCulloch, Nat. Commun., 2016, 7, 11585.

102 D. Baran, R. S. Ashraf, D. A. Hanifi, M. Abdelsamie, N. Gasparini, J. A. Röhr, S. Holliday, A. Wadsworth, S. Lockett, M. Neophytou, C. J. M. Emmott, J. Nelson, C. J. Brabec, A. Amassian, A. Salleo, T. Kirchartz, J. R. Durrant and I. McCulloch, Nat. Mater., 2017, 16, 363-369.

103 X. Jia, Z. Chen, C. Duan, Z. Wang, Q. Yin, F. Huang and Y. Cao, J. Mater. Chem. C, 2019, 7, 314-323.

104 X. Xu, G. Zhang, L. Yu, R. Li and Q. Peng, Adv. Mater., 2019, 31, 1906045.
105 C. Yang, S. Zhang, J. Ren, M. Gao, P. Bi, L. Ye and J. Hou, Energy Environ. Sci., 2020, 13, 2864-2869.

106 B. Zheng, L. Huo and Y. Li, NPG Asia Mater., 2020, 12, 3.

107 W. Li, K. H. Hendriks, M. M. Wienk and R. A. J. Janssen, Acc. Chem. Res., 2016, 49, 78-85.

108 Y.-W. Su, Y.-C. Lin and K.-H. Wei, J. Mater. Chem. A, 2017, 5, 24051-24075.

109 S.-H. Liao, H.-J. Jhuo, Y.-S. Cheng and S.-A. Chen, Adv. Mater., 2013, 25, 4766-4771.

110 J. Zhao, Q. Li, S. Liu, Z. Cao, X. Jiao, Y.-P. Cai and F. Huang, ACS Energy Lett., 2020, 5, 367-375.

111 D. Qian, L. Ye, M. Zhang, Y. Liang, L. Li, Y. Huang, X. Guo, S. Zhang, Z. Tan and J. Hou, Macromolecules, 2012, 45, 9611-9617.

112 S. C. Price, A. C. Stuart, L. Yang, H. Zhou and W. You, J. Am. Chem. Soc., 2011, 133, 4625-4631.

113 Z. Zheng, O. M. Awartani, B. Gautam, D. Liu, Y. Qin, W. Li, A. Bataller, K. Gundogdu, H. Ade and J. Hou, Adv. Mater., 2017, 29, 1604241.

114 Y. Wang and T. Michinobu, J. Mater. Chem. C, 2016, 4, 6200-6214.

115 C. Chang, W. Li, X. Guo, B. Guo, C. Ye, W. Su, Q. Fan and M. Zhang, Org. Electron., 2018, 58, 82-87.

116 D. H. Kim, T. T. Trang Bui, S. Rasool, C. E. Song, H. K. Lee, S. K. Lee, J.-C. Lee, W.-W. So and W. S. Shin, ACS Appl. Mater. Interfaces, 2019, 11, 2189-2196.

117 Y. An, X. Liao, L. Chen, J. Yin, Q. Ai, Q. Xie, B. Huang, F. Liu, A. K.-Y. Jen and Y. Chen, Adv. Funct. Mater., 2018, 28, 1706517.

118 S. Li, L. Ye, W. Zhao, H. Yan, B. Yang, D. Liu, W. Li, H. Ade and J. Hou, J. Am. Chem. Soc., 2018, 140, 7159-7167.

119 S. Li, W. Zhao, J. Zhang, X. Liu, Z. Zheng, C. He, B. Xu, Z. Wei and J. Hou, Chem. Mater., 2020, 32, 1993-2003.

120 Y. Cui, H. Yao, L. Hong, T. Zhang, Y. Xu, K. Xian, B. Gao, J. Qin, J. Zhang, Z. Wei and J. Hou, Adv. Mater., 2019, 31, 1808356.

121 H. Yao, Y. Cui, D. Qian, C. S. Ponseca, A. Honarfar, Y. Xu, J. Xin, Z. Chen, L. Hong, B. Gao, R. Yu, Y. Zu, W. Ma, P. Chabera, T. Pullerits, A. Yartsev, F. Gao and J. Hou, J. Am. Chem. Soc., 2019, 141, 7743-7750.

122 C. Yao, Y. Zhu, K. Gu, J. Zhao, J. Ning, D. F. Perepichka, Y.-L. Loo and H. Meng, J. Mater. Chem. A, 2020, 8, 12149-12155.

123 B. Fan, D. Zhang, M. Li, W. Zhong, Z. Zeng, L. Ying, F. Huang and Y. Cao, Sci. China: Chem., 2019, 62, 746-752.

124 U. Huynh, T. Basel, T. Xu, L. Lu, T. Zheng, L. Yu and V. Vardeny, in Physical Chemistry of Interfaces and Nanomaterials Xiii, ed. N. Banerji, S. C. Hayes and C. Silva, Spie-Int Soc Optical Engineering, Bellingham, 2014, vol. 9165, p. UNSP91650Z.

125 S. Zhang, M. A. Uddin, W. Zhao, L. Ye, H. Y. Woo, D. Liu, B. Yang, H. Yao, Y. Cui and J. Hou, Polym. Chem., 2015, 6, 2752-2760.

126 L. Ye, S. Zhang, W. Zhao, H. Yao and J. Hou, Chem. Mater., 2014, 26, 3603-3605.

127 D. Liu, B. Yang, B. Jang, B. Xu, S. Zhang, C. He, H. Y. Woo and J. Hou, Energy Environ. Sci., 2017, 10, 546-551. 
128 Q. Fan, Q. Zhu, Z. Xu, W. Su, J. Chen, J. Wu, X. Guo, W. Ma, M. Zhang and Y. Li, Nano Energy, 2018, 48, 413-420.

129 M. Zhang, X. Guo, W. Ma, H. Ade and J. Hou, Adv. Mater., 2015, 27, 4655-4660.

130 R. Ma, T. Liu, Z. Luo, Q. Guo, Y. Xiao, Y. Chen, X. Li, S. Luo, X. Lu, M. Zhang, Y. Li and H. Yan, Sci. China: Chem., 2020, 63, 325-330.

131 Y. Wu, C. An, L. Shi, L. Yang, Y. Qin, N. Liang, C. He, Z. Wang and J. Hou, Angew. Chem., Int. Ed., 2018, 57, 12911-12915.

132 Z. Xu, Q. Fan, X. Meng, X. Guo, W. Su, W. Ma, M. Zhang and Y. Li, Chem. Mater., 2017, 29, 4811-4818.

133 Q. Fan, Z. Xu, X. Guo, X. Meng, W. Li, W. Su, X. Ou, W. Ma, M. Zhang and Y. Li, Nano Energy, 2017, 40, 20-26.

134 L. Ye, Y. Xie, K. Weng, H. S. Ryu, C. Li, Y. Cai, H. Fu, D. Wei, H. Y. Woo, S. Tan and Y. Sun, Nano Energy, 2019, 58, 220-226.

135 W. Li, G. Li, H. Guo, X. Guo, B. Guo, Q. Zhu, Q. Fan, W. Ma, M. Zhang and Y. Li, J. Mater. Chem. A, 2019, 7, 1307-1314.

136 Y. Wu, H. Yang, Y. Zou, Y. Dong, J. Yuan, C. Cui and Y. Li, Energy Environ. Sci., 2019, 12, 675-683.

137 Y. Li, D. Liu, J. Wang, Z.-G. Zhang, Y. Li, Y. Liu, T. Zhu, X. Bao, M. Sun and R. Yang, Chem. Mater., 2017, 29, 8249-8257.

138 P. Chao, M. Guo, Y. Zhu, H. Chen, M. Pu, H.-H. Huang, H. Meng, C. Yang and F. He, Macromolecules, 2020, 53, 2893-2901.

139 H. Sun, T. Liu, J. Yu, T.-K. Lau, G. Zhang, Y. Zhang, M. Su, Y. Tang, R. Ma, B. Liu, J. Liang, K. Feng, X. Lu, X. Guo, F. Gao and H. Yan, Energy Environ. Sci., 2019, 12, 3328-3337.

140 H. Bin, Y. Yang, Z. Peng, L. Ye, J. Yao, L. Zhong, C. Sun, L. Gao, H. Huang, X. Li, B. Qiu, L. Xue, Z.-G. Zhang, H. Ade and Y. Li, Adv. Energy Mater., 2018, 8, 1702324.

141 H. Bin, L. Gao, Z.-G. Zhang, Y. Yang, Y. Zhang, C. Zhang, S. Chen, L. Xue, C. Yang, M. Xiao and Y. Li, Nat. Commun., 2016, 7, 13651.

142 H. Bin, L. Zhong, Y. Yang, L. Gao, H. Huang, C. Sun, X. Li, L. Xue, Z.-G. Zhang, Z. Zhang and Y. Li, Adv. Energy Mater., 2017, 7, 1700746.

143 L. Xue, Y. Yang, J. Xu, C. Zhang, H. Bin, Z.-G. Zhang, B. Qiu, X. Li, C. Sun, L. Gao, J. Yao, X. Chen, Y. Yang, M. Xiao and Y. Li, Adv. Mater., 2017, 29, 1703344.

144 Z. Liao, Y. Xie, L. Chen, Y. Tan, S. Huang, Y. An, H. S. Ryu, X. Meng, X. Liao, B. Huang, Q. Xie, H. Y. Woo, Y. Sun and Y. Chen, Adv. Funct. Mater., 2019, 29, 1808828.

145 W. Su, G. Li, Q. Fan, Q. Zhu, X. Guo, J. Chen, J. Wu, W. Ma, M. Zhang and Y. Li, J. Mater. Chem. A, 2019, 7, 2351-2359.

146 Z. Li, X. Xu, G. Zhang, T. Yu, Y. Li and Q. Peng, Sol. RRL, 2018, 2, 1800186.

147 W. Li, G. Li, X. Guo, B. Guo, Z. Bi, H. Guo, W. Ma, X. Ou, M. Zhang and Y. Li, J. Mater. Chem. A, 2017, 5, 19680-19686.

148 W. Li, G. Li, X. Guo, Y. Wang, H. Guo, Q. Xu, M. Zhang and Y. Li, J. Mater. Chem. A, 2018, 6, 6551-6558.

149 W. Chen, G. Huang, X. Li, Y. Li, H. Wang, H. Jiang, Z. Zhao, D. Yu, E. Wang and R. Yang, ACS Appl. Mater. Interfaces, 2019, 11, 33173-33178.
150 D. Liu, K. Zhang, Y. Zhong, C. Gu, Y. Li and R. Yang, J. Mater. Chem. A, 2018, 6, 18125-18132.

151 L. Lan, Z. Chen, Q. Hu, L. Ying, R. Zhu, F. Liu, T. P. Russell, F. Huang and Y. Cao, Adv. Sci., 2016, 3, 1600032.

152 A. Tang, Q. Zhang, M. Du, G. Li, Y. Geng, J. Zhang, Z. Wei, X. Sun and E. Zhou, Macromolecules, 2019, 52, 6227-6233.

153 S. Xu, X. Wang, L. Feng, Z. He, H. Peng, V. Cimrová, J. Yuan, Z.-G. Zhang, Y. Li and Y. Zou, J. Mater. Chem. A, 2018, 6, 3074-3083.

154 W. Li, Q. Liu, K. Jin, M. Cheng, F. Hao, W.-Q. Wu, S. Liu, Z. Xiao, S. Yang, S. Shi and L. Ding, Mater. Chem. Front., 2020, 4, 1454-1458.

155 T. Yu, X. Xu, G. Zhang, J. Wan, Y. Li and Q. Peng, Adv. Funct. Mater., 2017, 27, 1701491.

156 X. Xu, T. Yu, Z. Bi, W. Ma, Y. Li and Q. Peng, Adv. Mater., 2018, 30, 1703973.

157 G. Xu, L. Chen, H. Lei, Z. Liao, N. Yi, J. Liu and Y. Chen, J. Mater. Chem. A, 2019, 7, 4145-4152.

158 S. Wen, Y. Li, N. Zheng, I. O. Raji, C. Yang and X. Bao, J. Mater. Chem. A, 2020, 8, 13671-13678.

159 S. J. Jeon, Y. W. Han and D. K. Moon, Small, 2019, 15, 1902598.

160 J. Xiong, K. Jin, Y. Jiang, J. Qin, T. Wang, J. Liu, Q. Liu, H. Peng, X. Li, A. Sun, X. Meng, L. Zhang, L. Liu, W. Li, Z. Fang, X. Jia, Z. Xiao, Y. Feng, X. Zhang, K. Sun, S. Yang, S. Shi and L. Ding, Sci. Bull., 2019, 64, 1573-1576.

161 J. Liu, L. Liu, C. Zuo, Z. Xiao, Y. Zou, Z. Jin and L. Ding, Sci. Bull., 2019, 64, 1655-1657.

162 T. Wang, J. Qin, Z. Xiao, X. Meng, C. Zuo, B. Yang, H. Tan, J. Yang, S. Yang, K. Sun, S. Xie and L. Ding, Sci. Bull., 2020, 65, 179-181.

163 Y. Qin, M. A. Uddin, Y. Chen, B. Jang, K. Zhao, Z. Zheng, R. Yu, T. J. Shin, H. Y. Woo and J. Hou, Adv. Mater., 2016, 28, 9416-9422.

164 Y.-S. Wu, Y.-C. Lin, S.-Y. Hung, C.-K. Chen, Y.-C. Chiang, C.-C. Chueh and W.-C. Chen, Macromolecules, 2020, 53, 4968-4981.

165 K. He, X. Li, H. Liu, Z. Zhang, P. Kumar, J. H. L. Ngai, J. Wang and Y. Li, Asian J. Org. Chem., 2020, 9, 1301-1308.

166 J. Yu, P. Chen, C. W. Koh, H. Wang, K. Yang, X. Zhou, B. Liu, Q. Liao, J. Chen, H. Sun, H. Y. Woo, S. Zhang and X. Guo, Adv. Sci., 2018, 1801743.

167 C. Sun, F. Pan, H. Bin, J. Zhang, L. Xue, B. Qiu, Z. Wei, Z.-G. Zhang and Y. Li, Nat. Commun., 2018, 9, 743.

168 D. Yuan, F. Pan, L. Zhang, H. Jiang, M. Chen, W. Tang, G. Qin, Y. Cao and J. Chen, Sol. RRL, 2020, 2000062.

169 F. Li, A. Tang, B. Zhang and E. Zhou, ACS Macro Lett., 2019, 8, 1599-1604.

170 D. Tang, J. Wan, X. Xu, Y. W. Lee, H. Y. Woo, K. Feng and Q. Peng, Nano Energy, 2018, 53, 258-269.

171 C. Sun, S. Qin, R. Wang, S. Chen, F. Pan, B. Qiu, Z. Shang, L. Meng, C. Zhang, M. Xiao, C. Yang and Y. Li, J. Am. Chem. Soc., 2020, 142, 1465-1474.

172 W. Su, Q. Fan, X. Guo, X. Meng, Z. Bi, W. Ma, M. Zhang and Y. Li, Nano Energy, 2017, 38, 510-517.

173 H. Hwang, D. H. Sin, C. Park and K. Cho, Sci. Rep., 2019, 9, 12081. 
174 Q. Li, Y. Sun, X. Xue, S. Yue, K. Liu, M. Azam, C. Yang, Z. Wang, F. Tan and Y. Chen, ACS Appl. Mater. Interfaces, 2019, 11, 3299-3307.

175 M.-A. Pan, T.-K. Lau, Y. Tang, Y.-C. Wu, T. Liu, K. Li, M.-C. Chen, X. Lu, W. Ma and C. Zhan, J. Mater. Chem. A, 2019, 7, 20713-20722.

176 J. Wang, J. Xu, N. Yao, D. Zhang, Z. Zheng, S. Xie, X. Zhang, F. Zhang, H. Zhou, C. Zhang and Y. Zhang, J. Phys. Chem. Lett., 2019, 10, 4110-4116.

177 Q. Yue, H. Wu, Z. Zhou, M. Zhang, F. Liu and X. Zhu, Adv. Mater., 2019, 31, 1904283.

178 B. Fan, K. Zhang, X.-F. Jiang, L. Ying, F. Huang and Y. Cao, Adv. Mater., 2017, 29, 1606396.

179 Y. He and Y. Li, Phys. Chem. Chem. Phys., 2011, 13, 1970-1983.

180 C. Zhang, S. Langner, A. V. Mumyatov, D. V. Anokhin, J. Min, J. D. Perea, K. L. Gerasimov, A. Osvet, D. A. Ivanov, P. Troshin, N. Li and C. J. Brabec, J. Mater. Chem. A, 2017, 5, 17570-17579.

181 W. Liu, J. Zhang, Z. Zhou, D. Zhang, Y. Zhang, S. Xu and X. Zhu, Adv. Mater., 2018, 30, 1800403.

182 J. Sun, X. Ma, Z. Zhang, J. Yu, J. Zhou, X. Yin, L. Yang, R. Geng, R. Zhu, F. Zhang and W. Tang, Adv. Mater., 2018, 30, 1707150.

183 C. Huang, X. Liao, K. Gao, L. Zuo, F. Lin, X. Shi, C.-Z. Li, H. Liu, X. Li, F. Liu, Y. Chen, H. Chen and A. K.-Y. Jen, Chem. Mater., 2018, 30, 5429-5434.

184 W. Gao, T. Liu, R. Ming, Z. Luo, K. Wu, L. Zhang, J. Xin, D. Xie, G. Zhang, W. Ma, H. Yan and C. Yang, Adv. Funct. Mater., 2018, 28, 1803128.

185 J. Cao, S. Qu, J. Yu, Z. Zhang, R. Geng, L. Yang, H. Wang, F. Du and W. Tang, Mater. Chem. Front., 2020, 4, 924-932.

186 H. Bin, L. Zhong, Z.-G. Zhang, L. Gao, Y. Yang, L. Xue, J. Zhang, Z. Zhang and Y. Li, Sci. China: Chem., 2016, 59, 1317-1322.

187 J. Min, Z.-G. Zhang, S. Zhang and Y. Li, Chem. Mater., 2012, 24, 3247-3254.

188 Y. Li, L. Zhong, J.-D. Lin, F.-P. Wu, H.-J. Bin, Z. Zhang, L. Xu, Z.-Q. Jiang, Z.-G. Zhang, F. Liu, T. P. Russell, Y. Li, L.-S. Liao and S. R. Forrest, Sol. RRL, 2017, 1, 1700107.

189 A. Patra and M. Bendikov, J. Mater. Chem., 2010, 20, 422-433.

190 S. S. Zade, N. Zamoshchik and M. Bendikov, Chem. - Eur. J., 2009, 15, 8613-8624.

191 L. Liu, G. Zhang, B. He, S. Liu, C. Duan and F. Huang, Mater. Chem. Front., 2017, 1, 499-506.

192 Y. Xu, H. Yao, L. Ma, J. Wang and J. Hou, Rep. Prog. Phys., 2020, 83, 082601.

193 A. C. Jakowetz, M. L. Böhm, A. Sadhanala, S. Huettner, A. Rao and R. H. Friend, Nat. Mater., 2017, 16, 551-557.

194 S. Gélinas, A. Rao, A. Kumar, S. L. Smith, A. W. Chin, J. Clark, T. S. van der Poll, G. C. Bazan and R. H. Friend, Science, 2014, 343, 512-516.

195 B. A. Gregg, J. Phys. Chem. Lett., 2011, 2, 3013-3015.

196 Y. Dong, X. Hu, C. Duan, P. Liu, S. Liu, L. Lan, D. Chen, L. Ying, S. Su, X. Gong, F. Huang and Y. Cao, Adv. Mater., 2013, 25, 3683-3688.
197 M. Wang, X. Hu, P. Liu, W. Li, X. Gong, F. Huang and Y. Cao, J. Am. Chem. Soc., 2011, 133, 9638-9641.

198 Y. Li, J. Geng, Y. Liu, S. Yu and G. Zhao, ChemMedChem, 2013, 8, 27-41.

199 R. Po, G. Bianchi, C. Carbonera and A. Pellegrino, Macromolecules, 2015, 48, 453-461.

200 Q. Fan, W. Su, Y. Wang, B. Guo, Y. Jiang, X. Guo, F. Liu, T. P. Russell, M. Zhang and Y. Li, Sci. China: Chem., 2018, 61, 531-537.

201 S. Zhang, Y. Qin, J. Zhu and J. Hou, Adv. Mater., 2018, 30, 1800868.

202 C. Cui, X. Fan, M. Zhang, J. Zhang, J. Min and Y. Li, Chem. Commun., 2011, 47, 11345.

203 Q. Fan, W. Su, X. Meng, X. Guo, G. Li, W. Ma, M. Zhang and Y. Li, Sol. RRL, 2017, 1, 1700020.

204 B. Guo, W. Li, X. Guo, X. Meng, W. Ma, M. Zhang and Y. Li, Adv. Mater., 2017, 29, 1702291.

205 S. J. Jeon, Y. W. Han and D. K. Moon, Sol. RRL, 2019, 3, 1900094.

206 X. Guo, N. Zhou, S. J. Lou, J. Smith, D. B. Tice, J. W. Hennek, R. P. Ortiz, J. T. L. Navarrete, S. Li, J. Strzalka, L. X. Chen, R. P. H. Chang, A. Facchetti and T. J. Marks, Nat. Photonics, 2013, 7, 825-833.

207 Y. Xie, Y. Cai, L. Zhu, R. Xia, L. Ye, X. Feng, H. Yip, F. Liu, G. Lu, S. Tan and Y. Sun, Adv. Funct. Mater., 2020, 2002181.

208 Y. Wu, Y. Zheng, H. Yang, C. Sun, Y. Dong, C. Cui, H. Yan and Y. Li, Sci. China: Chem., 2020, 63, 265-271.

209 Y. Lin, F. Zhao, Y. Wu, K. Chen, Y. Xia, G. Li, S. K. K. Prasad, J. Zhu, L. Huo, H. Bin, Z.-G. Zhang, X. Guo, M. Zhang, Y. Sun, F. Gao, Z. Wei, W. Ma, C. Wang, J. Hodgkiss, Z. Bo, O. Inganäs, Y. Li and X. Zhan, Adv. Mater., 2017, 29, 1604155.

210 Y. Geng, A. Tang, K. Tajima, Q. Zeng and E. Zhou, J. Mater. Chem. A, 2019, 7, 64-96.

211 J. Zhang, L. Zhu and Z. Wei, Small Methods, 2017, 1, 1700258.

212 H. Lee, C. Park, D. H. Sin, J. H. Park and K. Cho, Adv. Mater., 2018, 30, 1800453.

213 S. Namuangruk, S. Jungsuttiwong, N. Kungwan, V. Promarak, T. Sudyoadsuk, B. Jansang and M. Ehara, Theor. Chem. Acc., 2016, 135, 14.

214 B. F. Minaev, G. V. Baryshnikov and V. A. Minaeva, Dyes Pigm., 2012, 92, 531-536.

215 Z. Sun, Y. Jiang, L. Zeng and L. Huang, ChemSusChem, 2019, 12, 1325-1333.

216 S. Jungsuttiwong, T. Yakhanthip, Y. Surakhot, J. Khunchalee, T. Sudyoadsuk, V. Promarak, N. Kungwan and S. Namuangruk, J. Comput. Chem., 2012, 33, 1517-1523.

217 H. Yao, J. Wang, Y. Xu, S. Zhang and J. Hou, Acc. Chem. Res., 2020, 53, 822-832.

218 Q. Zhang, M. A. Kelly, N. Bauer and W. You, Acc. Chem. Res., 2017, 50, 2401-2409.

219 J. Yuan, L. Qiu, Z.-G. Zhang, Y. Li, Y. Chen and Y. Zou, Nano Energy, 2016, 30, 312-320.

220 Y. Wu, Y. Zou, H. Yang, Y. Li, H. Li, C. Cui and Y. Li, ACS Appl. Mater. Interfaces, 2017, 9, 37078-37086. 
221 Y. Li, N. Zheng, L. Yu, S. Wen, C. Gao, M. Sun and R. Yang, Adv. Mater., 2019, 31, 1807832.

222 X. Jiao, L. Ye and H. Ade, Adv. Energy Mater., 2017, 7, 1700084.

223 L. Ye, W. Zhao, S. Li, S. Mukherjee, J. H. Carpenter, O. Awartani, X. Jiao, J. Hou and H. Ade, Adv. Energy Mater., 2017, 7, 1602000.

224 J. Song, M. Zhang, M. Yuan, Y. Qian, Y. Sun and F. Liu, Small Methods, 2018, 2, 1700229.

225 T. Liu, L. Huo, S. Chandrabose, K. Chen, G. Han, F. Qi, X. Meng, D. Xie, W. Ma, Y. Yi, J. M. Hodgkiss, F. Liu, J. Wang, C. Yang and Y. Sun, Adv. Mater., 2018, 30, 1707353.

226 J. Chen, Z. Bi, X. Xu, Q. Zhang, S. Yang, S. Guo, H. Yan, W. You and W. Ma, Adv. Sci., 2019, 6, 1801560.

227 L. Yang, Z. Hu, Z. Zhang, J. Cao, H. Wang, J. Yu, F. Zhang and W. Tang, J. Mater. Chem. A, 2020, 8, 5458-5466.

228 L. Ye, B. A. Collins, X. Jiao, J. Zhao, H. Yan and H. Ade, Adv. Energy Mater., 2018, 8, 1703058.

229 H. Fu, Z. Wang and Y. Sun, Angew. Chem., Int. Ed., 2019, 58, 4442-4453.

230 S. Xiao, Q. Zhang and W. You, Adv. Mater., 2017, 29, 1601391.

231 S. Holliday, Y. Li and C. K. Luscombe, Prog. Polym. Sci., 2017, 70, 34-51.

232 L. Ye, S. Li, X. Liu, S. Zhang, M. Ghasemi, Y. Xiong, J. Hou and H. Ade, Joule, 2019, 3, 443-458.

233 M. Ghasemi, H. Hu, Z. Peng, J. J. Rech, I. Angunawela, J. H. Carpenter, S. J. Stuard, A. Wadsworth, I. McCulloch, W. You and H. Ade, Joule, 2019, 3, 1328-1348.

234 L. Ye, H. Hu, M. Ghasemi, T. Wang, B. A. Collins, J.-H. Kim, K. Jiang, J. H. Carpenter, H. Li, Z. Li, T. McAfee, J. Zhao, X. Chen, J. L. Y. Lai, T. Ma, J.-L. Bredas, H. Yan and H. Ade, Nat. Mater., 2018, 17, 253-260.

235 N. Yi, Q. Ai, W. Zhou, L. Huang, L. Zhang, Z. Xing, X. Li, J. Zeng and Y. Chen, Chem. Mater., 2019, 31, 10211-10224.

236 X. Xue, K. Weng, F. Qi, Y. Zhang, Z. Wang, J. Ali, D. Wei, Y. Sun, F. Liu, M. Wan, J. Liu and L. Huo, Adv. Energy Mater., 2019, 9, 1802686.

237 H. Cha, G. Fish, J. Luke, A. Alraddadi, H. H. Lee, W. Zhang, Y. Dong, S. Limbu, A. Wadsworth, I. P. Maria, L. Francàs, H. L. Sou, T. Du, J.-S. Kim, M. A. McLachlan, I. McCulloch and J. R. Durrant, Adv. Energy Mater., 2019, 9, 1901254.

238 Z. Zheng, H. Yao, L. Ye, Y. Xu, S. Zhang and J. Hou, Mater. Today, 2020, 35, 115-130.

239 L.-M. Wang, Q. Li, S. Liu, Z. Cao, Y.-P. Cai, X. Jiao, H. Lai, W. Xie, X. Zhan and T. Zhu, ACS Appl. Mater. Interfaces, 2020, 12, 24165-24173.

240 C. Jiao, C. Pang and Q. An, Int. J. Energy Res., 2019, 43, 8716-8724.

241 M. Zhang, F. Zhang, Q. An, Q. Sun, W. Wang, X. Ma, J. Zhang and W. Tang, J. Mater. Chem. A, 2017, 5, 3589-3598.

242 M. B. Upama, N. K. Elumalai, M. A. Mahmud, M. Wright, D. Wang, C. Xu and A. Uddin, Sol. Energy Mater. Sol. Cells, 2018, 176, 109-118.
243 W. Li, J. Cai, Y. Yan, F. Cai, S. Li, R. S. Gurney, D. Liu, J. D. McGettrick, T. M. Watson, Z. Li, A. J. Pearson, D. G. Lidzey, J. Hou and T. Wang, Sol. RRL, 2018, 2, 1800114.

244 W. Ma, C. Yang, X. Gong, K. Lee and A. J. Heeger, Adv. Funct. Mater., 2005, 15, 1617-1622.

245 H. Hu, K. Jiang, P. C. Y. Chow, L. Ye, G. Zhang, Z. Li, J. H. Carpenter, H. Ade and H. Yan, Adv. Energy Mater., 2018, 8, 1701674.

246 S. Li, L. Zhan, Y. Jin, G. Zhou, T. Lau, R. Qin, M. Shi, C. Li, H. Zhu, X. Lu, F. Zhang and H. Chen, Adv. Mater., 2020, 2001160.

247 J. Yuan, T. Huang, P. Cheng, Y. Zou, H. Zhang, J. L. Yang, S.-Y. Chang, Z. Zhang, W. Huang, R. Wang, D. Meng, F. Gao and Y. Yang, Nat. Commun., 2019, 10, 570.

248 D. Qian, Z. Zheng, H. Yao, W. Tress, T. R. Hopper, S. Chen, S. Li, J. Liu, S. Chen, J. Zhang, X.-K. Liu, B. Gao, L. Ouyang, Y. Jin, G. Pozina, I. A. Buyanova, W. M. Chen, O. Inganäs, V. Coropceanu, J.-L. Bredas, H. Yan, J. Hou, F. Zhang, A. A. Bakulin and F. Gao, Nat. Mater., 2018, 17, 703-709.

249 L. Hong, H. Yao, R. Yu, Y. Xu, B. Gao, Z. Ge and J. Hou, ACS Appl. Mater. Interfaces, 2019, 11, 29124-29131.

250 S. M. Menke, N. A. Ran, G. C. Bazan and R. H. Friend, Joule, 2018, 2, 25-35.

251 G. Dennler, M. C. Scharber and C. J. Brabec, Adv. Mater., 2009, 21, 1323-1338.

252 M. Jeong, I. W. Choi, E. M. Go, Y. Cho, M. Kim, B. Lee, S. Jeong, Y. Jo, H. W. Choi, J. Lee, J.-H. Bae, S. K. Kwak, D. S. Kim and C. Yang, Science, 2020, 369, 1615.

253 Y. Ji, L. Xu, X. Hao and K. Gao, Sol. RRL, 2020, 4, 2000130.

254 Z.-H. Chen, P.-Q. Bi, X.-Y. Yang, M.-S. Niu, K.-N. Zhang, L. Feng and X.-T. Hao, J. Phys. Chem. C, 2019, 123, 12676-12683.

255 J. H. Bombile, M. J. Janik and S. T. Milner, Phys. Chem. Chem. Phys., 2019, 21, 11999-12011.

256 X. Jiang, J. Yang, S. Karuthedath, J. Li, W. Lai, C. Li, C. Xiao, L. Ye, Z. Ma, Z. Tang, F. Laquai and W. Li, Angew. Chem., Int. Ed., 2020, 59, 2-12.

257 K. Wang, Y. Li and Y. Li, Macromol. Rapid Commun., 2020, 41, 1900437.

258 W. R. Mateker and M. D. McGehee, Adv. Mater., 2017, 29, 1603940.

259 P. Cheng and X. Zhan, Chem. Soc. Rev., 2016, 45, 2544-2582.

260 M. Jørgensen, K. Norrman, S. A. Gevorgyan, T. Tromholt, B. Andreasen and F. C. Krebs, Adv. Mater., 2012, 24, 580-612.

261 M. Giannouli, V. M. Drakonakis, A. Savva, P. Eleftheriou, G. Florides and S. A. Choulis, ChemPhysChem, 2015, 16, 1134-1154.

262 G. A. dos, R. Benatto, B. Roth, M. Corazza, R. R. Søndergaard, S. A. Gevorgyan, M. Jørgensen and F. C. Krebs, Nanoscale, 2016, 8, 318-326.

263 X. Xu, J. Xiao, G. Zhang, L. Wei, X. Jiao, H.-L. Yip and Y. Cao, Sci. Bull., 2020, 65, 208-216.

264 J. Xiao, M. Ren, G. Zhang, J. Wang, D. Zhang, L. Liu, N. Li, C. J. Brabec, H.-L. Yip and Y. Cao, Sol. RRL, 2019, 3, 1900077. 
265 J. Guo, Y. Wu, R. Sun, W. Wang, J. Guo, Q. Wu, X. Tang, C. Sun, Z. Luo, K. Chang, Z. Zhang, J. Yuan, T. Li, W. Tang, E. Zhou, Z. Xiao, L. Ding, Y. Zou, X. Zhan, C. Yang, Z. Li, C. J. Brabec, Y. Li and J. Min, J. Mater. Chem. A, 2019, 7, 25088-25101.

266 X. Du, T. Heumueller, W. Gruber, A. Classen, T. Unruh, N. Li and C. J. Brabec, Joule, 2019, 3, 215-226.

267 N. Y. Doumon, M. V. Dryzhov, F. V. Houard, V. M. Le Corre, A. Rahimi Chatri, P. Christodoulis and L. J. A. Koster, ACS Appl. Mater. Interfaces, 2019, 11, 8310-8318.

268 Z. Li, W. Zhong, L. Ying, F. Liu, N. Li, F. Huang and Y. Cao, Nano Energy, 2019, 64, 103931.

269 Y. Zhang, Y. Xu, M. J. Ford, F. Li, J. Sun, X. Ling, Y. Wang, J. Gu, J. Yuan and W. Ma, Adv. Energy Mater., 2018, 8, 1800029.

270 K. Zhang, R. Xia, B. Fan, X. Liu, Z. Wang, S. Dong, H.-L. Yip, L. Ying, F. Huang and Y. Cao, Adv. Mater., 2018, 30, 1803166.

271 Y.-Y. Yu, C.-H. Chen, C.-C. Chueh, C.-Y. Chiang, J.-H. Hsieh, C.-P. Chen and W.-C. Chen, ACS Appl. Mater. Interfaces, 2017, 9, 27853-27862.

272 T. Kim, R. Younts, W. Lee, S. Lee, K. Gundogdu and B. J. Kim, J. Mater. Chem. A, 2017, 5, 22170-22179.

273 T. Kim, J. Choi, H. J. Kim, W. Lee and B. J. Kim, Macromolecules, 2017, 50, 6861-6871.

274 T. Kim, J.-H. Kim, T. E. Kang, C. Lee, H. Kang, M. Shin, C. Wang, B. Ma, U. Jeong, T.-S. Kim and B. J. Kim, Nat. Commun., 2015, 6, 8547.

275 Q. Burlingame, X. Huang, X. Liu, C. Jeong, C. Coburn and S. R. Forrest, Nature, 2019, 573, 394-397.

276 X. Meng, L. Zhang, Y. Xie, X. Hu, Z. Xing, Z. Huang, C. Liu, L. Tan, W. Zhou, Y. Sun, W. Ma and Y. Chen, Adv. Mater., 2019, 31, 1903649.
277 S. H. Park, S. Park, S. Lee, J. Kim, H. Ahn, B. J. Kim, B. Chae and H. J. Son, Nano Energy, 2020, 77, 105147.

278 P. Meredith and A. Armin, Nat. Commun., 2018, 9, 1-4.

279 J. Guo and J. Min, Adv. Energy Mater., 2019, 9, 1802521.

280 A. Gambhir, P. Sandwell and J. Nelson, Sol. Energy Mater. Sol. Cells, 2016, 156, 49-58.

281 N. Li and C. J. Brabec, Nat. Energy, 2017, 2, 772-773.

282 N. Li, I. McCulloch and C. J. Brabec, Energy Environ. Sci., 2018, 11, 1355-1361.

283 J. Min, Y. N. Luponosov, C. Cui, B. Kan, H. Chen, X. Wan, Y. Chen, S. A. Ponomarenko, Y. Li and C. J. Brabec, Adv. Energy Mater., 2017, 7, 1700465.

284 E. Bundgaard, F. Livi, O. Hagemann, J. E. Carlé, M. Helgesen, I. M. Heckler, N. K. Zawacka, D. Angmo, T. T. Larsen-Olsen, G. A. dos R. Benatto, B. Roth, M. V. Madsen, M. R. Andersson, M. Jørgensen, R. R. Søndergaard and F. C. Krebs, Adv. Energy Mater., 2015, 5, 1402186.

285 D. Hu, Q. Yang, H. Chen, F. Wobben, V. M. L. Corre, R. Singh, T. Liu, R. Ma, H. Tang, L. J. A. Koster, T. Duan, H. Yan, Z. Kan, Z. Xiao and S. Lu, Energy Environ. Sci., 2020, 13, 2134-2141.

286 R. Ilmi, A. Haque and M. S. Khan, Org. Electron., 2018, 58, 53-62.

287 S. Dong, K. Zhang, B. Xie, J. Xiao, H.-L. Yip, H. Yan, F. Huang and Y. Cao, Adv. Energy Mater., 2019, 9, 1802832.

288 K. An, W. Zhong and L. Ying, Org. Electron., 2020, 82, 105701.

289 S. Strohm, F. Machui, S. Langner, P. Kubis, N. Gasparini, M. Salvador, I. McCulloch, H.-J. Egelhaaf and C. J. Brabec, Energy Environ. Sci., 2018, 11, 2225-2234.

290 Y. Qin, L. Ye, S. Zhang, J. Zhu, B. Yang, H. Ade and J. Hou, J. Mater. Chem. A, 2018, 6, 4324-4330. 